"A FEA e a USP respeitam os direitos autorais deste trabalho. Nós acreditamos que a melhor proteção contra o uso ilegítimo deste texto é a publicação online. Além de preservar o conteúdo motiva-nos oferecer à sociedade o conhecimento produzido no âmbito da universidade pública e dar publicidade ao esforço do pesquisador. Entretanto, caso não seja do interesse do autor manter o documento online, pedimos compreensão em relação à iniciativa e o contato pelo e-mail bibfea@usp.br para que possamos tomar as providências cabíveis (remoção da tese ou dissertação da BDTD)." 
Universidade de São Paulo

Faculdade de Economia, Administração e Contabilidade

Instituto de Matemática e Estatística

Mestrado Profissionalizante "Modelagem Matemática em Finanças"

\title{
DERIVATIVOS DE CÂMBIO: IMPLEMENTAÇÃO DO MODELO DE HESTON PARA O MERCADO BRASILEIRO
}

\author{
Marcelo Nóbrega da Costa \\ Orientador: Professor Dr. Joe Akira Yoshino (FEA-USP)
}

São Paulo

2003 
Universidade de São Paulo

Faculdade de Economia, Administração e Contabilidade

Instituto de Matemática e Estatística

Mestrado Profissionalizante "Modelagem Matemática em Finanças"

\title{
DERIVATIVOS DE CÂMBIO: IMPLEMENTAÇÃO DO MODELO DE HESTON PARA O MERCADO BRASILEIRO
}

\author{
Marcelo Nóbrega da Costa
}

Dissertação apresentada à

Faculdade de Economia,

Contabilidade e Admnistração e ao

Instituto de Matemática e

Estatística da Universidade de São

Paulo para a obtenção do Título de

de Mestre.

Orientador: Professor Dr. Joe Akira Yoshino (FEA-USP)

São Paulo

2003 


\section{Resumo}

Com o fim do regime de bandas cambiais em 1999 adotado pelo Banco Central e as sucessivas crises econômicas globais, o mercado de derivativos brasileiro sofreu uma rápida transformação buscando principalmente atender fortes demandas por proteção aos riscos de mercado refletidos principalmente nos ativos atrelados ao câmbio e aos juros. Apesar do relativo avanço, as opções de câmbio são na sua maioria apreçadas através de modelos simples como Black ou Garman-Kohlhagen que "escondem" alguns efeitos quantitativos que poderiam ser melhores explorados utilizando-se, por exemplo, modelos de apreçamento com volatilidade estocástica. Calibrar e utilizar estes modelos representam um "estado da arte" dentro da teoria da engenharia financeira, principalmente em mercados emergentes que apresentam fortes volatilidades, frequentes mudanças de regimes e quase sempre escassez de liquidez para prazos mais longos. Este trabalho aborda o modelo de Heston para as opções de câmbio R \$/USD utilizando-se da matriz de volatilidade das opções de câmbio da Reuters. O Modelo de Heston apresenta 5 parâmetros (velocidade de reversão à média da variância, variância de longo prazo, volatilidade da volatilidade estocástica, correlação entre o retorno do ativo-objeto e da variância e o prêmio de risco da volatilidade). Apesar de apresentar uma solução analítica, as equações apresentam uma grande complexidade matemática onde a análise dos parâmetros acima é fundamental para a tentativa de calibração. Assim, o principal objetivo deste trabalho é apresentar uma análise dessas variáveis e propor uma forma alternativa para a implementação do modelo de Heston para o mercado brasileiro. 
Dedico este trabalho à minha esposa e companheira Bartíria Patrícia da Nóbrega, pela sua incansável compreensão e apoio durante os dias que me debrucei sobre este trabalho. 


\section{Agradecimentos}

Ao meu orientador e co-orientador, professores Dr. Joe Yoshino / Dr. Pedro Paulo Schirmer; todos os professores e coordenadores do Instituto de Matemática da USP e da Faculdade de Economia e Administração da USP que contribuíram para a minha formação.

Ao Prof. Dr. Eduardo Facó Lemgruber (COPPEAD-UFRJ) por ter participado da banca examinadora desta dissertação.

À Reuters do Brasil e aos Bancos participantes do Pool de Volatilidades de opções de câmbio pela permissão do uso dos dados de mercado para a calibração dos modelos.

Aos inúmeros amigos que fiz na FEA no decorrer desses dois anos de curso.

Ao Dresdner Bank Brasil pelo patrocínio financeiro e pelo incentivo dado à formação de seus profissionais.

À minha família e a Deus. 


\section{Conteúdo}

1 Introdução 1

2 O Modelo de Volatilidade Estocástica de Heston 5

2.1 O Modelo de Heston . . . . . . . . . . . . . . . . . . 5

2.2 O Modelo de Heston Generalizado Para Opções de Câmbio . . . . . . . . 10

2.3 Uma Abordagem sobre o Prêmio de Risco da Volatilidade . . . . . . . . . 13

2.4 O Modelo de Referência para a Calibração dos Modelos de Volatilidade Estocástica - Modelo de Garman-Kohlhagen . . . . . . . . . . . . . . 15

3 O Mercado de Derivativos de Câmbio Brasileiro - Fatos Estilizados 16

3.1 Uma Breve Descrição . . . . . . . . . . . . . . . . . . . . . . . . 16

3.2 Descrição dos Dados de Mercado Utilizados . . . . . . . . . . . . . . 22

3.3 Tratamento dos Dados de Mercado . . . . . . . . . . . . . . . . . . 28

4 Calibração do Modelo de Heston 31

4.1 Determinação dos Valores Iniciais para os Parâmetros do Modelo de Heston 33

4.2 Uma Análise sobre os Efeitos da Correlação e da Volatilidade da Volatilidade no Comportamento das Opções . . . . . . . . . . . . . . . . 36

4.3 Comportamento da Integral da Fórmula de Heston . . . . . . . . . . 42

4.4 Determinação da Função Objetivo e Base de Dados para a Calibração . . . 43

4.5 Resultados da Calibração . . . . . . . . . . . . . . . . . . . . . 46 
Apêndice I - Tabelas de Dados Utilizados na Calibração do Modelo de Heston

Apêndice II - Resultados das Calibrações do Modelo de Heston

Apêndice II - Códigos em MATLAB

Função calibration_rho_sigma.m . . . . . . . . . . . . . . . . 67

Função Heston_call_rho_sigma2.m . . . . . . . . . . . . . . . . . 69

Função calibration_rho_sigma_theta.m . . . . . . . . . . . . . . 72

Função Heston_call_rho_sigma_theta.m . . . . . . . . . . . . . . . . . . 74

Função CallHeston_MC.m . . . . . . . . . . . . . . . . . 76

Função moneyness.m . . . . . . . . . . . . . . . . . . . . . 80

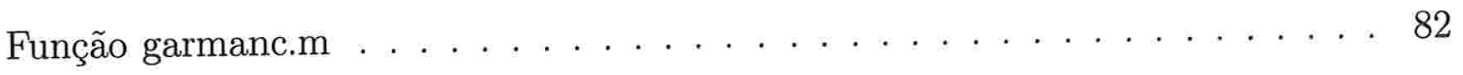

Função taxa_cont.m . . . . . . . . . . . . . . . . . . . . . . . 84 


\section{Capítulo 1}

\section{Introdução}

A história das opções no último século esteve em grande parte voltada a responder à pergunta de como a aversão ao risco dos investidores poderia influenciar o preço das mesmas, ou seja, a relação entre a função de utilidade desses investidores e o preço das opções. Outra forma de abordar o assunto seria questionar se o preço de uma opção estaria abaixo do preço justo dado o interesse do investidor de se tomar ou não tal risco. Estas perguntas começaram a ser respondidas de uma forma mais efetiva em 1973 quando este "quebra-cabeça" foi resolvido por Black e Scholes onde eles propunham um modelo de avaliação de opções onde o ativo-objeto seguia a dinâmica de um processo browniano geométrico (isto implicava que os retornos dos ativos assumiriam uma distribuição normal com uma média e uma variância conhecidas e constantes). Assim, a volatilidade era uma previsão para o movimento futuro dos preços do ativo-objeto e que muitas vezes não apresentava relações razoáveis com as volatilidades históricas para o mesmo ativo-objeto. Por serem constantes, a volatilidade e a taxa de juros não requeriam um prêmio de risco como acontecia para o ativo-base.

Apesar do grande sucesso da modelagem de B-S(Black\&Scholes), boa parte da solução foi simplificada assumindo-se uma hipótese de que o mundo era "risco-neutro", ou seja, todos os investidores seriam capazes de construir um portfolio replicante, neutralizando o risco da variação do ativo-objeto daquele derivativo e este portfolio seria remunerado por 
uma taxa livre de risco para diferentes tipos de opções e portfolios replicantes. A taxa livre de risco neste caso surge da hipótese da existência de mercados completos também assumidas por B-S. Desta forma o modelo B-S respondia a pergunta acima desde que fosse obtida a neutralidade ao risco e também assumidas as limitações da volatilidade e as taxas de juros constantes.

Com o passar do tempo e com os avanços da econometria, foi-se descobrindo através de testes empíricos que a hipótese de volatilidade constante era facilmente rejeitada para a maioria dos ativos-objetos e vários estudos começaram a ser desenvolvidos no campo das finanças. Esses estudos basicamente compreendiam a modelagem de um processo de difusão para a volatilidade de forma também a se seguir um processo estocástico, daí a denominação volatilidade estocástica. Com a utilização dos modelos de volatilidade estocástica, os efeitos de "sorriso " e de "assimetria" começaram a ser visto de forma mais coerente, caminhando-se assim para uma teoria mais realista e abrangente para a estrutura a termo das volatilidades implícitas. Esta nova modelagem que agora incorporaria o efeito da variação da variância do ativo-objeto, logicamente assumiria a existência de um prêmio de risco para esta "incerteza da volatilidade" e isto deveria refletir nos preços das opções. Obviamente, uma nova dificuldade surgiu na definição desta modelagem: qual seria a aversão ao risco do investidor à volatilidade de uma dada opção.

Vários trabalhos na tentativa de definir um processo de difusão da volatilidade e conseqüentemente os seus efeitos na avaliação dos preços das opções podem ser citados. Wiggins (1987), Scott (1987), Hull and White (1987 e 1988) generalizaram o modelo que abrange a volatilidade estocástica. Melino e Turnbull (1991) explicam que este modelo é bem-sucedido para explicar o preço de opções de câmbio para alguns mercados do G-7. Os trabalhos acima apresentam uma grande desvantagem por não apresentarem uma solução analítica e requererem assim o uso de técnicas de métodos numéricos para a resolução de equações diferencias parciais bi-dimensionais.

Stein e Stein (1991) e Heston (1993) foram os responsáveis por tratar este problema de forma analítica. Stein e Stein assumiram que a volatilidade não apresentava correlação 
com o ativo-objeto e utilizaram a média da fórmula de B-S para diferentes caminhos da volatilidade. Eles utilizaram o método das transformadas de Fourier para se determinar a distribuição de probabilidade do caminho do ativo-objeto.

Mais tarde, Heston (1993) obteve uma solução analítica para o preço de uma opção européia a partir da função característica da probabilidade ajustada ao risco e da transformada inversa de Fourier. $\mathrm{Na}$ sua modelagem, Heston assumiu a existência de uma correlação entre o termo estocástico da equação de difusão da volatilidade e o termo estocástico da equação de difusão do ativo-objeto, que de forma prática traz uma informação adicional para o modelo.

Mesmo com os avanços acima citados, é fato que no mercado de opções de câmbio no Brasil e no exterior, os modelos mais simples ainda são utilizados, como o Black (1973) e o de Garman-Kohlhagen (1983), assumindo todas as simplificações antes descritas.

Assim a motivação deste trabalho surge basicamente de duas fontes: primeiramente o comportamento do mercado de câmbio brasileiro leva a crer que modelos de volatilidade estocástica podem evidenciar efeitos não visíveis quando utilizados modelos mais simples de precificação de opções e segundo pelo desafio de se implementar e entender modelos mais robustos como o modelo de Heston.

Este trabalho tem como objetivo apresentar um modelo de volatilidade estocástica generalizado proposto por Heston (1993) e realizar uma calibração deste modelo para sua utilização ao mercado de opções européias de câmbio R\$/USD. O trabalho utiliza o modelo de Garman-Kohlhagen como o modelo de referência para se extrair os preços implícitos na matriz de volatilidade para que a posteriori se possa realizar a calibração através da minimização de erros quadráticos entre os preços de mercado e os preços extraídos da fórmula de Heston.

Inicialmente, faz-se uma apresentação matemática do modelo de Heston, mostrando os principais passos seguidos para sua formulação final. Adiante é feita uma breve descrição do mercado de câmbio brasileiro e dos dados de mercado utilizados para a modelagem e, finalmente, uma análise dos parâmetros e calibração do modelo. O modelo de Heston 
foi escolhido dentre vários modelos de apreçamento com volatilidade estocástica devido à sua relativa simplicidade de implementação e por apresentar uma forma analítica não havendo a necessidade de se recorrer aos métodos numéricos para a solução das equações diferenciais parciais.

Esta dissertação está organizada da seguinte forma:

O segundo capítulo abordará o modelo de Heston já apresentando uma forma final para sua aplicação ao mercado de opções de câmbio. No terceiro capítulo, inicia-se uma abordagem sobre os fenômenos observados no mercado de câmbio que motivaram a calibração do modelo de Heston de forma a se justificar o uso de uma correlação entre os termos estocásticos da volatilidade e do preço do ativo-objeto e também a própria volatilidade estocástica. Neste capítulo também são descritos os dados de mercado utilizados para a calibração do modelo de Heston e também os métodos de tratamento destes dados (métodos de interpolação das taxas de juros, matriz de volatilidade, cálculo de moneyness, etc).

No quarto capítulo, descreve-se a análise dos parâmetros do modelo de Heston e apresenta-se os resultados da calibração. O quinto e último capítulo aborda as conclusões e considerações finais do trabalho.

No apêndice, estão tabelados os dados utilizados em cada calibração e os resultados também de cada calibração assim como estão descritos os códigos em MATLAB para as funções utilizadas na modelagem. 


\section{Capítulo 2}

\section{O Modelo de Volatilidade}

\section{Estocástica de Heston}

\subsection{O Modelo de Heston}

O Modelo de Heston assume que o ativo-objeto no tempo $t$ segue o processo de difusão dado pela equação:

$$
d S(t)=\mu S d t+\sqrt{v(t)} S d z_{1}(t)
$$

Onde $z_{1}(t)$ é um processo de Wiener e $v(t)$ é a variância. ${ }^{1}$ A volatilidade segue um processo de Ornstein-Unlenbeck(por exemplo, utilizado por Stein e Stein (1991)),

$$
d \sqrt{v(t)}=-\beta \sqrt{v(t)} d t+\delta d z_{2}(t)
$$

\footnotetext{
${ }^{1}$ Observe que neste modelo a variância não é constante como definido no modelo de Garman-Kohlhagen ou Black-Scholes.
} 
Através do Lema de Itô pode-se mostrar que a variância $v(t)$ segue o processo de difusão abaixo:

$$
d v(t)=\left[\delta^{2}-2 \beta v(t)\right] d t+2 \delta \sqrt{v(t)} d z_{2}(t)
$$

A equação acima pode ser reescrita de uma forma mais familiar do processo da raiz quadrada: ${ }^{2}$

$$
d v(t)=k[\theta-v(t)] d t+\sigma \sqrt{v(t)} d z_{2}(t)
$$

onde $z_{2}(t)$ apresenta uma correlação $\rho$ com $z_{1}(t)$. Através da fórmula acima percebe-se claramente que este processo de difusão da volatilidade apresenta um parâmetro $\theta$ que representa uma variância de longo prazo,e um parâmetro $k$ que representa a velocidade de reversão à média desta variância. Observa-se também o parâmetro $\sigma$ que representa a volatilidade da volatilidade.

No modelo assume-se a simplificação de uma taxa de juros não estocástica, ou seja, o preço no tempo $t$ de uma unidade de um título "livre de risco"descontado e que tem vencimento em $t+\tau$ é dado por

$$
P(t, t+\tau)=e^{-r \tau}
$$

As hipóteses utilizadas até aqui ainda são insuficientes para precificar o derivativo porque ainda não foram tomadas as hipóteses que abordam o prêmio de risco da volatilidade. Seguindo os argumentos de arbitragem de B-S (1973) e Merton (1973) demonstra-se que o valor de qualquer derivativo $U(s, v, t)$ deve satisfazer a equação diferencial parcial abaixo: ${ }^{3}$

$$
\frac{1}{2} v S^{2} \frac{\partial^{2} U}{\partial S^{2}}+\rho \sigma v S \frac{\partial^{2} U}{\partial S \partial v}+\frac{1}{2} \sigma^{2} v \frac{\partial^{2} U}{\partial v^{2}}+r S \frac{\partial U}{\partial S}+
$$

\footnotetext{
${ }^{2}$ Esta equação de difusão foi utilizada por Cox, Ingersoll e Ross (1985).

${ }^{3}$ Observe que tomando-se $v(t)=\sigma^{2}$ constante encontra-se a equação diferencial de B-S.
} 


$$
+\{k[\theta-v(t)]-\lambda(S, v, t)\} \frac{\partial U}{\partial v}-r U+\frac{\partial U}{\partial t}=0
$$

O termo não especificado acima, $\lambda(S, v, t)$, representa o prêmio de risco da volatilidade e que deve ser independente do ativo-objeto considerado. ${ }^{4}$

Uma opção européia de compra com preço de exercício K e vencimento em T satisfaz a EDP anterior sujeita às condições de contorno. ${ }^{5}$

Por analogia ao modelo de B-S, sugere-se a solução na forma

$$
C(s, v, t)=S P_{1}-K P(t, T) P_{2}
$$

Onde o primeiro termo significa o valor presente do ativo-objeto sobre o exercício ("optimal exercise"), e o segundo termo é o valor presente do pagamento do preço de exercício. Ambos os termos devem satisfazer a EDP original 2.6.

O Modelo de Heston também assume a lognormalidade dos preços do ativo-objeto de tal forma que é conveniente transformá-la para a variável normal $x$,onde

\footnotetext{
${ }^{4}$ Lamoureux e Lastrapes (1993) apresentam evidências de que esse termo não é zero para opções de câmbio. Na próxima seç̧ão deste capítulo apresenta-se uma descrição mais detalhada sobre o prêmio da volatilidade.

${ }^{5}$ As condições de contorno são:
}

$$
\begin{gathered}
U(S, v, T)=\max (0, S-K) \\
U(0, v, t)=0 \\
\frac{\partial U}{\partial S}(\infty, v, t)=1 \\
U(S, \infty, t)=S \\
r S \frac{\partial U}{\partial S}(S, 0, t)+k \theta \frac{\partial U}{\partial v}-r U(S, 0, t)+U_{t}(S, 0, t)=0
\end{gathered}
$$




$$
x=\ln [S]
$$

Substituindo-se a solução proposta 2.7 na EDP 2.6 e isolando-se os termos em $K$, mostra-se que P1 e P2 devem satisfazer a EDP abaixo

$$
\begin{gathered}
\frac{1}{2} v \frac{\partial^{2} P_{j}}{\partial x^{2}}+\rho \sigma v \frac{\partial^{2} P_{j}}{\partial x \partial v}+\frac{1}{2} \sigma^{2} v \frac{\partial^{2} P_{j}}{\partial v^{2}}+\left(r+u_{j} v\right) \frac{\partial P_{j}}{\partial x}+ \\
\left(a_{j}-b_{j} v\right) \frac{\partial P_{j}}{\partial v}+\frac{\partial P_{j}}{\partial t}=0
\end{gathered}
$$

onde para $j=1,2$ valem as seguintes identidades

$$
u_{1}=\frac{1}{2}, \quad u_{2}=-\frac{1}{2}, \quad a=k \theta, \quad b_{1}=k+\lambda-\rho \sigma, \quad b_{2}=k+\lambda
$$

Reescrevendo a condição de contorno terminal em T sobre $C(S, v, t)$ (equação 2.7), em termos das condições de contorno de $P_{1}$ e $P_{2}$, obtem-se uma condição de contorno terminal para as funções de probabilidade:

$$
P_{j}(x, v, T)=1_{\{x \geq \ln [K]\}}
$$

Esta equação pode ser reescrita na forma de uma probabilidade condicional onde a opção expira "in-the-money".

$$
P_{j}(x, v, T ; \ln [K])=\operatorname{Pr}[x(T) \geq \ln [K] \mid x(t)=x, v(t)=v]
$$

As probabilidades acima não estão disponíveis imediatamente numa fórmula fechada e por isso é necessário o uso de funções características para se determiná-las.

Heston demonstra que as funções características, $f_{1}(x, v, T ; \phi)$ e $f_{2}(x, v, T ; \phi)$ respectivamente satisfazem a mesma EDP 2.9, sujeitas as condições terminais ${ }^{6}$

\footnotetext{
${ }^{6} \mathrm{~A}$ demonstração utiliza-se do lema de Itô para $f$ e assume-se que $f$ é um martingale (método das esperanças interadas).
} 


$$
f_{j}(x, v, T ; \phi)=e^{i \phi x}
$$

A solução da função característica dada por

$$
f_{j}(x, v, t ; \phi)=e^{C(T-t ; \phi)+D(T-t ; \phi) v+i \phi x}
$$

onde

$$
\begin{gathered}
C(\tau ; \phi)=r \phi i \tau+\frac{a}{\sigma^{2}}\left(\left(b_{j}-\rho \sigma \phi i+d\right) \tau-2 \ln \left[\frac{1-g e^{d \tau}}{1-g}\right]\right) \\
D(\tau ; \phi)=\frac{b_{j}-\rho \sigma \phi i+d}{\sigma^{2}}\left[\frac{1-e^{d \tau}}{1-g e^{d \tau}}\right] \\
g=\frac{b_{j}-\rho \sigma \phi i+d}{b_{j}-\rho \sigma \phi i-d} \\
d=\sqrt{\left(\rho \sigma \phi i-b_{j}\right)^{2}-\sigma^{2}\left(2 u_{j} \phi i-\phi^{2}\right)}
\end{gathered}
$$

Pode-se inverter as funções características utilizando a transformada inversa de Fourier para se obter as probabilidades desejadas:

$$
P_{j}(x, v, T ; \ln [K])=\frac{1}{2}+\frac{1}{\pi} \int_{0}^{+\infty} \operatorname{Re}\left[\frac{e^{-i \phi l n[k]} f_{j}(x, v, T ; \phi)}{i \phi}\right] d \phi
$$

Assim, com as equações $2.18,2.13$ e 2.7, pode-se determinar o preço de uma opção européia de compra. Para opções de venda o desenvolvimento é análogo mudando-se somente as condições de contorno da EDP inicial do problema. 


\subsection{O Modelo de Heston Generalizado Para Opções de Câmbio}

Conforme introduzido anteriormente, será aplicado o modelo de Heston para o mercado de opções de câmbio R \$/USD. De forma a se manter a convenção assume-se que a moeda doméstica será o Real e a moeda estrangeira, o Dólar Americano.

De forma semelhante à equação 2.1 pode-se escrever a equação de difusão do Preço do câmbio à vista como:

$$
d S(t)=\left(r_{d}-r_{f}\right) S d t+\sqrt{v(t)} S d z_{1}(t)
$$

Através dos mesmos artifícios matemáticos, encontra-se a EDP abaixo:

$$
\begin{gathered}
\frac{1}{2} v S^{2} \frac{\partial^{2} U}{\partial S^{2}}+\rho \sigma v S \frac{\partial^{2} U}{\partial S \partial v}+\frac{1}{2} \sigma^{2} v \frac{\partial^{2} U}{\partial v^{2}}+\left(r_{d}-r_{f}\right) S \frac{\partial U}{\partial S}+ \\
\{k[\theta-v(t)]-\lambda(S, v, t)\} \frac{\partial U}{\partial v}-r_{d} U+\frac{\partial U}{\partial t}=0
\end{gathered}
$$

Para a equação acima tem-se condições de contorno para o caso de uma opção de compra. ${ }^{7}$

\footnotetext{
${ }^{7}$ As condições de contorno são dadas por:

$$
\begin{gathered}
U(S, v, T)=\max (0, S-K) \\
U(0, v, t)=0 \\
\frac{\partial U}{\partial S}(\infty, v, t)=e^{-r_{f} \tau} \\
U(S, \infty, t)=S e^{-r_{f} \tau} \\
\left(r_{d}-r_{f}\right) S \frac{\partial U}{\partial S}(S, 0, t)+k \theta \frac{\partial U}{\partial v}-r U(S, 0, t)+U_{t}(S, 0, t)=r_{d} U(S, 0, t)
\end{gathered}
$$
}


A solução inicial para o preço da opção expresso na forma

$$
C(s, v, t)=S F(t, T) P_{1}-K P(t, T) P_{2}
$$

onde de forma análoga $F(t, T)$ o preço no tempo $t$ de uma unidade de um título "livre de risco"na moeda estrangeira com vencimento em $t+\tau$, ou seja, ${ }^{8}$

$$
F(t, t+\tau)=e^{-r_{f} \tau}
$$

A variável $x$ é expressa por:

$$
\begin{gathered}
x=\ln \frac{S F(t ; T)}{P(t ; T)}=\ln \left(S e^{\left(r_{f}-r_{d}\right) \tau}\right) \\
f_{j}(x, v, T ; \phi)=e^{i \phi x}
\end{gathered}
$$

A solução da função característica dada por

Para a determinação das variáveis implicítas na função característica, tem-se:

$$
f_{j}(x, v, t ; \phi)=e^{C(T-t ; \phi)+D(T-t ; \phi) v+i \phi x}
$$

onde

$$
\begin{gathered}
C(\tau ; \phi)=r_{d} \phi i \tau+\frac{a}{\sigma^{2}}\left(\left(b_{j}-\rho \sigma \phi i+d\right) \tau-2 \ln \left[\frac{1-g e^{d \tau}}{1-g}\right]\right) \\
D(\tau ; \phi)=\frac{b_{j}-\rho \sigma \phi i+d}{\sigma^{2}}\left[\frac{1-e^{d \tau}}{1-g e^{d \tau}}\right]
\end{gathered}
$$

${ }^{8} \mathrm{~A}$ taxa de juros na moeda estrangeira também é considerada não estocástica. Para maiores detalhes sobre o apreçamento de opções de câmbio para o mercado brasileiro com juros estocásticos, vide LEMGRUBER(2002). A equação 2.21 pode ser reescrita numa forma mais próxima de G-K:

$$
C(s, v, t)=S e^{-r_{f} \tau} P_{1}-K e^{-r_{d} \tau} P_{2}
$$




$$
\begin{gathered}
g=\frac{b_{j}-\rho \sigma \phi i+d}{b_{j}-\rho \sigma \phi i-d} \\
d=\sqrt{\left(\rho \sigma \phi i-b_{j}\right)^{2}-\sigma^{2}\left(2 u_{j} \phi i-\phi^{2}\right)}
\end{gathered}
$$




\subsection{Uma Abordagem sobre o Prêmio de Risco da Vo- latilidade}

Pelo fato de modelos de volatilidade estocástica considerarem a existência de incerteza da volatilidade, considera-se por definição a existência de um prêmio de risco da volatilidade $(\lambda)$. No modelo de B-S por se considerar a volatilidade determinística este prêmio passa a não existir. Assumindo-se a existência de um mercado completo, o prêmio de risco do ativo-objeto para o portfolio replicante (market price of risk) é nulo e o retorno do portfolio replicante é a taxa de juros livre de risco ${ }^{9}$.

Nos modelos de volatilidade estocástica esta última suposição também é utilizada para o risco do ativo-objeto e adicionalmente se incorpora o prêmio de risco da volatilidade.

Seja a equação do diferencial do preço de uma opção dada pela expansão de Taylor abaixo:

$$
\begin{gathered}
d U(S, v, t)=\frac{\partial U}{\partial t} d t+\frac{\partial U}{\partial S} d S+\frac{\partial U}{\partial v} d v+\frac{1}{2 !} \frac{\partial^{2} U}{\partial t^{2}} d t^{2}+\frac{1}{2 !} \frac{\partial^{2} U}{\partial S^{2}} d S^{2}+ \\
\frac{1}{2 !} \frac{\partial^{2} U}{\partial v^{2}} d v^{2}+\frac{1}{2 !} \frac{\partial^{2} U}{\partial v \partial S} d v d S+\frac{1}{2 !} \frac{\partial^{2} U}{\partial S \partial t} d t d S+\frac{1}{2 !} \frac{\partial^{2} U}{\partial v \partial t} d v d t+\ldots
\end{gathered}
$$

Substituindo-se as equações 2.1 e 2.4 , chega-se a:

$$
\begin{aligned}
d U & =\left(\frac{\partial U}{\partial t}+a \frac{\partial U}{\partial v}+S r \frac{\partial U}{\partial S}+S^{2} v \frac{1}{2} \frac{\partial^{2} U}{\partial S^{2}}+\sigma^{2} v \frac{1}{2} \frac{\partial^{2} U}{\partial v^{2}}\right. \\
& \left.+\frac{\partial^{2} U}{\partial v \partial S} \rho \sigma v S\right) d t+\frac{\partial U}{\partial S} S \sqrt{v} d z_{1}+\sigma \sqrt{v} \frac{\partial U}{\partial v} d z_{2}
\end{aligned}
$$

Assumindo-se que o retorno esperado do portfolio replicante para esta opção para um dado intervalo de tempo, $L(U)$, reflete os prêmios de risco do ativo-objeto, $r$, e da volatilidade, $\lambda$, pode-se escrevê-lo da sequinte forma:

\footnotetext{
${ }^{9}$ Para uma descrição de avaliação de neutralidade ao risco no modelo Black-Scholes vide Wilmmott.

Market Price of risk $\lambda=\frac{\mu-r}{\sigma} ; \lambda=0 \rightarrow \mu=r$
} 


$$
L(U)=r U+\lambda \frac{\partial U}{\partial v}
$$

Igualando-se a equação 2.32 ao termo de tendência da equação 2.31 chega-se a equação 2.6 descrita anteriormente como a equação diferencial parcial do modelo de Heston.

Observa-se na equação 2.32 que o prêmio de risco da volatilidade, $\lambda$, representa um coeficiente da variação do preço da opção em relação a variância estocástica, $\frac{\partial U}{\partial v}$, ou seja, quanto o investidor está disposto a "consumir" daquela opção para uma dada variação da variância ${ }^{10}$.

\footnotetext{
${ }^{10}$ Para motivar a escolha de $\lambda$, recorreu-se ao modelo de consumo de Breeden (1979) a equação:

$$
\lambda(s, v, t) d t=\gamma \operatorname{cov}\left[d v, \frac{d C}{C}\right]
$$

onde $C(t)$ é a taxa de consumo e $\gamma$ é a aversão relativa ao risco do investidor. Considere o processo para consumo que emerge do modelo (equilíbrio geral) de Cox, Ingersoll e Ross (1985)

$$
d C(t)=\mu_{C} v(t) C d t+\sigma_{C} \sqrt{v(t)} C d z_{3}(t)
$$

onde o crescimento de consumo tem uma constante correlação com o retorno do ativo. Isto gera um prêmio de risco proporcional a $v, \lambda(S, v, t)=\lambda v$. Embora Heston se utilize desta forma para o prêmio de risco, os resultados do apreçamento são obtidos por arbitragem (e não por equilíbrio geral) e não depende das premissas de Breeden (1979) e Cox, Ingerson e Ross (1985).Contudo, o modelo de Heston é consistente com a heterocedasticidade condicional no crescimento do consumo assim como do retorno do ativo.
} 


\subsection{O Modelo de Referência para a Calibração dos Modelos de Volatilidade Estocástica - Modelo de Garman-Kohlhagen}

Conforme mencionado na introdução, o modelo de Garman-Kohlhagen será utilizado como o modelo de referência para a determinação dos preços das opções, ou seja, assumese que o mercado utiliza este modelo para a determinação dos preços das opções européias no Brasil.

O modelo de Garman-Kohlhagen (1983) é uma modificação do modelo de Black que também é usualmente utilizado para o apreçamento de opções européias de câmbio. O modelo é similar ao modelo de Merton (1973) que foi apresentado anos antes, onde a única diferença é que o rendimento do dividendo $q$ é substituído pela taxa de juros "livre de risco" na moeda estrangeira da opção, $r_{f}$.

Abaixo são descritas as fórmulas dos preços das opções de compra (call) e venda (put) segundo o modelo de Garman-Kohlhagen: ${ }^{11}$

$$
\begin{gathered}
\text { call }=S e^{-r_{f} T} N\left(d_{1}\right)-K e^{-r T} N\left(d_{2}\right) \\
p u t=K e^{-r T} N\left(-d_{2}\right)-S e^{-r_{f} T} N\left(-d_{1}\right)
\end{gathered}
$$

Onde

$$
\begin{gathered}
d_{1}=\frac{\ln (S / K)+\left(\left(r-r_{f}+\sigma^{2} / 2\right) T\right.}{\sigma \sqrt{T}} \\
d_{2}=\frac{\ln (S / K)+\left(\left(r-r_{f}-\sigma^{2} / 2\right) T\right.}{\sigma \sqrt{T}}=d_{1}-\sigma \sqrt{T}
\end{gathered}
$$

\footnotetext{
${ }^{11}$ Maiores detalhes sobre o modelo de Garman-Kohlhagen serão abordados na seç̧ão de descrição dos dados de mercado. No apêndice, encontra-se a função garmanc.m que calcula os preços do modelo Garman-Kohlhagen.
} 


\section{Capítulo 3}

\section{O Mercado de Derivativos de}

\section{Câmbio Brasileiro - Fatos Estilizados}

\subsection{Uma Breve Descrição}

A economia brasileira dos anos 80 e inícios dos anos 90 foi caracterizada por um período de fortes pressões inflacionárias, chegando-se a existir uma indexação dos preços à moeda norte-americana. A introdução do Plano Real em dezembro de 1993, tinha como objetivo principal o controle deste processo inflacionário que se tornava cada vez mais insustentável para o país. Anteriormente, alguns choques econômicos foram tentados mas todos fracassaram: alta de impostos, congelamento de preços, bloqueio de contas bancárias, etc. Assim, uma nova moeda fora criada de forma que juntamente com uma série de medidas econômicas (privatizações, redução de déficit fiscal, implementação de reformas estruturais, etc) a estabilização econômica fosse alcançada. A nova moeda e principal símbolo do Plano, o Real, era administrada pelo Banco Central através de uma política de "bandas", onde a intenção era a realização de uma desvalorização cambial gradual, à medida que o governo implementava suas reformas juntamente com o Congresso.

Com as inesperadas crises da Ásia em julho de 1997 e da Rússia em agosto de 1998, 
tornou-se cada vez mais difícil a implementação dessas reformas o que levou o mercado internacional a "especular" sobre a viabilidade deste regime cambial. Após alguns ataques especulativos contra o Real, o Banco Central anunciou uma nova "definição" para a banda cambial (a tão conhecida "banda diagonal exógena") não sendo suficiente para conter os ataques especulativos daquele dia, 12 de janeiro de 1999. Assim, no dia seguinte, o Banco Central decidiu abandonar o sistema de bandas e passou a adotar uma política de câmbio flutuante para o Real (vide figura 1 abaixo).

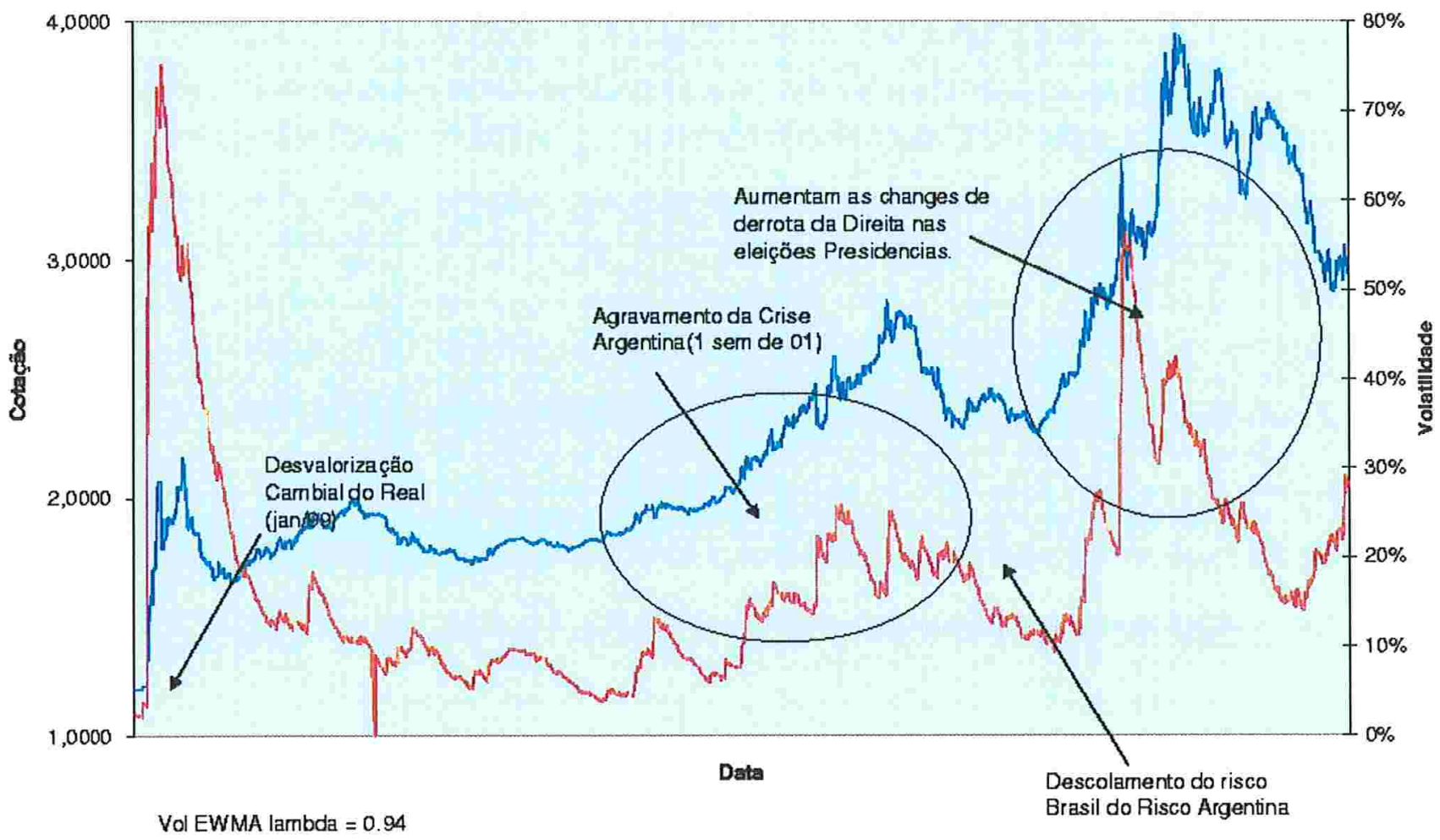

Figura' -Gráfico da Evolução da Cotação $\theta$ Volatilidade R\$/USD entre Dez/1998 e Mar/2003

Com a adoção deste novo regime cambial, o Banco Central pôde-se utilizar de intervenções no mercado de câmbio como um instrumento de política monetária, onde até então, as taxas de juros eram utilizadas como instrumento de atuação direta.

Após a desvalorização cambial vários outros episódios ocorreram na economia brasileira e mundial tais como a crise da Argentina, atentados do 11 de setembro, eleições presiden- 
ciais, etc. Isto tudo forçou o Banco Central a ter no câmbio seu principal instrumento de defesa da economia brasileira e levou também as instituições financeiras e empresas a buscarem proteção contra possíveis desvalorizações cambiais ou possíveis cenários de estresse.

Nesse contexto, o mercado foi "forçado" a utilizar e difundir um mercado de derivativos mais eficiente tal que os agentes econômicos pudessem buscar formas de proteção ("hedge") mais diversificadas e transparentes. Além dos contratos de derivativos de balcão como swaps e opções de moedas, os contratos futuros da BM\&F se tornaram bastante atraentes pois seu sistema de margens de garantias diversificava o risco de crédito das contra-partes resultando teoricamente apenas num risco de crédito sistêmico, barateando assim, o custo de capital para estas operações.

É notório salientar que dadas as particularidades do mercado de câmbio no Brasil, alguns fatos estilizados são facilmente observados e que podem comprometer a mensuração das suas medidas de risco ou até propriamente os preços de negociação do seus derivativos.

Abaixo estão listados alguns desses fatos estilizados e seus efeitos no apreçamento dos ativos e hedge. Conforme descrito, evidencia-se que a utilização do modelo de Heston é bem mais robusta que o modelo de Garman-Kohlhagen para estes fatos estilizados.

\section{A não lognormalidade da cotação $\mathrm{R} \$ / \mathrm{USD}$}

O modelo de Garman-Kohlhagen, por exemplo, assume que o ativo-objeto de uma opção européia é lognormal, o que não é verdade para a cotação R \$/USD principalmente para trajetórias de curto prazo (como para os prazos médios das opções de câmbio da BM\&F). Mesmo considerando-se janelas maiores para a trajetória do câmbio pode-se ter esta inconsistência. Pelo fato do Brasil estar sob um desequilíbrio macro-econômico - descontrole inflacionário em relação à moeda americana, os preços futuros da cotação R $\$ / U S D$ geralmente projetam uma desvalorização do Real frente ao Dólar, isto mostra que existe uma maior probabilidade de uma depreciação do Real que uma valorização, de forma que não se pode assumir que os retornos são normalmente distribuídos (vide figura 2). Apesar do modelo de Heston 
também assumir que os preços são lognormais, tem-se uma volatilidade estocástica incorporada à equação de difusão do preço do ativo-objeto da opção.
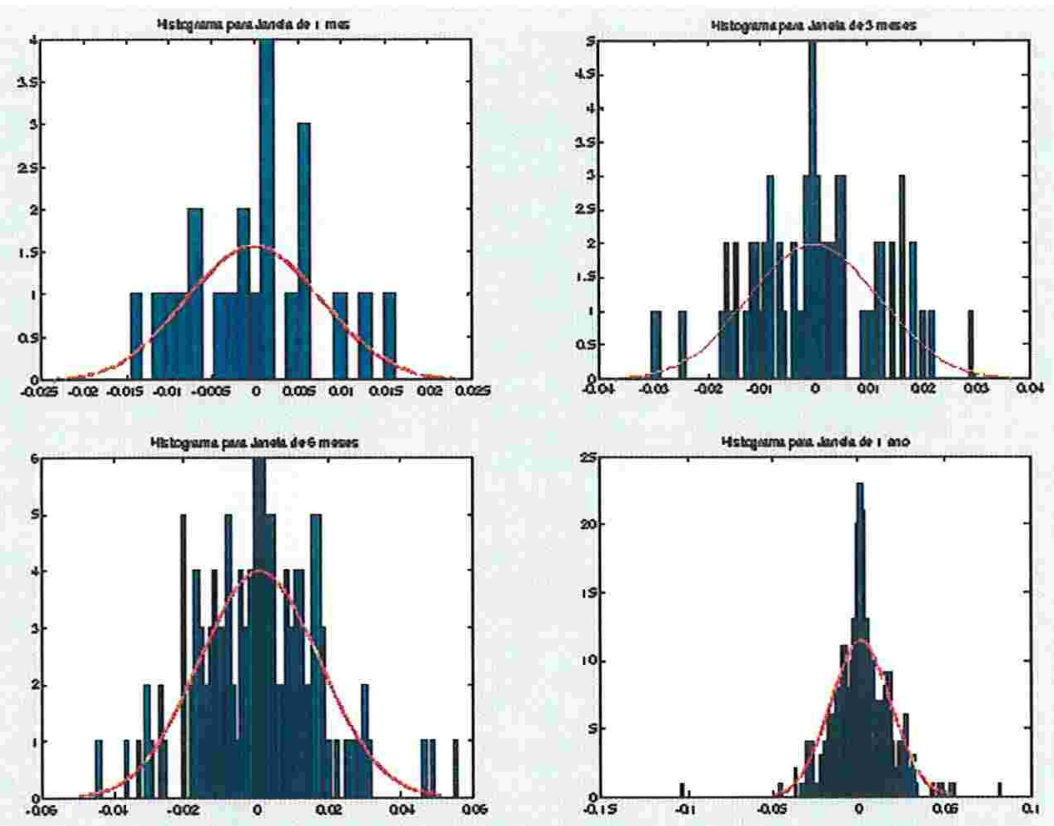

Figura 2 - Histograma para diferentes janelas dos retornos logarítmicos do R\$/USD Data-base = 28/02/2003 ( ủltima observação)

2. A existência de uma correlação entre a volatilidade da cotação R\$/USD e os retornos desta cotação

Empiricamente, observa-se que em momentos de crise ou desvalorização do Real, existe um aumento relativamente maior na volatilidade do que quando se tem uma valorização do Real. Efeito similar ocorre também no mercado acionário. Em momentos de crise, os preços caem e as volatilidades aumentam. O modelo de GarmanKohlhagen não incorpora esta premissa e este fato é adicionado aos seus preços intuitivamente pelo mercado. Conforme mencionado, o modelo de Heston apresenta esta correlação $(\rho)$ explicitamente como um dos fatores do modelo.

3. Existência de processos de saltos na cotação $\mathbf{R} \$ /$ USD 
Devido à forte atuação da autoridade monetária no mercado à vista para conter ataques especulativos e algumas vezes à própria falta de liquidez, a cotação R\$/USD é passiva de ocorrência de saltos na sua dinâmica, o que também não é incorporado no modelo de Garman-Kohlhagen. Apesar do modelo de Heston não possuir parâmetros explícitos para capturar este fenômeno, o modelo de Bakshi et al (1997), modelo estendido de Heston, incorpora este fato estilizado através de um parâmetro de frequência de saltos, modelado por uma distribuição de Poisson para suas intensidades.

\section{Existência de cupom cambial com valores negativos}

Em alguns momentos, as taxas de cupom cambial podem apresentar valores negativos (mesmo o cupom limpo!). Isto ocorre devido a situações onde a oferta de moeda norte-americana à vista é bem maior que a oferta dos contratos futuros.

\section{5. "Sorrisos" das opções quase sempre não apresentam a forma esperada}

Dado que o mercado brasileiro apresenta constantemente maiores probabilidades de desvalorização do que valorização do Real, o valor das volatilidades para opções de compra fora do dinheiro apresenta uma volatilidade bem maior que as opções bastante dentro do dinheiro. Isto faz com que o "sorriso" não seja simétrico conforme é esperado na teoria (vide figuras 3.a e 3.b). 


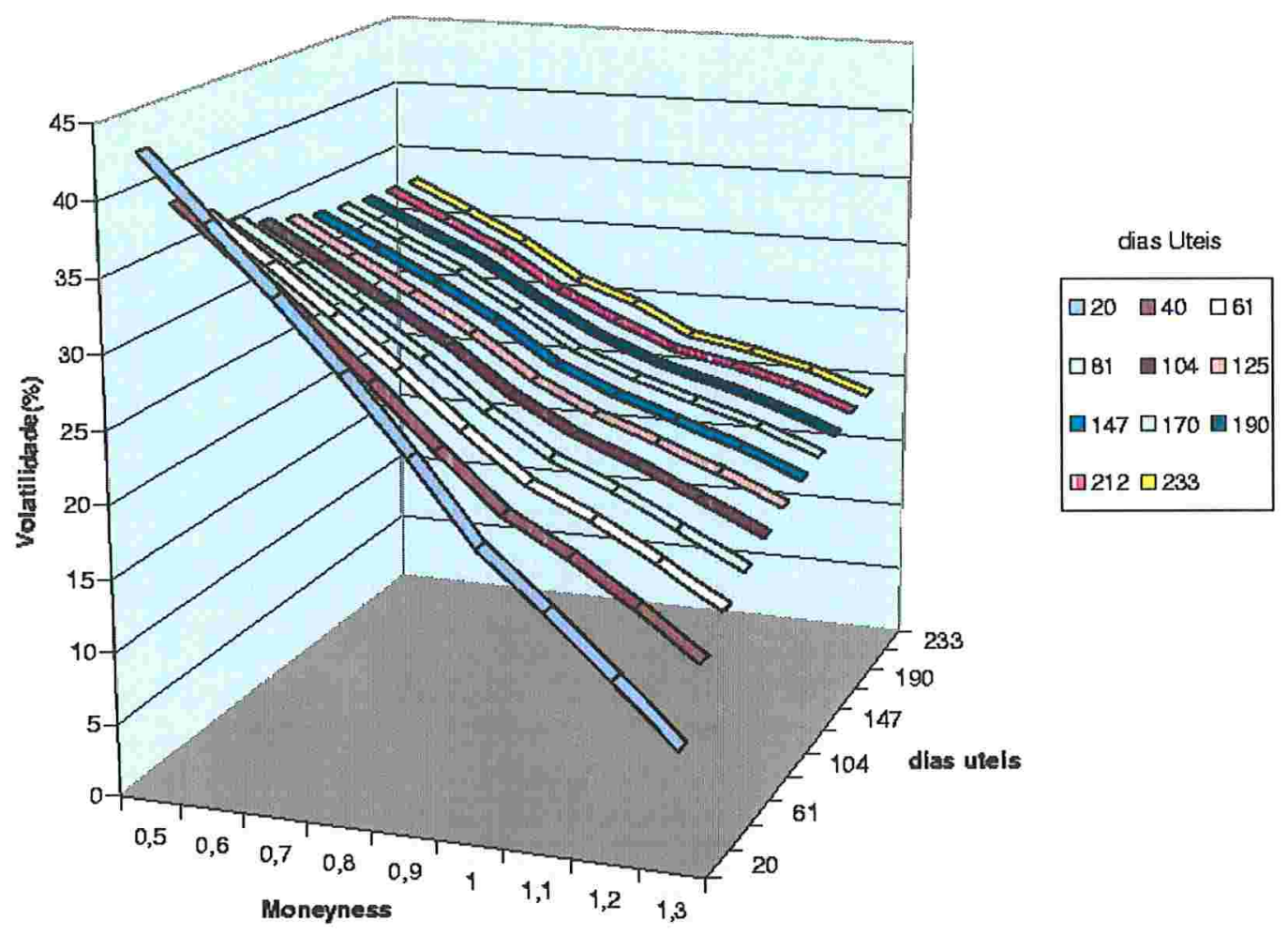

Figura 3.a - Smile de Volatilidade para Calls R\$/USD om 28/02/2003

Para se produzir o "sorriso" das opções pelo modelo de Garman-Kohlhagen, as volatilidades precisam ser ajustadas para cada prazo e preço de exercício. No modelo de Heston, o "sorriso" das opções é capturado através dos seus parâmetros, pois neles se incorpora o prêmio de risco da volatilidade. 


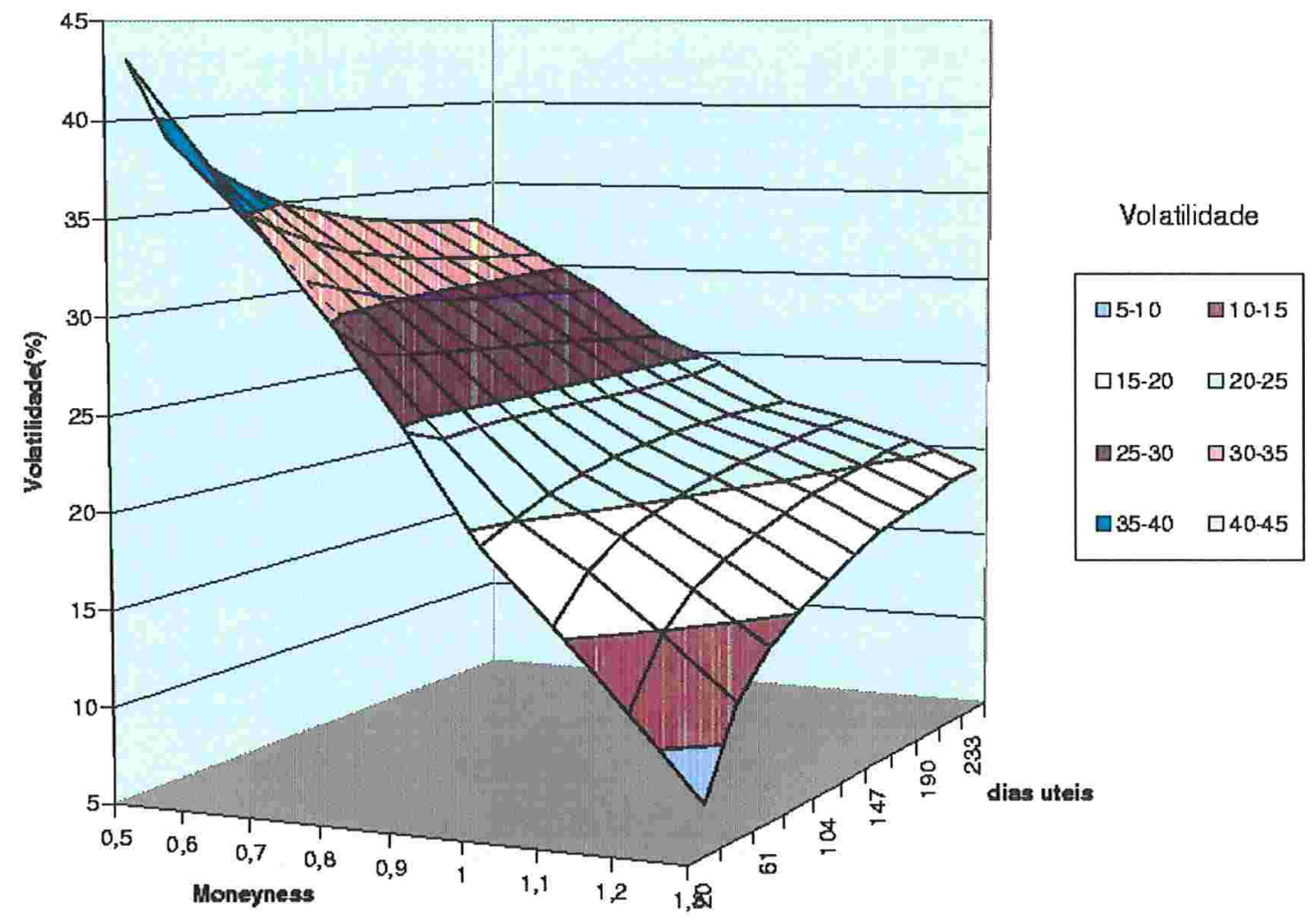

Figura 3.b - Superficie de Volatilidade para diferentes Prazos e Moneyness em 28/02/2003

\subsection{Descrição dos Dados de Mercado Utilizados}

Para o apreçamento das opções conforme descrito nos modelos anteriores, utilizou-se dados de mercados conforme descrito abaixo.

- Volatilidade Implícita das Opções de Câmbio R\$/USD

A matriz de volatilidade da Reuters é publicada diariamente como uma referência das volatilidade implícitas de fechamento do mercado de opções de câmbio R $\$ /$ USD para aquela data. Este pool de contribuintes é formado por instituições financeiras que participam efetivamente deste mercado tal que se pode considerar que os dados realmente refletem o mercado doméstico para este tipo de opção. A matriz está formatada para diferentes prazos: $1 \mathrm{M}, 2 \mathrm{M}, 3 \mathrm{M}, \ldots, 12 \mathrm{M}$, onde $1 \mathrm{M}$ significa o próximo 
vencimento dos contratos futuros de $R \$ / U S D$ da $B M \& F, 2 M$ representa o segundo vencimento e assim por diante até o $12^{\circ}$ vencimento, ou seja, tem-se os "vértices" mensais até o horizonte de um ano. A matriz também é dividida por diferentes valores de "deltas forward" ou $N(d 1)$ conforme a tabela a seguir:"

\begin{tabular}{|l|l|l|l|}
\hline $10 \%$ & $25 \%$ & $37 \%$ & ATM \\
\hline
\end{tabular}

Através da fórmula $N(d 1)_{\text {call }}=1-N(d 1)_{\text {put }}$ pode-se encontrar as volatilidades para os "deltas forward" de $90 \%, 75 \%$ e $63 \%$ para as Calls e Puts. Após a montagem dos dados pela conversão acima pôde-se redimensionar a tabela acima para os seguintes pontos:

\begin{tabular}{|l|l|l|l|l|l|l|}
\hline $10 \%$ & $25 \%$ & $37 \%$ & ATM & $63 \%$ & $75 \%$ & $90 \%$ \\
\hline
\end{tabular}

Para os prazos e os "deltas-forward" acima, a matriz está particionada em volatilidades para valores de BID (compra) e ASK (venda). Na calibração considerou-se somente os preços médios dos dois valores de compra e venda. Um exemplo da matriz de volatilidade da Reuters pode ser vista na figura 4 a seguir.

\footnotetext{
${ }^{1} \mathrm{O}$ delta para opções de câmbio é dado por $\Delta=\frac{\partial C}{\partial S}=e^{-r_{f} \tau} N\left(d_{1}\right)$ onde $N\left(d_{1}\right)$ é o delta forward.
} 


\begin{tabular}{|c|c|c|c|c|c|c|c|}
\hline Date & Currency & Type & BID/ASK & Time_Maturit & Time_Maturit & Delta & Volatility \\
\hline 5-mar-03 & USD & CALL & ASK & $1 \mathrm{M}$ & 30 & \begin{tabular}{l|l}
0,10 \\
\end{tabular} & 20,140 \\
\hline 5-mar-03 & USD & CALL & ASK & $2 \mathrm{M}$ & 60 & 0,10 & 20,950 \\
\hline 5-mar-03 & USD & CALL & ASK & $3 \mathrm{M}$ & 90 & \begin{tabular}{l|}
0,10 \\
\end{tabular} & 23,780 \\
\hline 5-mar-03 & USD & CALL & ASK & $4 \mathrm{M}$ & 120 & 0,10 & 24,870 \\
\hline 5-mar-03 & USD & CALL & ASK & $5 \mathrm{M}$ & 150 & 0,10 & 25,730 \\
\hline 5-mar-03 & USD & CALL & ASK & $6 \mathrm{M}$ & 180 & 0,10 & 26,270 \\
\hline 5-mar-03 & USD & CALL & ASK & $7 \mathrm{M}$ & 210 & 0,10 & 26,850 \\
\hline 5-mar-03 & USD & CALL & ASK & $8 \mathrm{M}$ & 240 & 0,10 & 27,170 \\
\hline 5-mar-03 & USD & CALL & ASK & $9 \mathrm{M}$ & 270 & \begin{tabular}{l|l}
0,10 \\
\end{tabular} & 27,620 \\
\hline 5-mar-03 & USD & CALL & ASK & $10 \mathrm{M}$ & 300 & \begin{tabular}{l|l|}
0,10 \\
\end{tabular} & 28,010 \\
\hline 5-mar-03 & USD & CALL & ASK & $11 \mathrm{M}$ & 330 & 0,10 & 28,440 \\
\hline 5-mar-03 & USD & CALL & ASK & $12 \mathrm{M}$ & 360 & \begin{tabular}{l|l|}
0,10 \\
\end{tabular} & 28,800 \\
\hline 5-mar-03 & USD & CALL & ASK & $1 \mathrm{M}$ & 30 & 0,25 & 29,110 \\
\hline 5-mar-03 & USD & CALL & ASK & $2 M$ & 60 & 0,25 & 20,650 \\
\hline 5-mar-03 & USD & CALL & ASK & $3 \mathrm{M}$ & 90 & 0,25 & 23,740 \\
\hline 5-mar-03 & USD & CALL & ASK & $4 \mathrm{M}$ & 120 & 0,25 & 24,980 \\
\hline 5-mar-03 & USD & CALL & ASK & $5 \mathrm{M}$ & 150 & 0,25 & 25,790 \\
\hline 5-mar-03 & USD & CALL & ASK & $6 \mathrm{M}$ & 180 & 0.25 & 26,520 \\
\hline 5-mar-03 & USD & CALL & ASK & $7 \mathrm{M}$ & 210 & 0,25 & 26,920 \\
\hline 5-mar-03 & USD & CALL & ASK & $8 \mathrm{M}$ & 240 & 0,25 & 27,370 \\
\hline 5-mar-03 & USD & CALL & ASK & $9 \mathrm{M}$ & 270 & 0,25 & 27,940 \\
\hline 5-mar-03 & USD & CALL & ASK & $10 \mathrm{M}$ & 300 & 0,25 & 28,460 \\
\hline 5-mar-03 & USD & CALL & ASK & $11 \mathrm{M}$ & 330 & 0,25 & 28,630 \\
\hline 5-mar-03 & USD & CALL & ASK & $12 M$ & 360 & 0,25 & 28,890 \\
\hline 5-mar-03 & USD & CALL & ASK & $1 \mathrm{M}$ & 30 & \begin{tabular}{l|l|}
0,37 \\
\end{tabular} & 29,240 \\
\hline 5-mar-03 & USD & CALL & ASK & $2 M$ & 60 & \begin{tabular}{l|l}
0,37 \\
\end{tabular} & 19,350 \\
\hline 5-mar-03 & USD & CALL & ASK & $3 M$ & 90 & \begin{tabular}{l|l|}
0,37 \\
\end{tabular} & 22,260 \\
\hline 5-mar-03 & USD & CALL & ASK & $4 \mathrm{M}$ & 120 & 0,37 & 23,280 \\
\hline 5-mar-03 & USD & CALL & ASK & $5 \mathrm{M}$ & 150 & \begin{tabular}{|l|l|}
0,37 \\
\end{tabular} & 24,000 \\
\hline 5-mar-03 & USD & CALL & ASK & $6 \mathrm{M}$ & 180 & 0,37 & 24,520 \\
\hline 5-mar-03 & USD & CALL & ASK & $7 \mathrm{M}$ & 210 & 0,37 & 24,960 \\
\hline 5-mar-03 & USD & CALL & ASK & $8 \mathrm{M}$ & 240 & 0,37 & 25,470 \\
\hline 5-mar-03 & USD & CALL & ASK & $9 \mathrm{M}$ & 270 & 0,37 & 25,780 \\
\hline 5-mar-03 & USD & CALL & ASK & $10 \mathrm{M}$ & 300 & 0,37 & 26,180 \\
\hline 5-mar-03 & USD & CALL & ASK & $11 \mathrm{M}$ & 330 & \begin{tabular}{l|l|}
0,37 \\
\end{tabular} & 26,340 \\
\hline 5-mar-03 & USD & CALL & ASK & $12 \mathrm{M}$ & 360 & \begin{tabular}{l|l|}
0,37 \\
\end{tabular} & 26,640 \\
\hline 5-mar-03 & USD & CALL & ASK & $1 \mathrm{M}$ & 30 & ATM & 26,910 \\
\hline 5-mar-03 & USD & CALL & ASK & $2 M$ & 60 & ATM & 18,220 \\
\hline 5-mar-03 & USD & CALL & ASK & $3 \mathrm{M}$ & 90 & ATM & 21,300 \\
\hline 5-mar-03 & USD & CALL & ASK & $4 \mathrm{M}$ & 120 & ATM & 22,090 \\
\hline 5-mar-03 & USD & CALL & ASK & $5 \mathrm{M}$ & 150 & ATM & 22,860 \\
\hline 5-mar-03 & USD & CALL & ASK & $6 \mathrm{M}$ & 180 & ATM & 23,340 \\
\hline 5-mar-03 & USD & CALL & ASK & $7 \mathrm{M}$ & 210 & ATM & 23,890 \\
\hline 5-mar-03 & USD & CALL & ASK & $8 \mathrm{M}$ & 240 & ATM & 24,360 \\
\hline 5-mar-03 & USD & CALL & ASK & $9 \mathrm{M}$ & 270 & ATM & 24,590 \\
\hline 5-mar-03 & USD & CALL & ASK & $10 \mathrm{M}$ & 300 & ATM & 25,020 \\
\hline 5-mar-03 & USD & CALL & ASK & $11 \mathrm{M}$ & 330 & ATM & 25,340 \\
\hline 5-mar-03 & USD & CALL & ASK & $12 M$ & 360 & ATM & 25,470 \\
\hline 5-mar-03 & USD & PUT & ASK & $1 \mathrm{M}$ & 30 & 0,10 & 25,580 \\
\hline 5-mar-03 & USD & PUT & ASK & $2 M$ & 60 & 0,10 & 16,670 \\
\hline 5-mar-03 & USD & PUT & ASK & $3 M$ & 90 & 0,10 & 18,970 \\
\hline 5-mar-03 & USD & PUT & ASK & $4 \mathrm{M}$ & 120 & \begin{tabular}{l|l}
0,10 \\
\end{tabular} & 19,670 \\
\hline 5-mar-03 & USD & PUT & ASK & $5 \mathrm{M}$ & 150 & 0,10 & 20,120 \\
\hline 5-mar-03 & USD & PUT & ASK & $6 M$ & 180 & 0,10 & 20,590 \\
\hline 5-mar-03 & USD & PUT & ASK & $7 M$ & 210 & 0,10 & 21,010 \\
\hline 5-mar-03 & USD & PUT & ASK & $8 M$ & 240 & 0,10 & 21,520 \\
\hline 5-mar-03 & USD & PUT & ASK & $9 \mathrm{M}$ & 270 & 0.10 & 21,780 \\
\hline 5-mar-03 & USD & PUT & ASK & $10 \mathrm{M}$ & 300 & 0,10 & 21,980 \\
\hline 5-mar-03 & USD & PUT & ASK & $11 \mathrm{M}$ & 330 & 0,10 & 22,330 \\
\hline 5-mar-03 & USD & PUT & ASK & $12 \mathrm{M}$ & 360 & 0.10 & 22,430 \\
\hline 5-mar-03 & USD & PUT & ASK & $1 \mathrm{M}$ & 30 & 0,25 & 22,510 \\
\hline 5-mar-03 & USD & PUT & ASK & $2 M$ & 60 & 0,25 & 17,180 \\
\hline 5-mar-03 & USD & PUT & ASK & $3 M$ & 90 & 0,25 & 19,720 \\
\hline 5-mar-03 & USD & PUT & ASK & $4 \mathrm{M}$ & 120 & 0,25 & 20,290 \\
\hline 5-mar-03 & USD & PUT & ASK & $5 \mathrm{M}$ & 150 & 0,25 & 20,920 \\
\hline 5-mar-03 & USD & PUT & ASK & $6 \mathrm{M}$ & 180 & 0,25 & 21,510 \\
\hline 5-mar-03 & USD & PUT & ASK & $7 \mathrm{M}$ & 210 & \begin{tabular}{l|l}
0,25 \\
\end{tabular} & 21,930 \\
\hline 5-mar-03 & USD & PUT & ASK & $8 \mathrm{M}$ & 240 & 0,25 & 22,400 \\
\hline 5-mar-03 & USD & PUT & ASK & $9 \mathrm{M}$ & 270 & 0,25 & 22,660 \\
\hline 5-mar-03 & USD & PUT & ASK & $10 \mathrm{M}$ & 300 & 0,25 & 23,120 \\
\hline 5-mar-03 & USD & PUT & ASK & $11 \mathrm{M}$ & 330 & 0,25 & 23,220 \\
\hline 5-mar-03 & USD & PUT & ASK & $12 \mathrm{M}$ & 360 & \begin{tabular}{l|l|}
0,25 \\
\end{tabular} & 23,360 \\
\hline 5-mar-03 & USD & PUT & ASK & IM & 30 & \begin{tabular}{l|l|}
0,37 \\
\end{tabular} & 23,490 \\
\hline 5-mar-03 & USD & PUT & ASK & $2 M$ & 60 & \begin{tabular}{l|l|}
0,37 \\
\end{tabular} & 17,850 \\
\hline 5-mar-03 & USD & PUT & ASK & $3 \mathrm{M}$ & 90 & \begin{tabular}{|l|}
0,37 \\
\end{tabular} & 20,220 \\
\hline 5-mar-03 & USD & PUT & ASK & $4 \mathrm{M}$ & 120 & \begin{tabular}{l|l|}
0,37 \\
\end{tabular} & 21,400 \\
\hline 5-mar-03 & USD & PUT & ASK & $5 M$ & 150 & \begin{tabular}{l|l|}
0,37 \\
\end{tabular} & 22,110 \\
\hline 5 -mar-03 & USD & PUT & ASK & $6 \mathrm{M}$ & 180 & \begin{tabular}{l|l|}
0,37 \\
\end{tabular} & 22,730 \\
\hline 5-mar-03 & USD & PUT & ASK & $7 \mathrm{M}$ & 210 & \begin{tabular}{l|l|}
0,37 \\
\end{tabular} & 23,150 \\
\hline 5-mar-03 & USD & PUT & ASK & $8 \mathrm{M}$ & 240 & 0,37 & 23,620 \\
\hline 5-mar-03 & USD & PUT & ASK & $9 \mathrm{M}$ & 270 & $\begin{array}{ll}0,37 \\
\end{array}$ & 23,870 \\
\hline 5-mar-03 & USD & PUT & ASK & $10 \mathrm{M}$ & 300 & \begin{tabular}{l|l|}
0,37 \\
\end{tabular} & 24,200 \\
\hline 5-mar-03 & USD & PUT & ASK & $11 \mathrm{M}$ & 330 & 0,37 & 24,420 \\
\hline 5-mar-03 & USD & PUT & ASK & $12 \mathrm{M}$ & 360 & 0,37 & 24,590 \\
\hline
\end{tabular}

\begin{tabular}{|c|c|c|c|c|c|c|c|}
\hline Date & Currency & Type & BID/ASK & Time_Maturit & Time_Maturit & Delta 15 & Volatility \\
\hline 5-mar-03 & USD & CALL & BID & $1 \mathrm{M}$ & 30 & 0,10 & 19,950 \\
\hline 5-mar-03 & USD & CALL & BID & $2 M$ & 60 & 0.10 & 22,780 \\
\hline 5-mar-03 & USD & CALL & BID & $3 M$ & 90 & 0,10 & 23,870 \\
\hline 5-mar-03 & USD & CALL & BID & $4 \mathrm{M}$ & 120 & 0,10 & 24,730 \\
\hline 5-mar-03 & USD & CALL & BID & $5 \mathrm{M}$ & 150 & 0,10 & 25,140 \\
\hline 5-mar-03 & USD & CALL & BID & $6 \mathrm{M}$ & 180 & 0,10 & 25,720 \\
\hline 5-mar-03 & USD & CALL & BID & $7 \mathrm{M}$ & 210 & 0,10 & 25,920 \\
\hline 5-mar-03 & USD & CALL & BID & $8 \mathrm{M}$ & 240 & 0,10 & 26,370 \\
\hline 5-mar-03 & USD & CALL & BID & $9 \mathrm{M}$ & 270 & 0.10 & 26,760 \\
\hline 5-mar-03 & USD & CALL & BID & $10 \mathrm{M}$ & 300 & 0,10 & 27,060 \\
\hline 5-mar-03 & USD & CALL & BID & $11 \mathrm{M}$ & 330 & 0,10 & 27,430 \\
\hline 5-mar-03 & USD & CALL & BID & $12 \mathrm{M}$ & 360 & 0.10 & 27,740 \\
\hline 5-mar-03 & USD & CALL & BID & $1 \mathrm{M}$ & $30 \mid$ & 0,25 & 19,650 \\
\hline 5-mar-03 & USD & CALL & BID & $2 \mathrm{M}$ & $60 \mid$ & 0,25 & 22,740 \\
\hline 5-mar-03 & USD & CALL & BID & $3 M$ & 90 & 0,25 & 23,980 \\
\hline 5-mar-03 & USD & CALL & BID & $4 \mathrm{M}$ & 120 & 0,25 & 24,790 \\
\hline 5-mar-03 & USD & CALL & BID & $5 \mathrm{M}$ & 150 & 0,25 & 25,520 \\
\hline 5-mar-03 & USD & CALL & BID & $6 \mathrm{M}$ & 180 & 0,25 & 25,920 \\
\hline 5-mar-03 & USD & CALL & BID & $7 \mathrm{M}$ & 210 & 0.25 & 26.240 \\
\hline 5-mar-03 & USD & CALL & BID & $8 \mathrm{M}$ & 240 & 0,25 & 26,810 \\
\hline 5-mar-03 & USD & CALL & BID & $9 \mathrm{M}$ & 270 & 0,25 & 27,210 \\
\hline 5-mar-03 & USD & CALL & BID & $10 \mathrm{M}$ & 300 & 0,25 & 27,380 \\
\hline 5-mar-03 & USD & CALL & BID & $11 \mathrm{M}$ & 330 & 0,25 & 27,640 \\
\hline 5-mar-03 & USD & CALL & BID & $12 \mathrm{M}$ & 360 & 0,25 & 27,990 \\
\hline 5-mar-03 & USD & CALL & BID & $1 \mathrm{M}$ & 30 & 0,37 & 18,350 \\
\hline 5-mar-03 & USD & CALL & BID & $2 \mathrm{M}$ & 60 & 0,37 & 21,260 \\
\hline 5-mar-03 & USD & CALL & BID & $3 \mathrm{M}$ & 90 & 0,37 & 22,280 \\
\hline 5-mar-03 & USD & CALL & BID & $4 \mathrm{M}$ & 120 & 0,37 & 23,000 \\
\hline 5-mar-03 & USD & CALL & BID & $5 \mathrm{M}$ & 150 & 0,37 & 23,520 \\
\hline 5-mar-03 & USD & CALL & BID & $6 \mathrm{M}$ & 180 & 0.37 & 23,960 \\
\hline 5-mar-03 & USD & CALL & BID & $7 \mathrm{M}$ & 210 & 0,37 & 24,340 \\
\hline 5-mar-03 & USD & CALL & $B I D$ & $8 \mathrm{M}$ & 240 & 0,37 & 24,650 \\
\hline 5-mar-03 & USD & CALL & BID & $9 \mathrm{M}$ & 270 & 0,37 & 24,930 \\
\hline 5-mar-03 & USD & CALL & BID & $10 \mathrm{M}$ & 300 & 0,37 & 25,090 \\
\hline 5-mar-03 & USD & CALL & BID & $11 \mathrm{M}$ & 330 & 0,37 & 25,390 \\
\hline 5-mar-03 & USD & CALL & BID & $12 \mathrm{M}$ & 360 & 0,37 & 25,660 \\
\hline 5-mar-03 & USD & CALL & BID & $1 \mathrm{M}$ & 30 & ATM & 17,220 \\
\hline 5-mar-03 & USD & CALL & BID & $2 M$ & 60 & ATM & 20,300 \\
\hline 5-mar-03 & USD & CALL & BID & $3 M$ & 90 & ATM & 21,090 \\
\hline 5-mar-03 & USD & CALL & BID & $4 \mathrm{M}$ & 120 & ATM & 21,860 \\
\hline 5-mar-03 & USD & CALL & BID & $5 \mathrm{M}$ & 150 & ATM & 22,340 \\
\hline 5-mar-03 & USD & CALL & BID & $6 \mathrm{M}$ & 180 & ATM & 22,890 \\
\hline 5-mar-03 & USD & CALL & $B I D$ & $7 M$ & 210 & ATM & 23,240 \\
\hline 5-mar-03 & USD & CALL & $B$ ID & $8 M$ & 240 & ATM & 23,460 \\
\hline 5-mar-03 & USD & CALL & $B$ ID & $9 \mathrm{M}$ & 270 & ATM & 23,770 \\
\hline 5-mar-03 & USD & CALL & BID & $10 \mathrm{M}$ & 300 & ATM & 24,090 \\
\hline 5-mar-03 & USD & CALL & BID & $11 \mathrm{M}$ & 330 & ATM & 24,220 \\
\hline 5-mar-03 & USD & CALL & BID & $12 \mathrm{M}$ & 360 & ATM & 24,330 \\
\hline 5-mar-03 & USD & PUT & BID & $1 \mathrm{M}$ & 30 & 0,10 & 15,670 \\
\hline 5-mar-03 & USD & PUT & $B I D$ & $2 M$ & 60 & 0,10 & 17,970 \\
\hline 5-mar-03 & USD & PUT & BID & $3 M$ & 90 & 0,10 & 18,670 \\
\hline 5-mar-03 & USD & PUT & $B$ ID & $4 \mathrm{M}$ & 120 & 0,10 & 19,120 \\
\hline 5-mar-03 & USD & PUT & BID & $5 \mathrm{M}$ & 150 & 0,10 & 19,460 \\
\hline 5-mar-03 & USD & PUT & BID & $6 \mathrm{M}$ & 180 & 0,10 & 19,890 \\
\hline 5-mar-03 & USD & PUT & BID & $7 \mathrm{M}$ & 210 & 0,10 & 20,270 \\
\hline 5-mar-03 & USD & PUT & $B I D$ & $8 \mathrm{M}$ & 240 & 0,10 & 20,530 \\
\hline 5-mar-03 & USD & PUT & $B$ BD & $9 \mathrm{M}$ & 270 & 0,10 & 20,730 \\
\hline 5-mar-03 & USD & PUT & $B I D$ & $10 \mathrm{M}$ & 300 & 0,10 & 20,950 \\
\hline 5-mar-03 & USD & PUT & BID & $11 \mathrm{M}$ & 330 & 0,10 & 21,050 \\
\hline 5-mar-03 & USD & PUT & BID & $12 \mathrm{M}$ & 360 & 0,10 & 21,140 \\
\hline 5-mar-03 & USD & PUT & $B$ BD & $1 \mathrm{M}$ & 30 & 0,25 & 16,180 \\
\hline 5-mar-03 & USD & PUT & BID & $2 \mathrm{M}$ & 60 & 0,25 & 18,720 \\
\hline 5-mar-03 & USD & PUT & $B$ BID & $3 \mathrm{M}$ & 90 & 0,25 & 19,290 \\
\hline 5-mar-03 & USD & PUT & BID & $4 \mathrm{M}$ & 120 & 0,25 & 19,920 \\
\hline 5-mar-03 & USD & PUT & BID & $5 \mathrm{M}$ & 150 & 0,25 & 20,510 \\
\hline 5-mar-03 & USD & PUT & BID & $6 \mathrm{M}$ & 180 & 0,25 & 20,930 \\
\hline 5-mar-03 & USD & PUT & BID & $7 \mathrm{M}$ & 210 & 0,25 & 21,270 \\
\hline 5-mar-03 & USD & PUT & $B$ BD & $8 \mathrm{M}$ & 240 & 0,25 & 21,540 \\
\hline 5-mar-03 & USD & PUT & BID & $9 \mathrm{M}$ & 270 & 0,25 & 21,870 \\
\hline 5-mar-03 & USD & PUT & BID & $10 \mathrm{M}$ & 300 & 0,25 & 21,970 \\
\hline 5-mar-03 & USD & PUT & BID & $11 \mathrm{M}$ & 330 & 0,25 & 22,110 \\
\hline 5-mar-03 & USD & PUT & BID & $12 \mathrm{M}$ & 360 & 0,25 & 22,240 \\
\hline 5-mar-03 & USD & PUT & BID & $1 \mathrm{M}$ & 30 & 0,37 & 16,850 \\
\hline 5-mar-03 & USD & PUT & BID & $2 M$ & 60 & 0,37 & 19,220 \\
\hline 5-mar-03 & USD & PUT & BID & $3 M$ & 90 & 0,37 & 20,400 \\
\hline 5-mar-03 & USD & PUT & BID & $4 \mathrm{M}$ & 120 & 0,37 & 21,110 \\
\hline 5-mar-03 & USD & PUT & BID & $5 \mathrm{M}$ & 150 & 0,37 & 21,730 \\
\hline 5-mar-03 & USD & PUT & BID & $6 M$ & 180 & 0,37 & 22,150 \\
\hline 5-mar-03 & USD & PUT & BID & $7 \mathrm{M}$ & 210 & 0,37 & 22,490 \\
\hline 5-mar-03 & USD & PUT & BID & $8 \mathrm{M}$ & 240 & 0,37 & 22,750 \\
\hline 5-mar-03 & USD & PUT & BID & $9 \mathrm{M}$ & 270 & 0,37 & 22,950 \\
\hline $5-\operatorname{mar}-03$ & USD & PUT & BID & $10 \mathrm{M}$ & 300 & 0,37 & 23,170 \\
\hline 5-mar-03 & USD & PUT & BID & $11 \mathrm{M}$ & 330 & 0,37 & 23,340 \\
\hline 5-mar-03 & USD & PUT & BID & $12 \mathrm{M}$ & 360 & 0,37 & 23,430 \\
\hline
\end{tabular}

Figura 4 - Matriz de Volatilidades Implícitas nas opçöes de câmbio R\$/USD. 


\section{- Taxas de Juros Pré-fixadas em Reais (PRÉ)}

Para os prazos determinados na matriz de volatilidade acima precisa-se encontrar as taxas de juros pré-fixadas em reais. Para isto, utilizou-se os preços de ajuste dos contratos de DI futuro da BM\&F e a taxa CDI publicada pela CETIP. A metodologia utilizada para a interpolação desta curva é dividida em duas etapas:

1. Determinação dos fatores de desconto para os prazos dos contratos de DI e para o prazo de 1 dia(Taxa CDI):

$$
\begin{gathered}
P R E_{1}=\left(1+\frac{C D I}{100}\right)^{\left(\frac{1}{252}\right)} \\
P R E_{i}=\frac{100000}{D I_{i}}
\end{gathered}
$$

2. Uma vez determinados os fatores de desconto acima utilizou-se a fórmula abaixo para a interpolação para todos os possíveis prazos.

$$
P R E_{t}=P R E_{i} \times\left(\frac{P R E_{j}}{P R E_{i}}\right)^{\left(\frac{d u_{t}-d u_{i}}{d u_{j}-d u_{i}}\right)}
$$

onde $P R E_{i}$ e $P R E_{j}$ são os futuros de DI adjacentes ao prazo da opção e $d u$ é o número de dias úteis aos respectivos prazos $i, j$ e $t$.

Como a matriz de volatilidades utilizada no trabalho é para opções até o prazo de 1 ano e tem-se um mercado de DI com vencimentos superiores a 1 ano, não será necessário se realizar métodos de extrapolação para a determinação das taxas de juros.

\section{- Taxas de Juros Doméstica Pré-Fixadas em USD (Cupom)}

De forma análoga à descrita acima precisa-se definir as taxas de juros para a moeda estrangeira que será a taxa de juros doméstica pré-fixada em USD, também conhecida como cupom cambial. Neste caso tem-se um passo a mais no processo de 
construção da curva que seria seu o "clean-up", visto que os contratos de DDIs da BM\&F são indexados ao PTAX publicado pelo Banco Central, e que é uma estimativa de um preço médio das operações interbancárias de USD à vista do dia anterior e que não reflete o mercado no momento da cotação de uma operação de opção cambial. $^{2}$

Como a partir do segundo vencimento dos contratos de futuros da BM\&F já se tem os preços para os FRCs ( taxas forward "limpas" do cupom cambial) precisa-se realizar o clean-up somente até o primeiro vencimento dos DDIs. Esta é razão pela qual se fez necessário o uso da Ptax na construção das curvas.

Por definição os fatores de desconto do cupom limpo são dados por:

$$
\text { Cupom }_{i}^{\text {limpo }}=\frac{P R E_{i}}{\frac{P \text { forward }}{\text { Spot }}}=\frac{P R E_{i} \times S p o t}{\text { forward }}
$$

onde $S p o t$ é a cotação à vista do R\$/USD, forward $i$ é o preço forward do R\$/USD para o prazo $i$ and $P R E_{i}$ é o fator de desconto pré-fixado em Reais para o prazo $i$. Para o cupom sujo, tem-se:

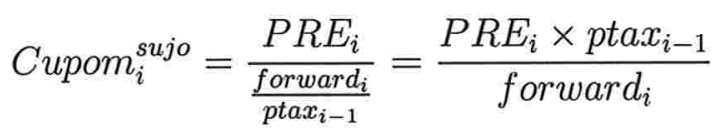

Com as equacões 3.4 e 3.5 é possível realizar a limpeza do cupom sujo.

Para a obtenção dos fatores acima, pode-se escrever a técnica abaixo:

- Para os preços sujos do DDI:

$$
B R D_{i}=\frac{100000}{D D I} \times \frac{S p o t}{\operatorname{Ptax}_{i-1}}
$$

\footnotetext{
${ }^{2}$ Maiores detalhes sobre cupons limpo e sujo vide LEMGRUBER (1999).
} 
- Para os preços dos FRCs, precisa-se do fator de desconto acima para o prazo inicial do contrato. Seja este fator denominado, $B R D_{\text {base. }}$ O fator de desconto para um prazo $i$ pode ser encontrado pela fórmula abaixo:

$$
B R D_{i}=B R D_{\text {base }} \times\left(1+\left(F R C \times \frac{t}{360}\right)\right)
$$

onde $F R C$ é a taxa forward do cupom limpo entre o primeiro vencimento dos futuros e o prazo da opção.

Uma vez interpoladas as curvas de cupom cambial e PRÉ, é necessário converter as taxas para a forma exponencial contínua conforme descrito na próxima secção de tratamento dos dados.

\section{- Preço de fechamento Spot de câmbio R\$/USD}

Este preço será utilizado como o preço do ativo-objeto das opções na calibração do modelo. Daí a importância de se trabalhar com taxas de cupom cambial "limpas" conforme citado acima.

Para os dados acima, coletou-se as cotações de fechamento entre as datas de 02/09/2002 e $05 / 03 / 2003$. 


\subsection{Tratamento dos Dados de Mercado}

Nesta secção são destacados alguns tratamentos que são dados as informações de mercado que tornam possível o apreçamento final das opções pelo modelo de GarmanKohlhagen e Heston.

Os principais tratamentos são:

\section{- Conversões para Taxas Exponenciais Contínuas}

Conforme mostrado nas fórmulas de Heston e Garman-Kohlhagen, as taxas de juros livres de risco $r_{d}$ e $r_{f}$ sempre devem ser expressas na forma exponencial contínua e na mesma convenção de contagem de dias que a forma como as volatilidades são expressas. Esta conversão deve obedecer o critério de que os fatores de desconto das taxas devem sempre ser os mesmos. Como as volatilidades estão expressas em termos anuais na convenção dias úteis/252, também deve-se utilizar a mesma convenção para as taxa de juros contínuas ${ }^{3}$, ou seja,

\section{Caso PRÉ:}

$$
\left(1+\frac{P R E_{t}}{100}\right)^{\frac{d u}{252}}=e^{r_{d}(t) \frac{d u}{252}} \Longrightarrow r_{d}(t)=\ln \left(1+\frac{P R E_{t}}{100}\right)
$$

\section{Caso CUPOM:}

$$
\left(1+\frac{C U P O M_{t}}{100} \frac{d c}{360}\right)=e^{r_{f}(t) \frac{d u}{252}} \Longrightarrow r_{f}(t)=\frac{252}{d u} \ln \left(1+\frac{C U P O M_{t}}{100} \frac{d c}{360}\right)
$$

\footnotetext{
${ }^{3}$ No Apêndice encontra-se o código em MATLAB para estas funções (função taxa_cont.m).
} 
- Cálculo do Moneyness utilizando as informações da Matriz de Volatilidade da Reuters

O moneyness é uma variável bastante utilizada na análise do comportamento das opções e definida como a razão entre o preço do ativo-objeto (preço R\$/USD) sobre o preço de exercício da op̧̧ão $(K)$. De acordo com o moneyness, as opções podem ser classificadas como fora do dinheiro (out-of-the-money), no dinheiro (at-the-money) e dentro do dinheiro (in-the-money).

\begin{tabular}{|l|l|}
\hline Tipo & Descrição \\
\hline In-the-money & $\begin{array}{l}\text { Opções que proporcionariam um fluxo de caixa positivo } \\
\text { para o seu detentor, caso exercidas imediatamente. }\end{array}$ \\
\hline At-the-money & $\begin{array}{l}\text { Opções que, caso exercidas, proporcionariam ao detentor } \\
\text { um fluxo de caixa nulo. }\end{array}$ \\
\hline Out-of-the-money & $\begin{array}{l}\text { Opções cujo exercício imediato implicaria num fluxo de } \\
\text { caixa negativo. }\end{array}$ \\
\hline
\end{tabular}

Como a matriz de volatilidade da Reuters nos fornece volatilidades como função de deltas forward, $N\left(d_{1}\right)$, não existe uma forma analítica de se determinar a moneyness diretamente. A única forma de se obter essa variável é através do algoritmo de aproximação numérica. Neste caso, utilizou-se o método de Newton-Rapson que apresentou uma rápida convergência para o valor final da moneyness.

O algoritmo deste método consiste em a partir de um valor inicial de moneyness e um passo fixo, encontrar-se o valor da moneyness fruto da convergência. Seja $(x(j))$ a moneyness para a $j$-ésima interação, o algoritmo é tal que ${ }^{4}$

\footnotetext{
${ }^{4}$ No Apêndice encontrar-se o código comentado em matlab para esta função (função moneyness.m).
} 


$$
x_{j+1}=x_{j}-\left[\frac{N\left(d_{1}\left(x_{j}\right)\right)-N\left(d_{1}\right)}{\left(\frac{\partial N\left(d_{1}\left(x_{j}\right)\right)}{\partial x_{j}}\right)}\right]
$$

onde

$$
\left|N\left(d_{1}\right)-N\left(d_{1}\left(x_{j+1}\right)\right)\right| \leqq \epsilon
$$

e

$$
\frac{\partial N\left(d_{1}\left(x_{j}\right)\right)}{\partial x_{j}}=\frac{N^{\prime}\left(d_{1}\left(x_{j}\right)\right)}{x_{j} \sigma \sqrt{T}}
$$

É importante observar que para o cálculo de moneyness não é preciso o preço do ativo-objeto(R\$/USD).

\section{- Cálculo de Vega Ponderado para Utilização na Calibração}

Conforme será apresentado no capítulo de calibração, também se faz necessário o cálculo do vega ponderado para os diferentes valores de deltas para opções de mesmo vencimento. Isto será aplicado como um dos pesos da função de minimização da calibração do modelo.

Seja vega definido como

$$
v e g a=S e^{-r_{f} T} N\left(d_{1}\right) \sqrt{T}
$$

Onde $\Delta_{i}=e^{-r_{f} T} N\left(d_{1}\right)$

O vega ponderado é definido como:

$$
v_{e g a}=\frac{S \Delta_{i} \sqrt{T}}{\sum_{\Delta_{i}} S \Delta_{i} \sqrt{T}}=\frac{\Delta_{i}}{\sum_{i} \Delta_{i}}
$$




\section{Capítulo 4}

\section{Calibração do Modelo de Heston}

Conforme escrito na introdução deste trabalho, a calibração de modelos estocásticos em finanças representa um "estado da arte" no mundo da engenharia financeira e por isso não existe um caminho único que deva ser seguido para se obter êxito e nem sempre o êxito é obtido mesmo que vários caminhos sejam seguidos.

Muitas vezes os caminhos são tortuosos e a análise dos dados e das funções de otimização são exaustivamente testadas, modificadas e analisadas novamente até se encontrar métodos e dados que convirjam para soluções plausíveis. Muitas vezes, o processo de calibração é tratado como uma "alquimia" e a persistência e a experiência do modelador é fundamental neste processo.

Na calibração do modelo de Heston, tentou-se seguir o fluxograma descrito na figura 5.

É importante observar que os passos seguidos neste fluxograma para a determinação dos preços Garman-Kohlhagen já foram descritos nos capítulos anteriores e que os preços Garman-Kohlhagen são obtidos das volatilidades da matriz da Reuters e não coletados diretamente do mercado. 


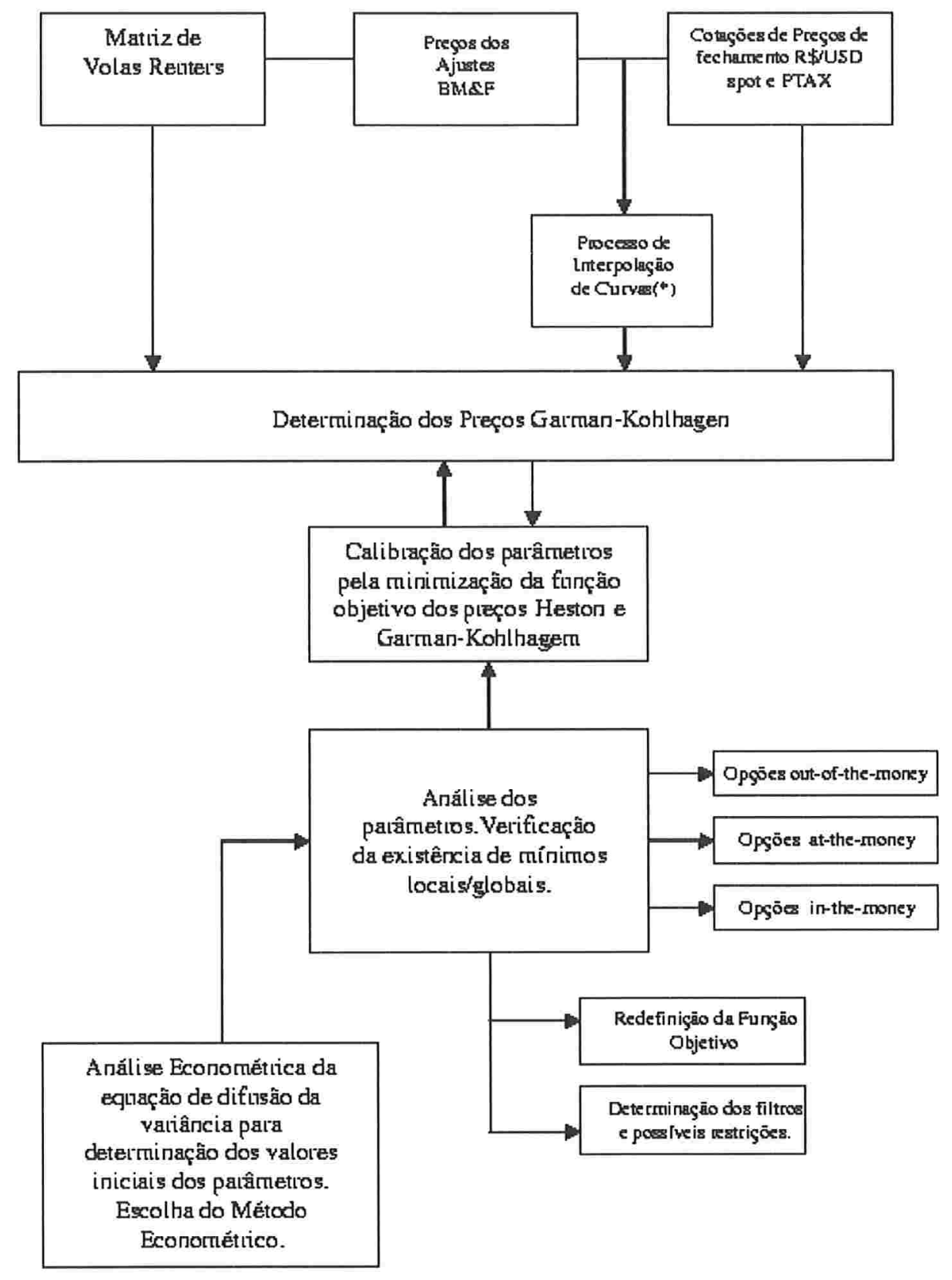

Figura 5 - Fluxograma de Calibra ção 


\subsection{Determinação dos Valores Iniciais para os Parâmetros do Modelo de Heston}

Em problemas de otimização, um dos principais desafios é encontrar valores iniciais para os parâmetros que se quer otimizar como também a determinação de uma região plausível (fronteiras de mínimo e máximo) onde estes parâmetros podem variar sem comprometer a plausibilidade do modelo. ${ }^{1}$ Muitas vezes encontrar pontos máximos ou mínimos que sejam globais e apresentem plausibilidade é um problema difícil de se resolver, especialmente quando se trabalha com funções não-lineares como as do modelo de Heston e assim, a escolha dos valores iniciais são a chave para a determinação desses pontos ótimos.

$\mathrm{Na}$ equação de difusão da variância (equação 2.4), três dos cinco parâmetros estão explícitos: velocidade de reversão à média $(k)$, variância de longo prazo $(\theta)$ e a volatilidade da volatilidade $(\sigma)$. Assim para a obtenção do "chute inicial" desses parâmetros utilizouse o método generalizado dos momentos (GMM), onde a janela das variâncias foi fixada entre as datas de 19/02/2001 e 17/01/2003. As variâncias foram calculadas com janelas móveis no período acima para retornos lognormais diários da cotação R $\$ /$ USD (cada série com 60 dias úteis - aproximadamente 100 dias corridos).

A discretização da equação de difusão é dada por:

$$
v_{t+1}-v_{t}=\theta k-k v_{t}+\varepsilon_{t+1}
$$

com

$$
E\left[\varepsilon_{t+1}\right]=0, E\left[\varepsilon_{t+1}^{2}\right]=\sigma^{2} v_{t}
$$

A partir das equações acima cria-se o vetor de $h\left(\phi_{t}, v_{t}\right)$ que é o produto de Kronecker do vetor de erros $\left[\varepsilon_{t+1}, \varepsilon_{t+1}^{2}-\sigma^{2} v_{t}\right]^{T}$ pelo vetor de variáveis instrumentais $\left[1, v_{t}\right]^{T}$ :

\footnotetext{
${ }^{1}$ Vide este passo no fluxograma da figura 5.
} 


$$
h_{t}\left(v_{t}, \phi\right)=\left[\begin{array}{c}
\varepsilon_{t+1} \\
\varepsilon_{t+1} v_{t} \\
\varepsilon_{t+1}^{2}-\sigma^{2} v_{t} \\
\left(\varepsilon_{t+1}^{2}-\sigma^{2} v_{t}\right) v_{t}
\end{array}\right]
$$

Onde $\phi_{t}=\left[\begin{array}{lll}\theta & k & \sigma\end{array}\right]$ é o vetor de parâmetros a ser estimado, respectivamente os parâmetros são variância de longo prazo, reversão à média da variância e volatilidade da volatilidade.

Pelos resultados observados para os parâmetros estimados (vide figura 7) para diferentes períodos, observou-se que a velocidade de reversão à média, $k$, é estável para esses períodos, já a variância de longo prazo não. De forma então a simplificar a calibração do modelo de Heston, tomou-se o parâmetro $k$ como determinado econometricamente. Iniciou-se a calibração utilizando o parâmetro $\theta$ determinístico e a posteriori fez-se o mesmo variar juntamente com os parâmetros $\rho$ e $\sigma$.

Observa-se que o valor estimado para $\sigma$ (volatilidade da volatilidade) na tabela da figura 7 é negativo. Isto não deve ser visto como uma volatilidade negativa e sim como a inversão de sinal do termo estocástico da equação de difusão da variância (equação 2.4).

Para o valor inicial da correlação $\rho$, utilizou-se a correlação histórica entre os retornos logarítmicos do R\$/USD à vista e sua variância para o mesmo período acima.

Pelo gráfico da figura 6 pode-se ver que existe uma correlação histórica entre os retornos históricos do ativo-objeto e do histórico da variância, apesar de apresentar valores bem próximos de zero. No modelo de Heston a correlação será extraída para os retornos esperados e as variâncias implícitas das respectivas opções.

Para o prêmio de risco da volatilidade $\lambda$ o valor inicial será tomado arbitrariamente como nulo. Os dados iniciais estão descritos na tabela da figura 7, onde $\mathrm{C}(1)$ é a variância de longo prazo $(\theta), \mathrm{C}(2)$ é taxa de reversão à média $(k)$ e $\mathrm{C}(3)$ é a volatilidade da volatilidade $(\sigma)$. 


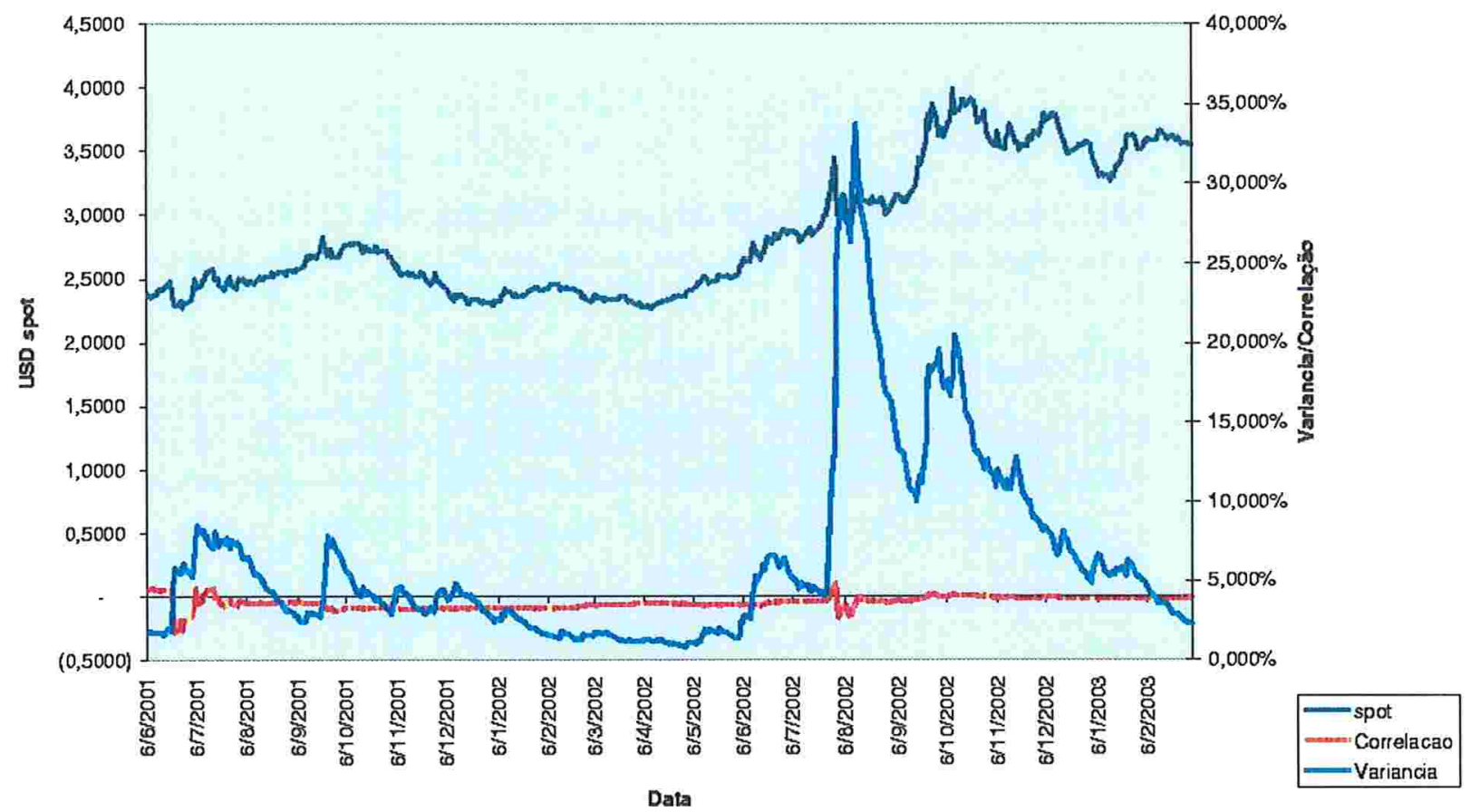

Figura 6 - Gráfico Histórico do Dolar x Variância x Correlacao de Heston

\begin{tabular}{|c|c|c|c|c|}
\hline \multicolumn{5}{|c|}{$\begin{array}{l}\text { Systern: GMM V CIR } \\
\text { Estimation Method: Generalized Method of Mornents } \\
\text { Date: } 08 / 01 / 02 \text { Time: } 22: 15 \\
\text { Sample: } 2499 \\
\text { Included observations: } 498 \\
\text { Total system (balanced) observations } 996 \\
\text { Instruments: C V(-1) } \\
\text { No prewhitening } \\
\text { Bandwidth: Fixed (5) } \\
\text { Kemel: Bartlett } \\
\text { Simultaneous weighting matrix \& coefficient iter ation } \\
\text { Convergence achieved after: } 4 \text { weight matricies, } 5 \text { tote } \\
\end{array}$} \\
\hline & Coefficient & Strd Error & $\mathrm{t}-\mathrm{St}$ & $\mathrm{Pr}$ \\
\hline & & & & \\
\hline \multicolumn{2}{|c|}{$\begin{array}{l}\text { Determinant residual covariance } \\
\text { J-statistic }\end{array}$} & $\begin{array}{l}1.15 \mathrm{E} \\
0.0008\end{array}$ & & \\
\hline \multicolumn{5}{|c|}{$\begin{array}{l}\text { Equation: } V-V(-1) \cdot\left(C(1)^{*} \mathrm{C}(2) \cdot \mathrm{C}(2)^{2} \mathrm{~V}(-1)\right) \\
\text { Observations: } 498\end{array}$} \\
\hline \multicolumn{5}{|c|}{$\begin{array}{l}\text { Squation: }\left(V-V(-1) \cdot\left(C(1)^{*} C(2)-C(2)^{*} V(-1)\right)^{\wedge} 2-\left(C(3)^{\wedge} 2\right)^{\wedge} V(-1)\right. \\
\text { Observations: } 498\end{array}$} \\
\hline $\begin{array}{l}\text { S.E. of regression } \\
\text { Durbin-Watson stat }\end{array}$ & $\begin{array}{l}0.000692 \\
1.941892 \\
\end{array}$ & \multicolumn{2}{|c|}{ Sum squared resid } & \\
\hline
\end{tabular}

\begin{tabular}{|c|c|c|}
\hline \multicolumn{2}{|c|}{ Parâmetro } & Valores iniciais \\
\hline Theta & $(C(1))$ & 0.063885 \\
\hline Sigma & $(\mathrm{C}(3))$ & -0.037858 \\
\hline & $(C(2))$ & 0.018074 \\
\hline Rho & & -0.05 \\
\hline lambd & & 0.0 \\
\hline
\end{tabular}

Figura 7 - Tabela de Resultado do Eviows para a regressão pelo Método GMM (Valores iniciais da Calibraçẫo). 


\subsection{Uma Análise sobre os Efeitos da Correlação e da Volatilidade da Volatilidade no Comportamento das Opções}

Antes de se descrever a calibração, é importante simular como a mudança nos parâmetros correlação $(\rho)$ e volatilidade da volatilidade $(\sigma)$ afetam a fdp (função densidade de probabilidade) dos retornos do ativo-objeto das opções.

Para esta análise considerou-se uma call cujo vencimento é de 3 meses com data-base em 28/02/2003, utilizando os seguintes valores do modelo de Heston:

$$
v=0.07 ; \quad \theta=0.07 ; \quad \sigma=0.05 ; \quad k=0.02 ; \quad \lambda=0
$$

Através de uma simulação Monte-Carlo os histogramas abaixo foram produzidos para opções fora(out), no(at) e dentro(in) do dinheiro. ${ }^{2}$

Para os histogramas optou-se por evidenciar os retornos da seguinte forma:

$$
\frac{(S(t, T)-S(t, 0))}{S(t, 0) V(t, T)}
$$

onde $S(t, T)$ é o preço do ativo-objeto e $V(t, T)$ é a variância do processo no tempo $t$ para a opção com vencimento em $T$.

Pelas figuras 8.a, 8.b e 8.c abaixo, percebe-se que a correlação( $(\rho)$ afeta somente a skewness (terceiro momento) da fdp dos retornos do ativo-objeto da opção. Uma correlação positiva significa maior variância quando os retornos do ativo-objeto são positivos e isto torna o lado direito da distribuição mais "pesado" e o lado esquerdo mais "estreito". Isto é chamado de assimetria positiva. O efeito contrário é observado no caso de uma correlação negativa, causando uma assimetria negativa. ${ }^{3}$ Observa-se também que este efeito

\footnotetext{
${ }^{2} \mathrm{O}$ código em MATLAB para a simulação Monte-Carlo encontra-se no apêndice (função CallHeston_MC.m).

${ }^{3}$ Este efeito não é visto no modelo de Garman-Kohlhagen.
} 
é visto nos três tipos das opções: fora, no e dentro do dinheiro. Na figura 8.d abaixo se descreve os valores das skewness para os diferentes valores de $\rho$ e o tipo da opção.
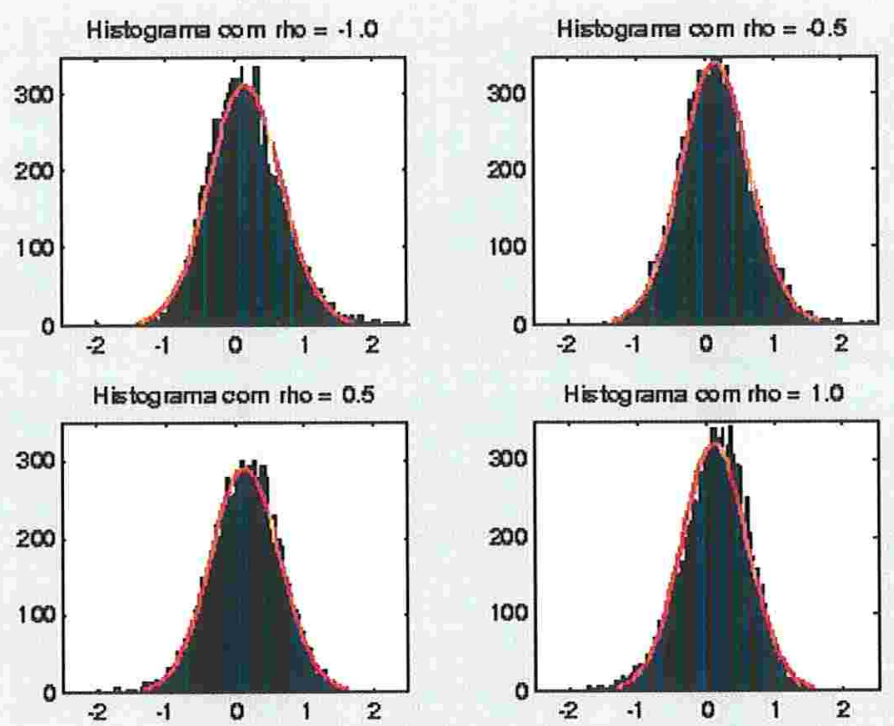

Figura 8.a. - Histogramas para diferentes valores de rho para uma opção out-of-the-money com vencimento em três meses. Data de referência 28/02/2003. 

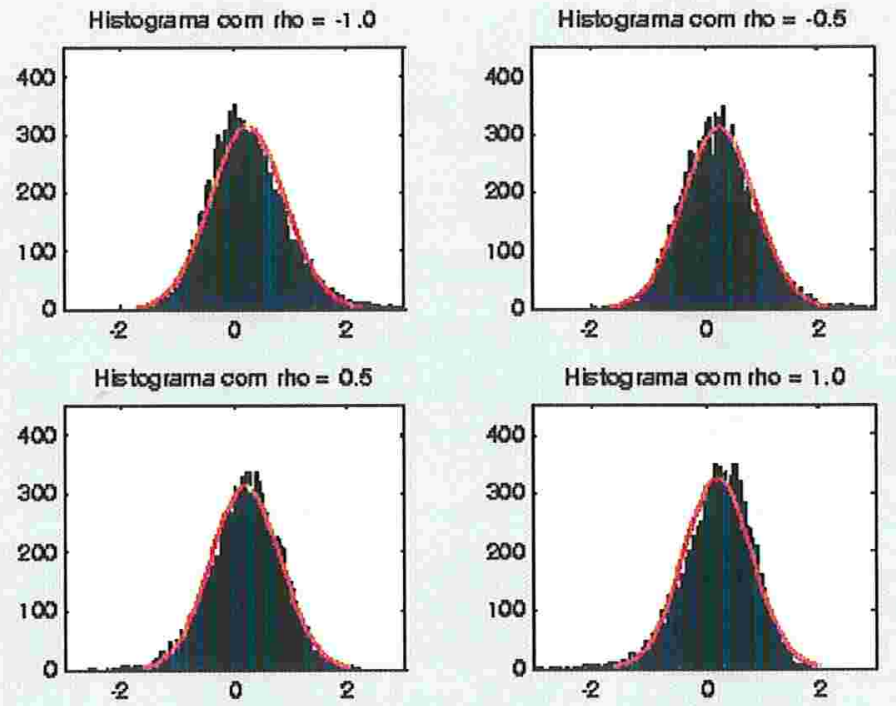

Figura 8.b. - Histogramas para diferentes valores de rho para uma opção at-the-money com vencimento em três meses. Data de referência 28/02/2003.
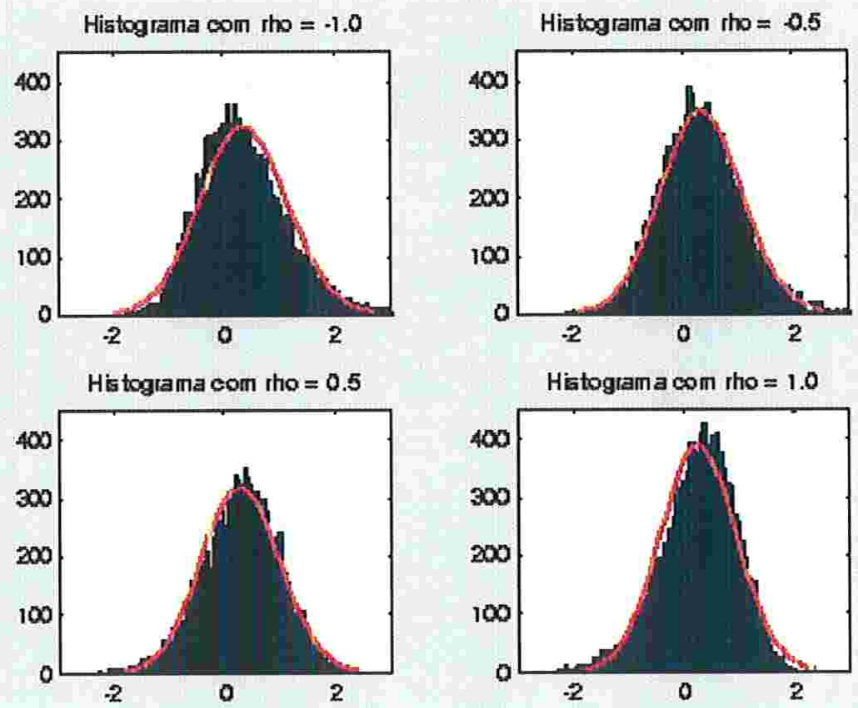

Figura 8.c. - Histogramas para diferentes valores de rho para uma opção in-the-money com vencimento em três meses. Data de referência 28/02/2003. 


\begin{tabular}{|c|c|c|c|c|c|c|}
\hline & Rho & -1 & $-0,5$ & 0 & 0,5 & 1 \\
\hline \multirow{3}{*}{ Skewness } & Out-of-the-money & 0,381 & 0,190 & 0,039 & $(0,186)$ & $(0,438)$ \\
\cline { 2 - 7 } & At-the-Money & 0,517 & 0,273 & $(0,030)$ & $(0,232)$ & $(0,546)$ \\
\cline { 2 - 7 } & in-the-money & 0,606 & 0,286 & 0,076 & $(0,314)$ & $(0,575)$ \\
\hline
\end{tabular}

Figura 8.d. - Tabela de Skewness para diferentes valores de rho e tipos de opçōes. Data de reierência 28/02/2003.

Para a análise do efeito do $\sigma$ na fdp dos retornos do ativo-objeto, utilizou-se a mesma opção com os seguintes parâmetros:

$$
v=0.07 ; \quad \theta=0.07 ; \quad \rho=0.05 ; \quad k=0.02 ; \lambda=0
$$

Através de uma simulação Monte-Carlo os histogramas abaixo foram produzidos para opções fora(out), no(at) e dentro(in) do dinheiro.

De acordo com os histogramas das figuras 9.a, 9.b e 9.c abaixo se conclui que $\sigma$ influencia a fdp somente em sua curtose (quarto momento) e não em sua assimetria (terceiro momento). Um aumento de $\sigma$ causa um aumento da curtose da fdp. Para um determinado valor de $\sigma$, observa-se que a curtose aumenta à medida que a opção se aproxima do dinheiro. Isto implica em um aumento dos preços das opções fora e dentro do dinheiro e uma diminuição do preço da opção no dinheiro quando comparado com o modelo de Garman-Kohlhagen. 

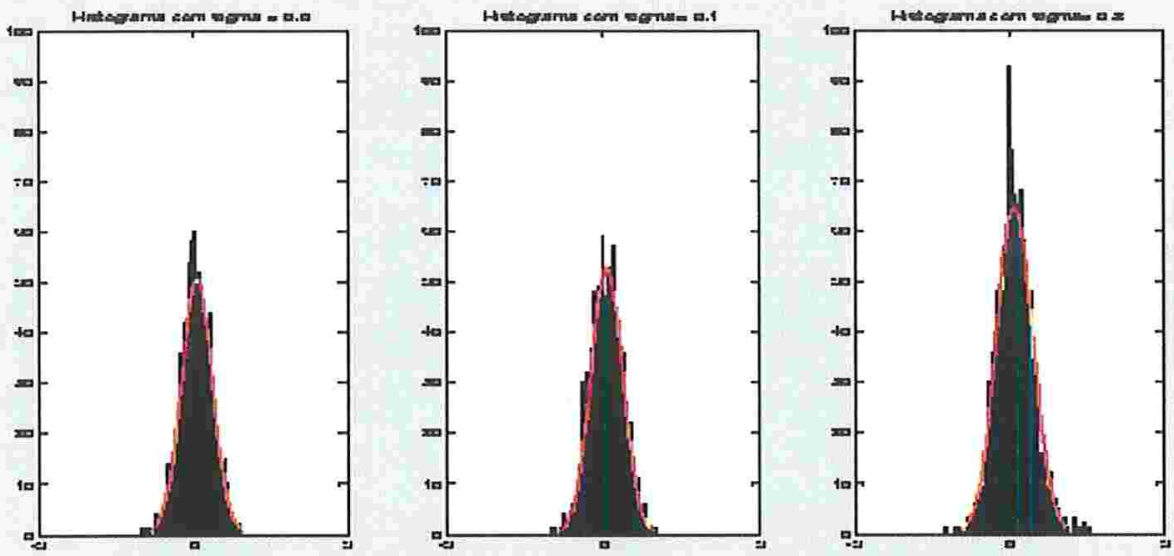

Figura 9.a- Histogramas para diferentes valores de sigma para uma opção out-of-the-money com ven cimento em três meses. Data de referência 28/02/2003.
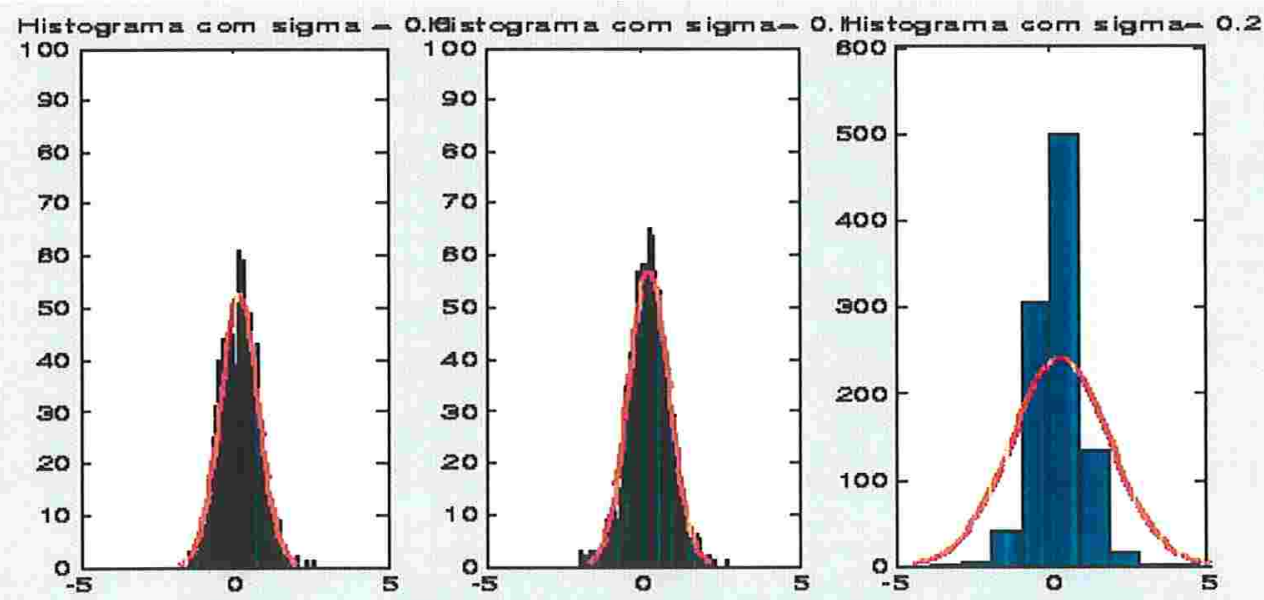

Figura 9.b. - Histogramas para diferentes valores de sigma para uma opção at-the-money com vencimento em três meses. Data de referência 28/02/2003. 

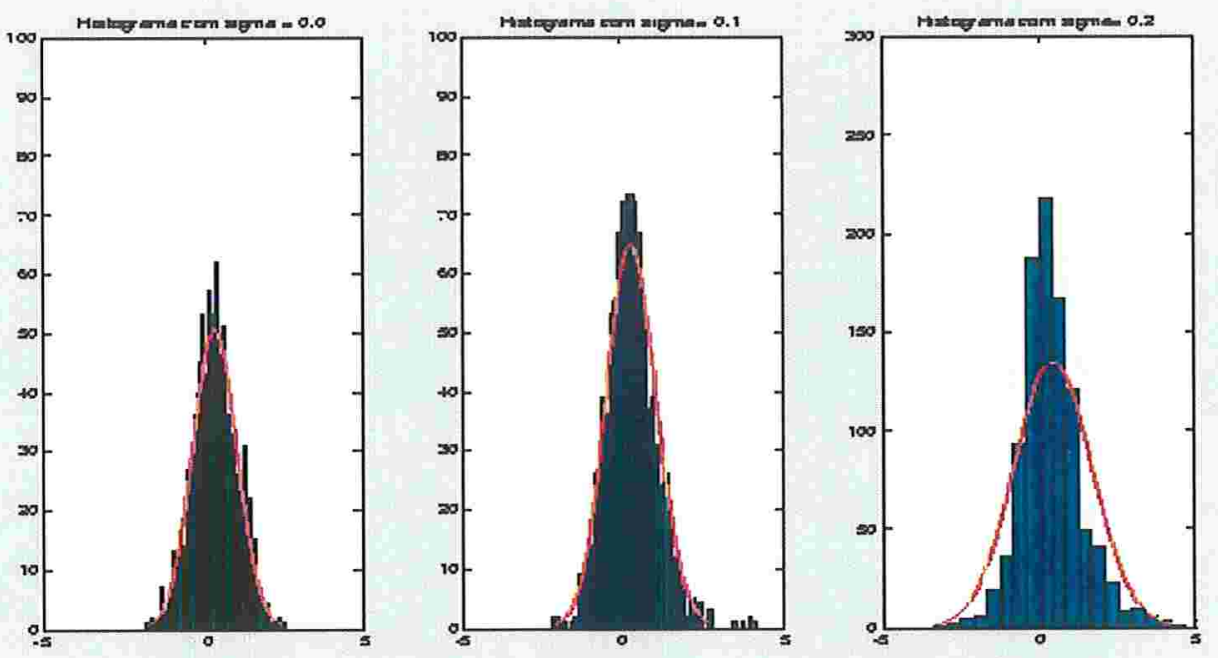

Figura 9.c. - Histogramas para diferentes valores de sigma para uma opção in-the-money com vencimento em três meses. Data de réerência $28 / 02 / 2003$.

Conforme visto na tabela da figura 9.d quando se tem $\sigma=0$, a curtose da distribuição é quase idêntica a uma distribuição normal conforme esperado.

\begin{tabular}{|l|c|r|r|r|}
\hline & Rho & \multicolumn{1}{|c|}{0} & 0,1 & \multicolumn{1}{c|}{0,2} \\
\hline \multirow{3}{*}{ Curtose } & Out-of-the-money & 2,915 & 2,932 & 4,121 \\
\cline { 2 - 5 } & At-the-Money & 2,929 & 3,589 & 52,170 \\
\cline { 2 - 5 } & in-the-money & 2,946 & 4,745 & 28,823 \\
\hline
\end{tabular}

Figura 9.d. - Tabela de Curtose para diferentes valores de sigma e tipos de opções. Data de referência 28/02/2003.

A análise acima procura mostrar como a parametrização do modelo de Heston muda com relação ao modelo de Garman-Kohlhagen. Acima, observou-se a mudança da fdp variando separadamente os parâmetros $(\rho$ e $\sigma)$. Na seção seguinte será realizada a calibração do modelo variando-se os dois parâmetros conjuntamente e determinando-se os pontos ótimos. 


\subsection{Comportamento da Integral da Fórmula de Hes- ton}

Conforme observado na equação 2.18 da fórmula de Heston existe uma integral que possui seus limites de integração entre 0 e $\infty$. Como esta integral será resolvida numericamente nesse trabalho, é importante mostrar seu comportamento de forma a se definir que limites de integração devem ser tomados para a variável de integração $\phi$.

$$
\operatorname{INTEGRANDO} O_{j}(x, v, T ; \ln [K])=R e\left[\frac{e^{-i \phi l n[k]} f_{j}(x, v, T ; \phi)}{i \phi}\right]
$$

Pelo gráfico da figura 10 se observa que a partir de $\phi>40$ a função acima já converge para zero. Assim tomou-se os limites de integração entre 0 e 50.

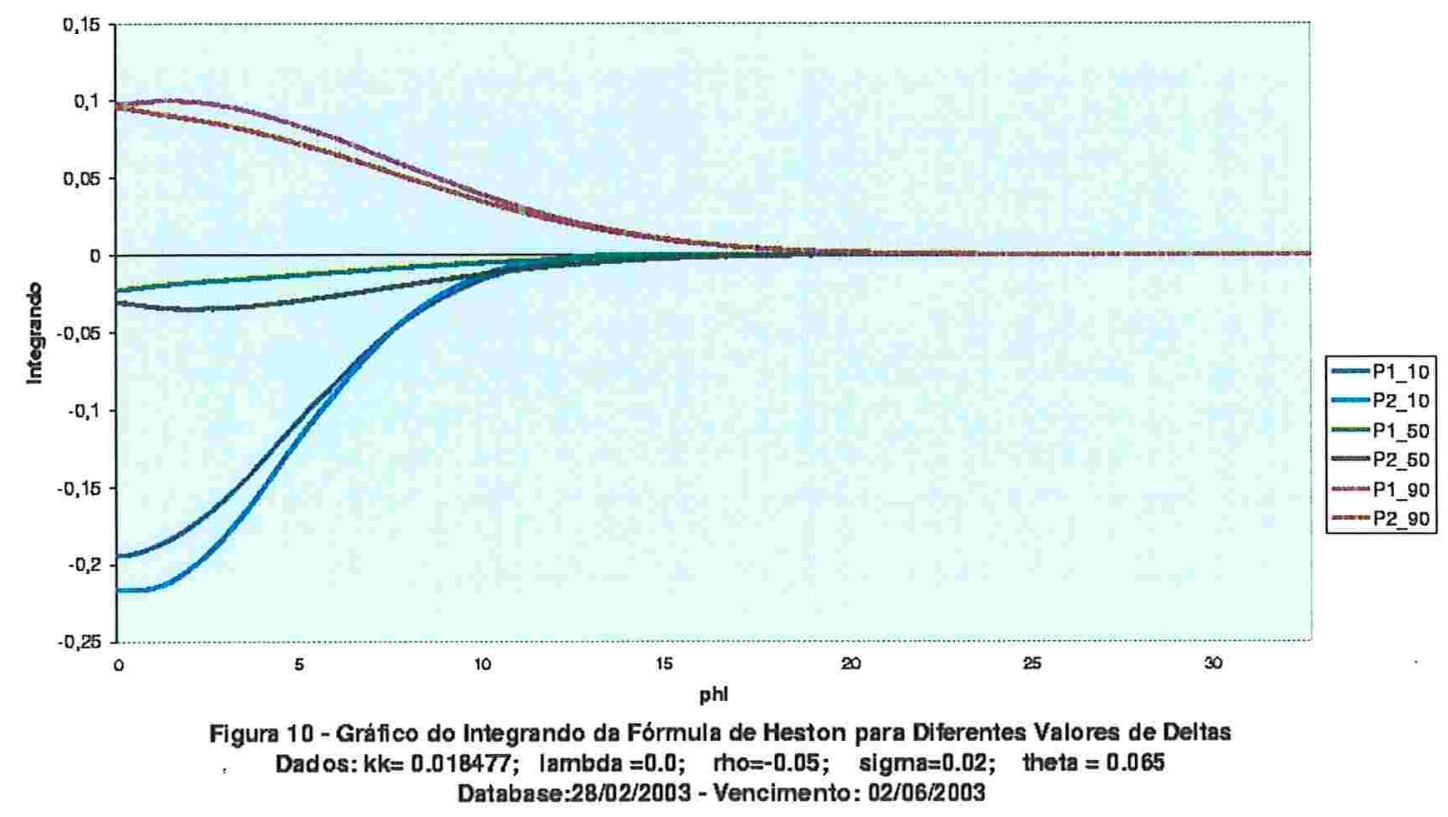




\subsection{Determinação da Função Objetivo e Base de Da- dos para a Calibração}

Para a calibração do modelo de Heston utilizou-se o método de minimização do quadrado das diferenças dos preços de Heston e de mercado(Garman-Kohlhagen), onde se aplicou diferentes pesos $w_{i}$ para as diferenças. A equação da função de minimização geral é dada abaixo:

$$
\min \Psi_{1}=\sum_{\text {parametros }}^{\text {parametros } *} \sum_{j=1}^{N} w_{i}\left(\operatorname{Preco}_{G K}(j)-\operatorname{Preco}_{\text {Heston }}(j ; \theta, k, \rho, \sigma)\right)^{2}
$$

Onde $w_{i}$ é o peso dado a cada uma das diferenças, Preco $_{G K}$ é o preço de Mercado e

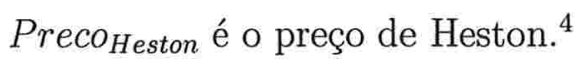

A lógica por trás desses pesos é que se inicie a poderação dos erros com valores bem simples como $w_{i}=1$ e a partir de uma investigação sobre os erros observados, novos pesos sejam definidos de forma a se obter uma menor margem de erro nas novas tentativas de calibração.

Esta calibração procurará minimizar o erro quadrático dos preços para uma mesma data de referência, ou seja, a calibração considera opções com diferentes vencimentos, moneyness e conseqüentemente diferentes preços. ${ }^{5}$ De forma a se evitar distorções nos preços utilizados na calibração, assumiu-se que a liquidez desse mercado é bem maior naqueles prazos em que há liquidez para os contratos de Dólar Futuro na BM\&F. Considerouse somente as opções com prazos inferiores ao terceiro vencimento dos contratos da BM\&F. Outra premissa que é assumida na modelagem é que os preços das opções extraídos da matriz de volatilidade são preços onde negócios são realizados. Como o mercado de opção é bem mais líquido para as opções no dinheiro, devemos observar erros menores para esses

\footnotetext{
${ }^{4}$ Relembrando que os preços de mercado são obtidos da matriz de volatilidades através do modelo de Garman-Kohlhagen.

${ }^{5}$ Vide o fluxograma da figura 7.
} 
tipos de opções e maiores para as opções fora do dinheiro.

Para se entender os dados no período considerado, construiu-se a figura 11,que mostra os valores médios das volatilidades implícitas para diferentes valores de Deltas-Forward entre as datas 02/09/2002 e 28/02/2003. Devido a aproximação da eleição presidencial e o aumento das chances de uma vitória dos partidos de esquerda, observa-se uma enorme variação dessas volatilidades principalmente no mês de setembro que antecede o primeiro turno das eleições. Após a vitória do Presidente Lula e a definição dos seus assessores, inicia-se um período de redução das volatilidades, havendo uma estabilização a partir do início de fevereiro de 2003. Conforme descrito acima, as opções fora do dinheiro apresentam um falta de liquidez superior às opções no dinheiro e isto gera uma maior variação dessa volatilidade implícita para essas opções do que as que estão próximas e dentro do dinheiro. Isto é evidente na figura 11 abaixo.

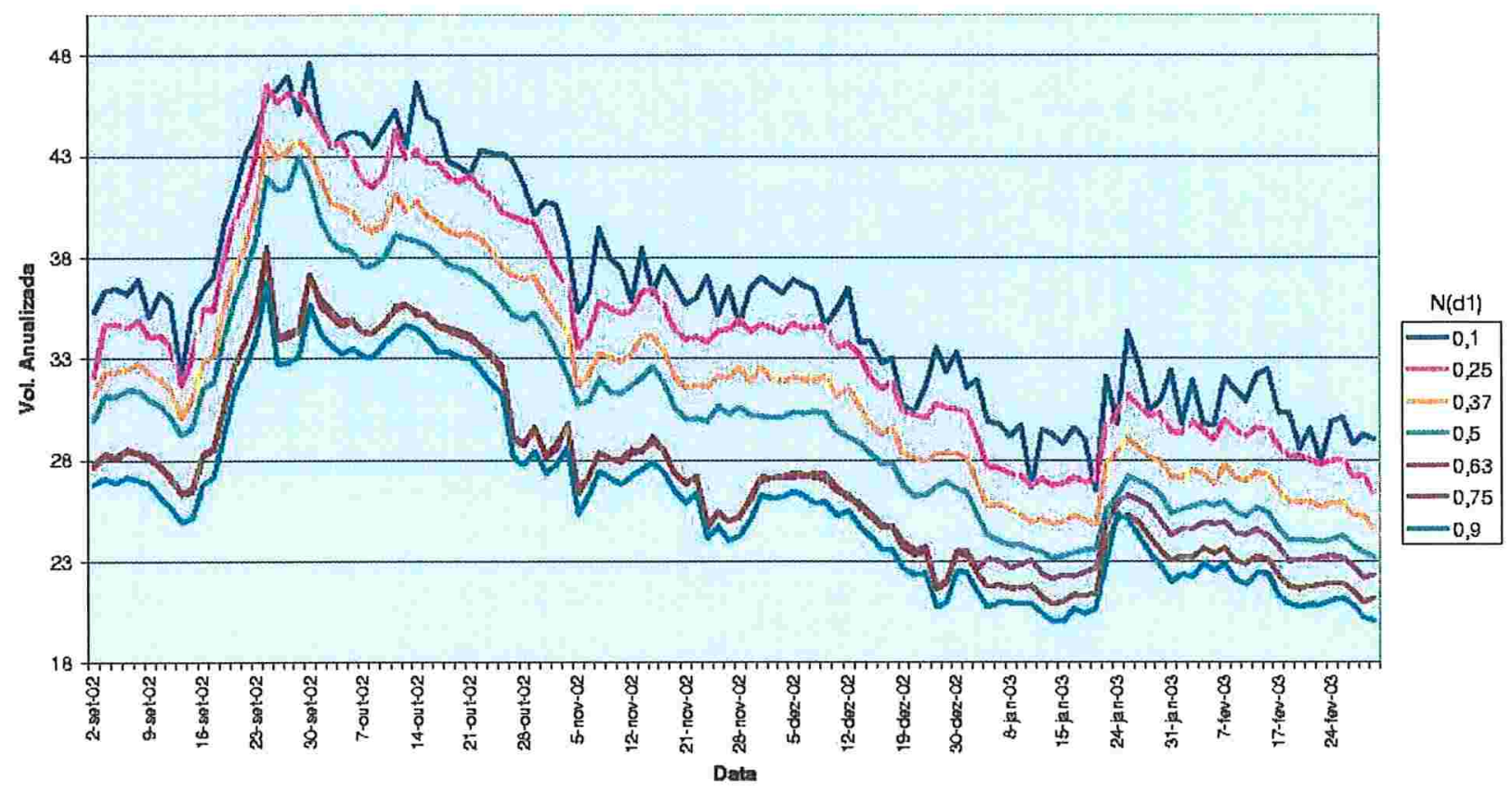

Figura 11 - Gráfico da Evolução das volatilidades Implicitas para o Periodo em Estudo para Opçóes R\$USD. 
Escolheu-se então as seguintes datas abaixo para a calibração:

- 21/02/2003 e 28/02/2003 - Representando um período de volatilidades implícitas estáveis.

- 02/01/2003 - Representando o início do governo do Presidente Lula.

- 02/09/2002 - Representando o instante que antecede o aumento das volatilidades.

As bases de dados utilizadas para estas datas podem ser vistas nas tabelas 1-4 no apêndice I.

A calibração foi realizada em duas partes:

- Calibração 1 - Inicialmente tentou-se calibrar o modelo assumindo-se um dados valor para $\theta$ (variância de longo-prazo), que é fornecido pela regressão econométrica (GMM) e somente ajustar os parâmetros $\rho$ e $\sigma$ na calibração do modelo de Heston;

- Calibração 2- Calibrou-se o modelo ajustando-se os três parâmetros variando: $\rho$, $\sigma$ e $\theta$;

Na calibração, utilizou-se três pesos diferentes:

- Peso1: $w_{i}=1$ - Trata-se da primeira tentativa de calibração do modelo.

- Peso 2: $w_{i}=$ vega $_{i}$ - Conforme mostrado adiante os erros aumentam para as opções fora do dinheiro, de forma que vega tentará "punir" estes efeitos.

- Peso 3: $w_{i}=\left(v e g a_{i}\right) \cdot($ Moneyness $)$ - Este peso foi utilizado para se punir ainda mais os erros encontrados para as opções fora do dinheiro.

Conforme será visto na análise dos resultados das calibrações abaixo, existe uma explicação para a escolha dos pesos acima. Inicialmente ao se utilizar o peso 1, observou-se que os erros são maiores para as opções fora do dinheiro. Como vega é bem menor para 
estas opções, optou-se por utilizá-lo como um peso adicional na tentativa de se minimizar os erros das opções fora do dinheiro.

Para alguns casos os erros ainda se mostraram altos e optou-se por utilizar um terceiro peso também na tentativa de punir os erros das opções fora do dinheiro.

\section{Algoritmo de Minimização}

O algoritmo de otimização utilizado para a calibração foi a função lsqnonlin do MATLAB que permite a minimização dos erros conforme a equação 4.3 e a determinação dos parâmetros ótimos do modelo. Para esta função de otimização se define os valores iniciais e as condições fronteira para os máximos e mínimos para os parâmetros do modelo.

\subsection{Resultados da Calibração}

No apêndice II, as tabelas 5-8 mostram os resultados das calibrações.

Os resultados da calibração do modelo de Heston para 28/02/2003 e 21/02/2003 se mostraram bastante satisfatórios. Em todas as calibrações houve a convergência dos parâmetros do modelo e os erros relativos apresentaram-se na média em torno de 2-4\% (vide figuras $12,13,14$ e 15). ${ }^{6}$ Os erros relativos se mostraram maiores para as opções fora do dinheiro conforme já esperado. A utilização do peso 3 tanto nas calibrações 1 e 2 apresentou uma boa eficiência na redução dos erros relativos dos preços das opções embora tenha mostrado um diferente comportamento para a calibração 1 e calibração 2 . Os parâmetros ótimos do modelo encontrados em todas as calibrações para estas datas se mostraram bastante plausíveis (vide figuras 14 e 15). Os parâmetros $\rho$ e $\sigma$ se mostraram estáveis tanto para as calibrações $\operatorname{com} \theta$ fixo como para $\theta$ variando. Na calibração 2 os valores de $\theta$ se mostraram acima do $\theta$ obtido pela regressão econométrica, apresentando valores semelhantes para os diferentes pesos da função de minimização. A calibração 2 apresentou erros quadráticos menores que a calibração 1, visto que se tem mais um

\footnotetext{
${ }^{6}$ Nessas figuras C1P1 significa calibração 1 com peso 1 .
} 
parâmetro de ajuste para a minimização. A calibração 2 com o peso 3 apresentou o menor erro quadrático para o dia 28/02/2003 e a calibração 3 com peso 2 para o dia $21 / 02 / 2003$ ambos na ordem de $10^{-6}$.

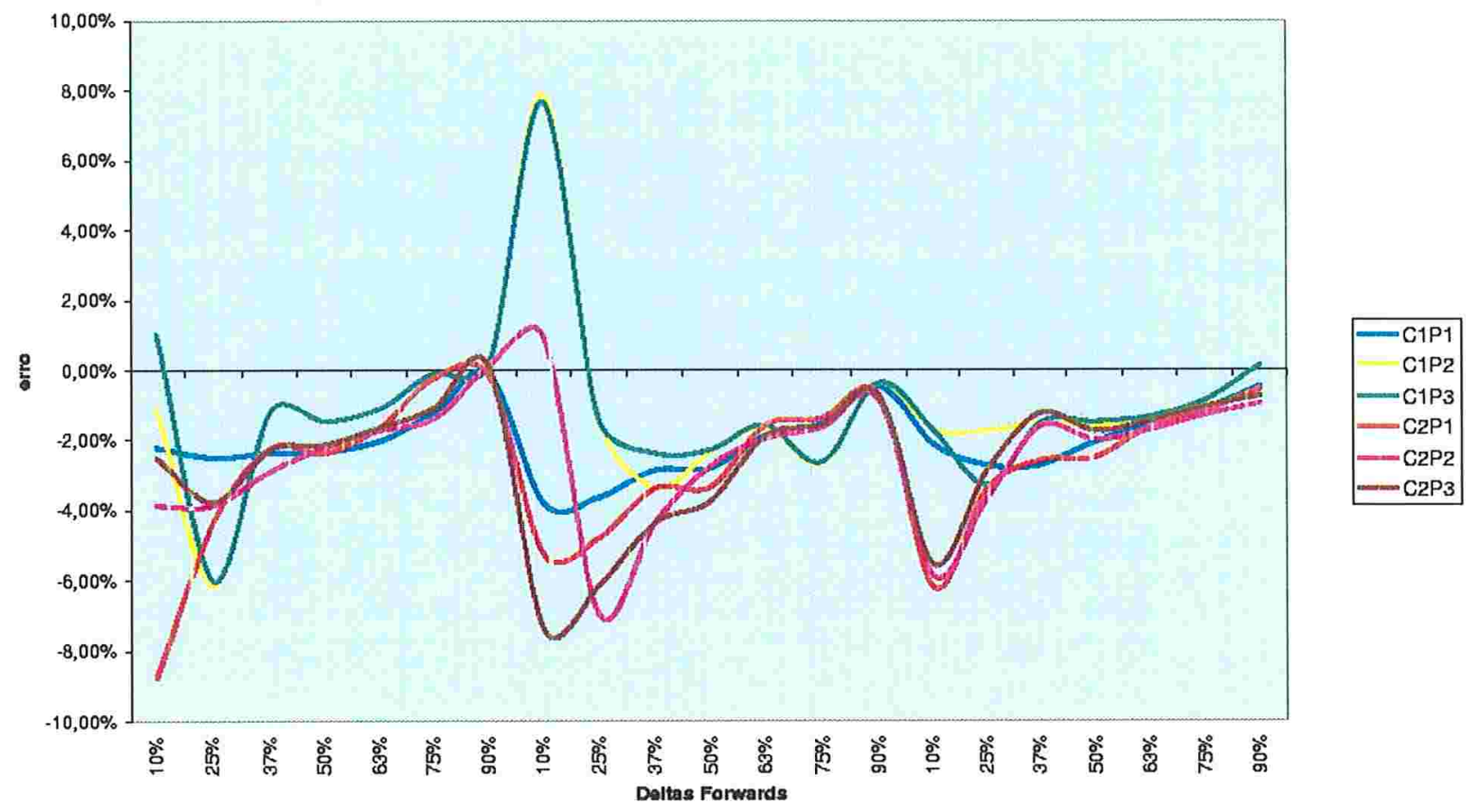

Figura 12 - Erros Relativos para a Calibraçáo em 28/02/2003. 

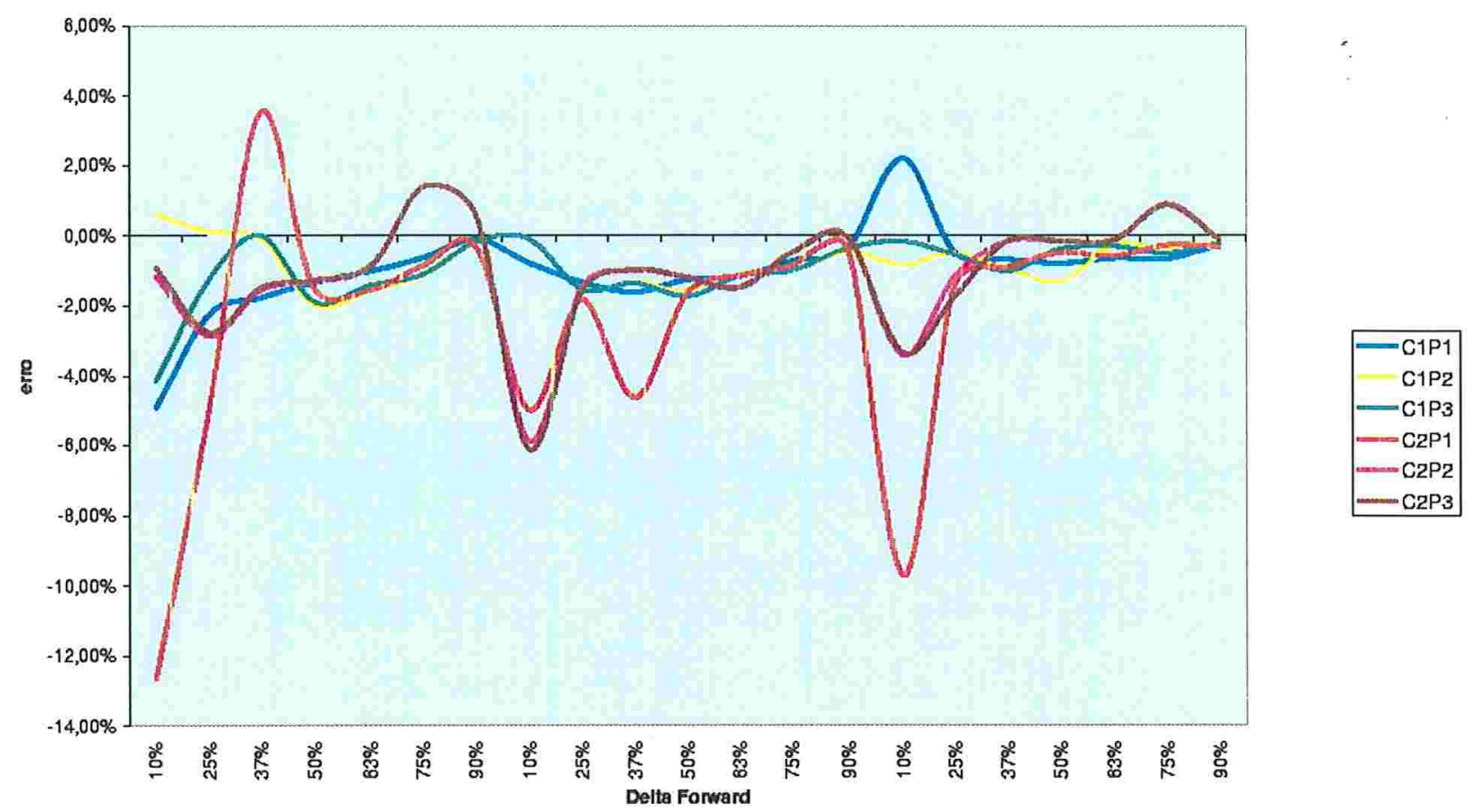

Figura 13 - Erros Relativos para a Calibração em 21/02/2003

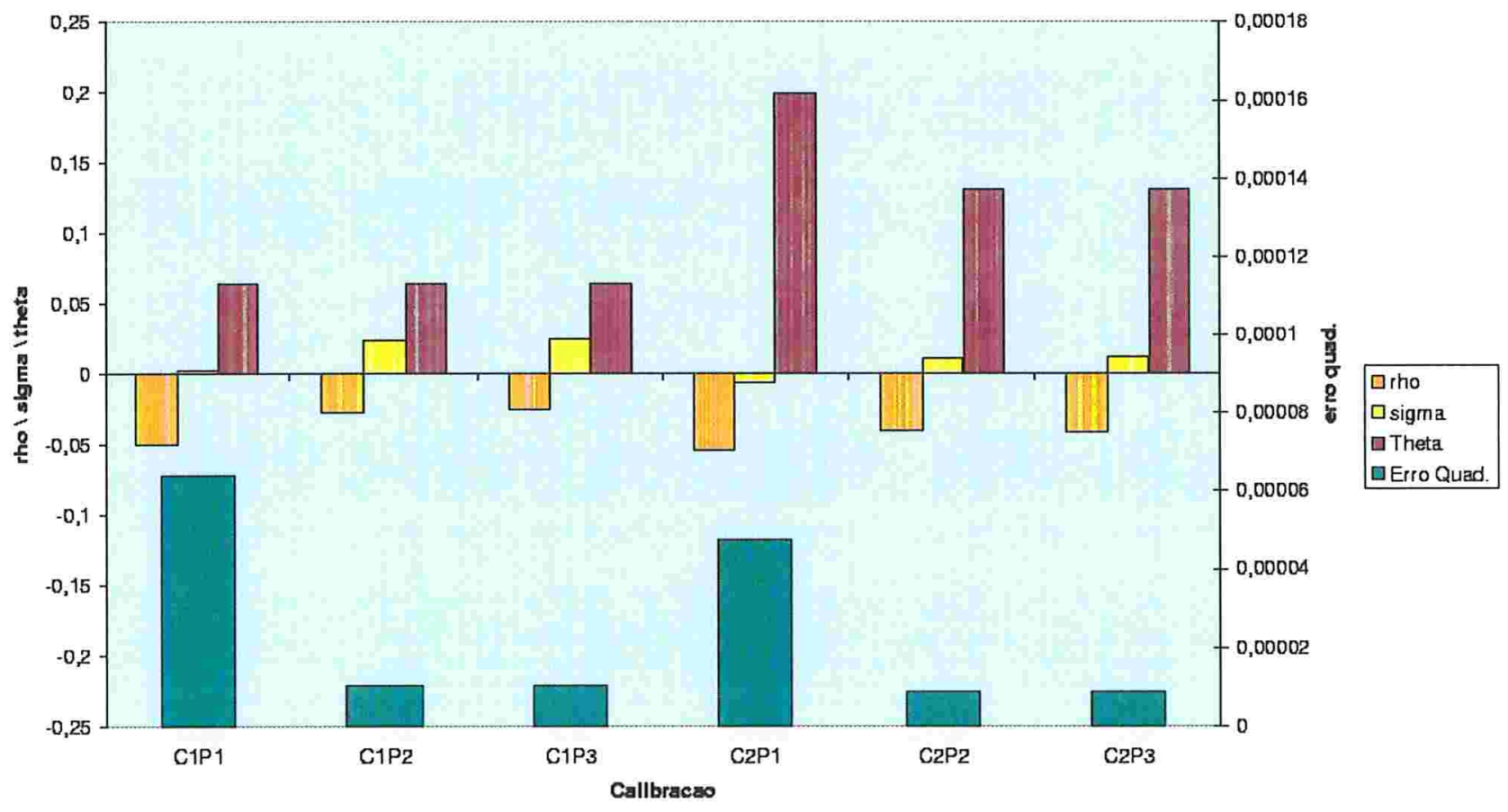

Figura 14 - Parametros Ajustados na Calibraçáo em 28/02/2003 


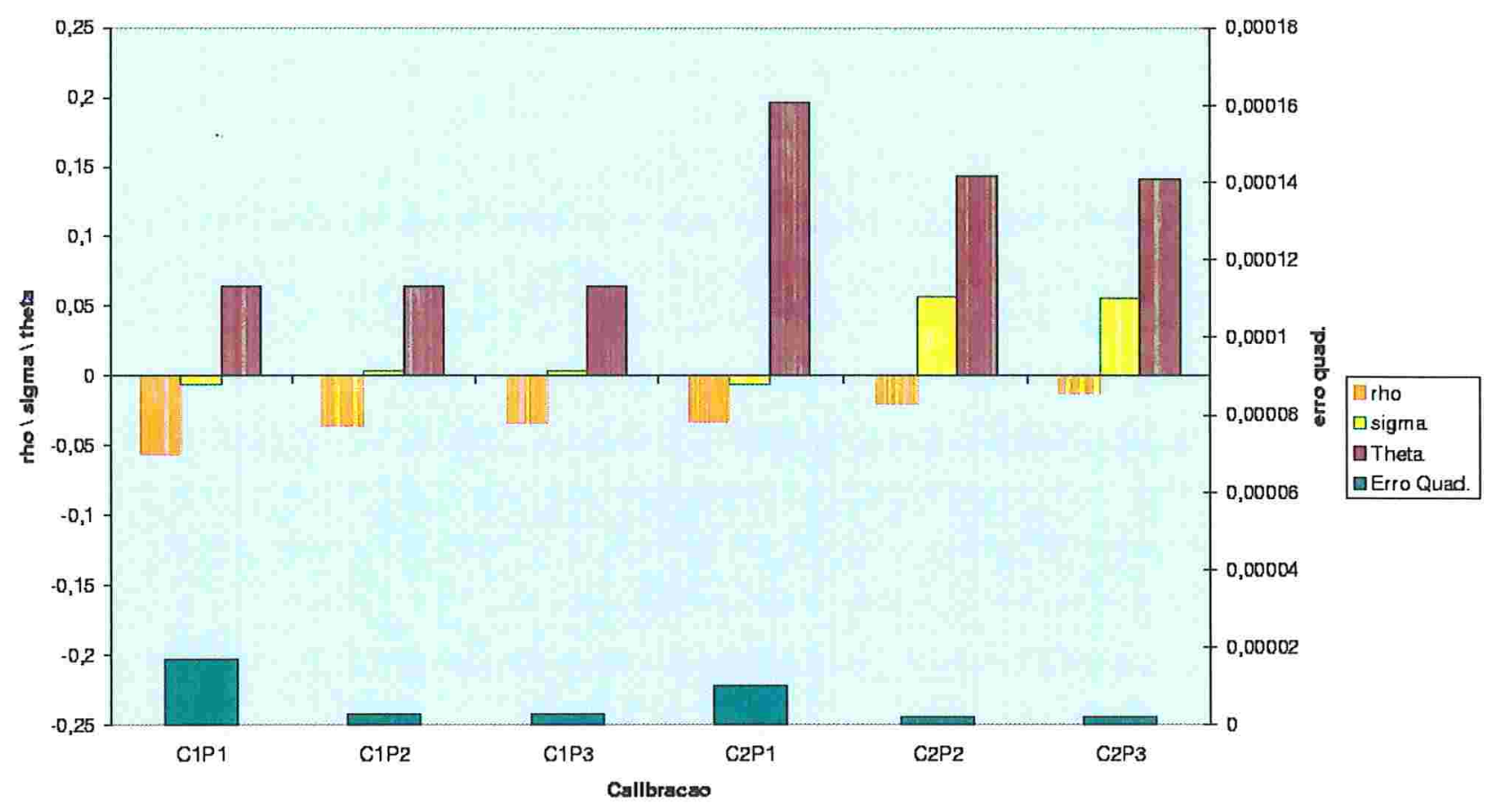

Figura 15 - Parametros Ajustados na Calibra ção ern 21/02/2003

Para o dia 02/01/2003 que representa um período de incerteza sobre as medidas do novo governo, verificou-se que os erros relativos apresentaram-se bem maiores que para os dias em fevereiro. Verificou-se também um erro maior para as opções fora do dinheiro e para algumas opções isoladamente. Neste último caso, as diferenças podem ser causadas por falta de liquidez para as respectivas opções (por exemplo, opções bastante dentro do dinheiro) neste dia. A aplicação dos pesos 2 e 3 apresentou uma redução nos erros relativos, porém não tão eficiente como nas calibrações para 28/02/2003 e 21/02/2003 (vide figuras 16 e 17). 
Apesar dos erros relativos serem maiores para esta data, observou-se que os parâmetros encontrados apresentaram-se estáveis para a maioria das minimizações, com exceção da calibração 2 com pesos 2 e 3 onde os valores de $\rho$ se desviaram do seu valor histórico. Vale salientar que nestes casos, o número de interações do algoritmo foi bem maior que para as demais simulações, o que se leva a crer que o modelo não se comportou adequadamente aos pesos aplicados a função de minimização para a presente massa de dados nesse dia. Os menores erros relativos e quadráticos se deram na calibração 1 com peso 2 , sendo o erro quadrático na ordem de $10^{-4}$, bem superior aos dias de fevereiro.

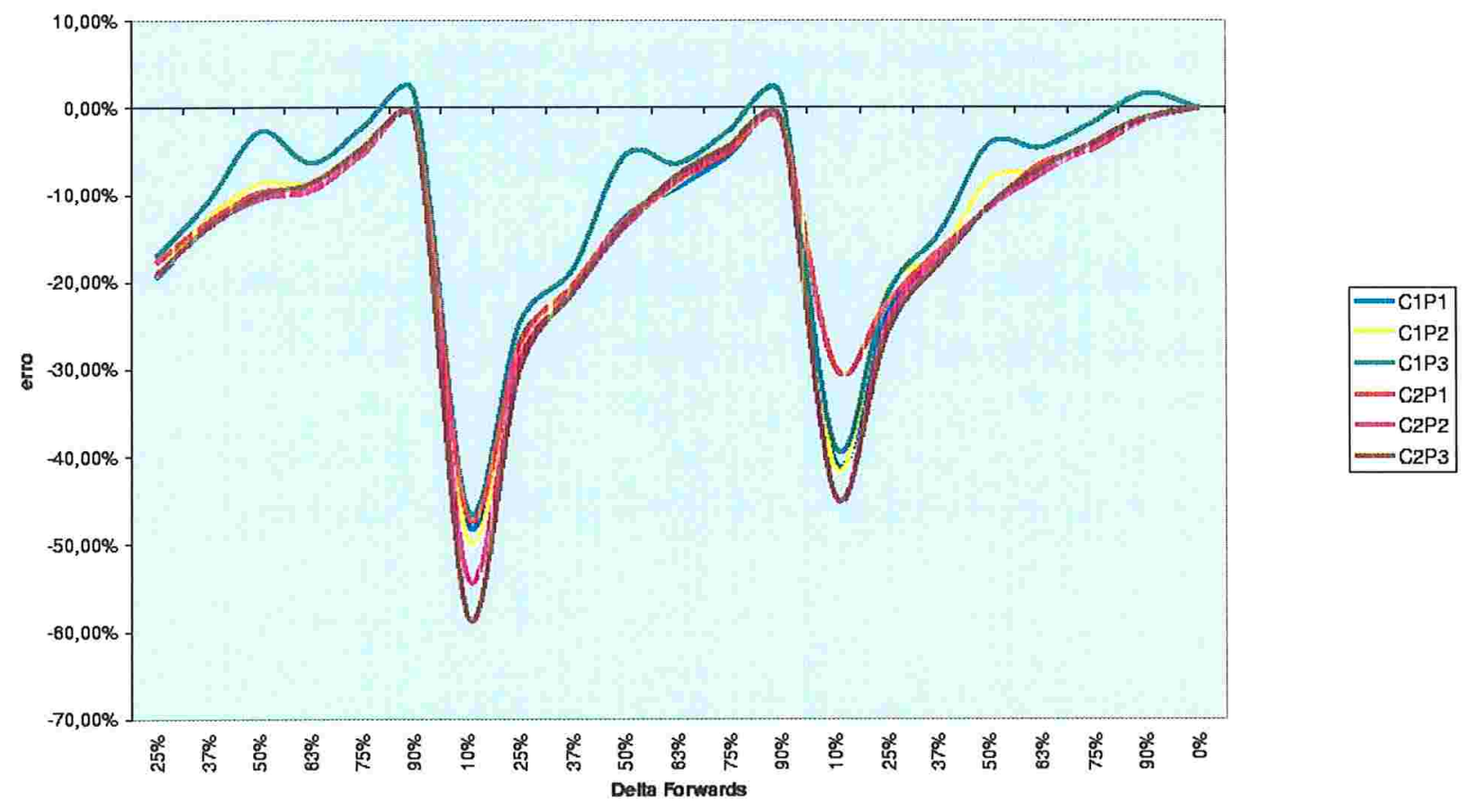

Figura 16 - Erros Relativos para a Calibração em 02/01/2003 


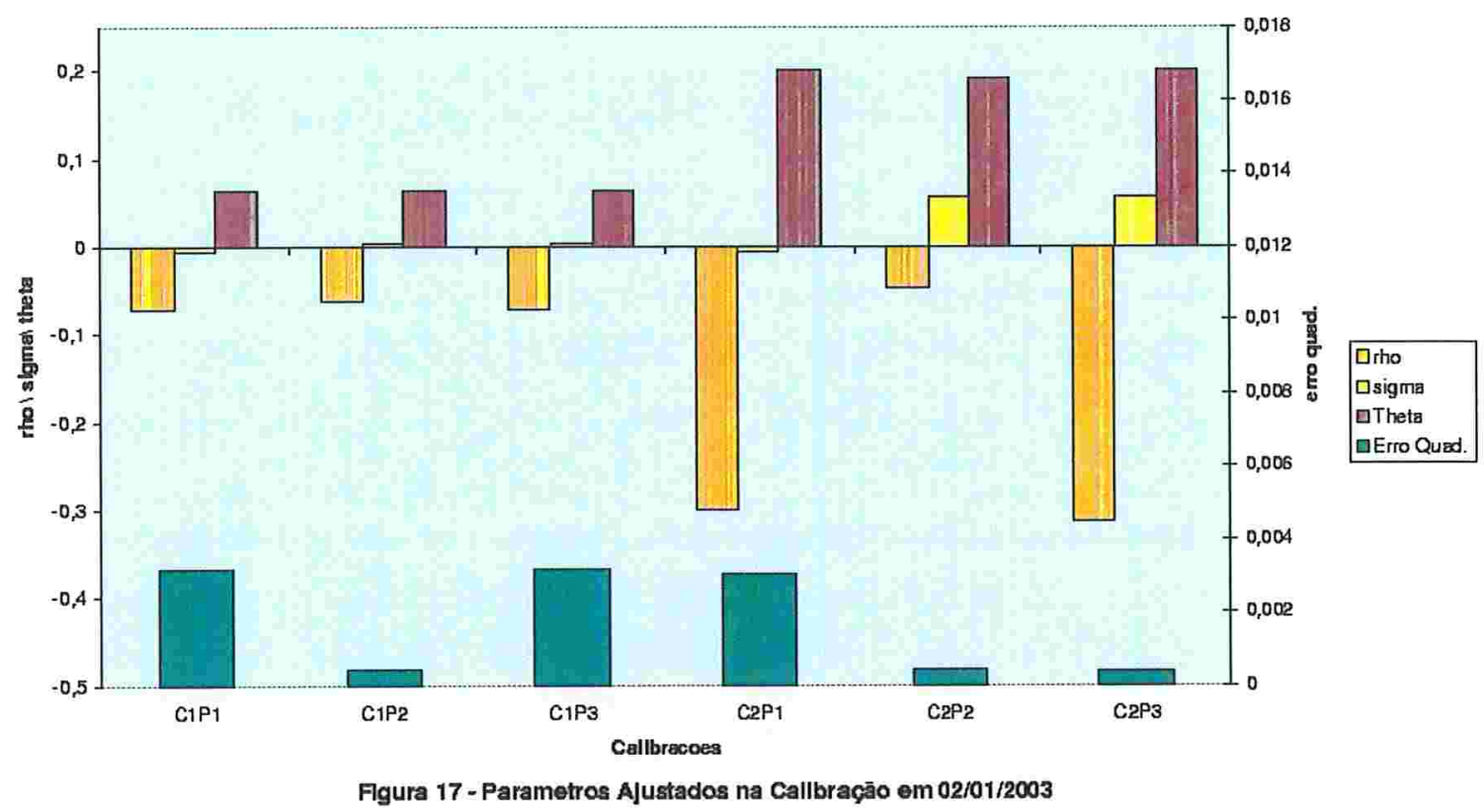

Para o dia 02/09/2002 que representa um momento já de incerteza sobre as expectativas do próximo governo mas ainda não tão volátil como na virada no ano, observou também erros relativos maiores que os observados em fevereiro e menores que os observados em janeiro. As opções fora do dinheiro apresentaram os maiores erros relativos. Para o primeiro vencimento $(01 / 10 / 2003)$ os erros se mostraram bem inferiores aos demais vencimentos. Para este primeiro vencimento, as volatilidades implícitas estão também inferiores aos demais prazos dada a eleição que ocorreria em outubro daquele ano. De todas as calibrações, as calibrações 1 e 2 com peso 1 covergiram para valores fora do esperado apresentando um número de interações bem superior às demais (20 - 24 interações). A calibração 2 com peso 3 apresentou o menor erro relativo e o menor erro quadrático (na ordem de $10^{-4}$ ), produzindo uma boa eficiência na redução dos erros (vide figuras $18 \mathrm{e}$ 19). 


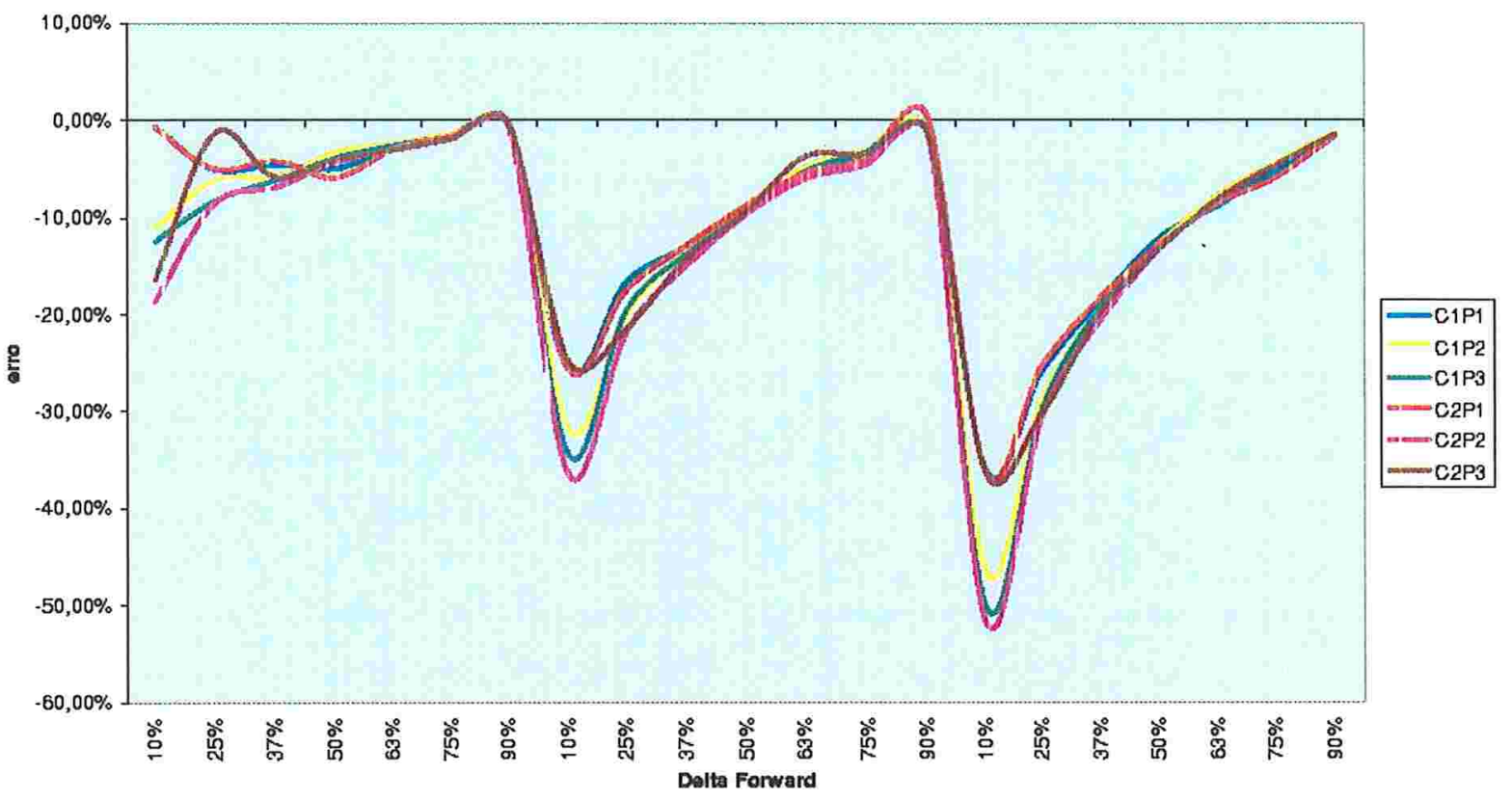

Figura 18 - Erros Relativos para a Calibração em 02/08/2002

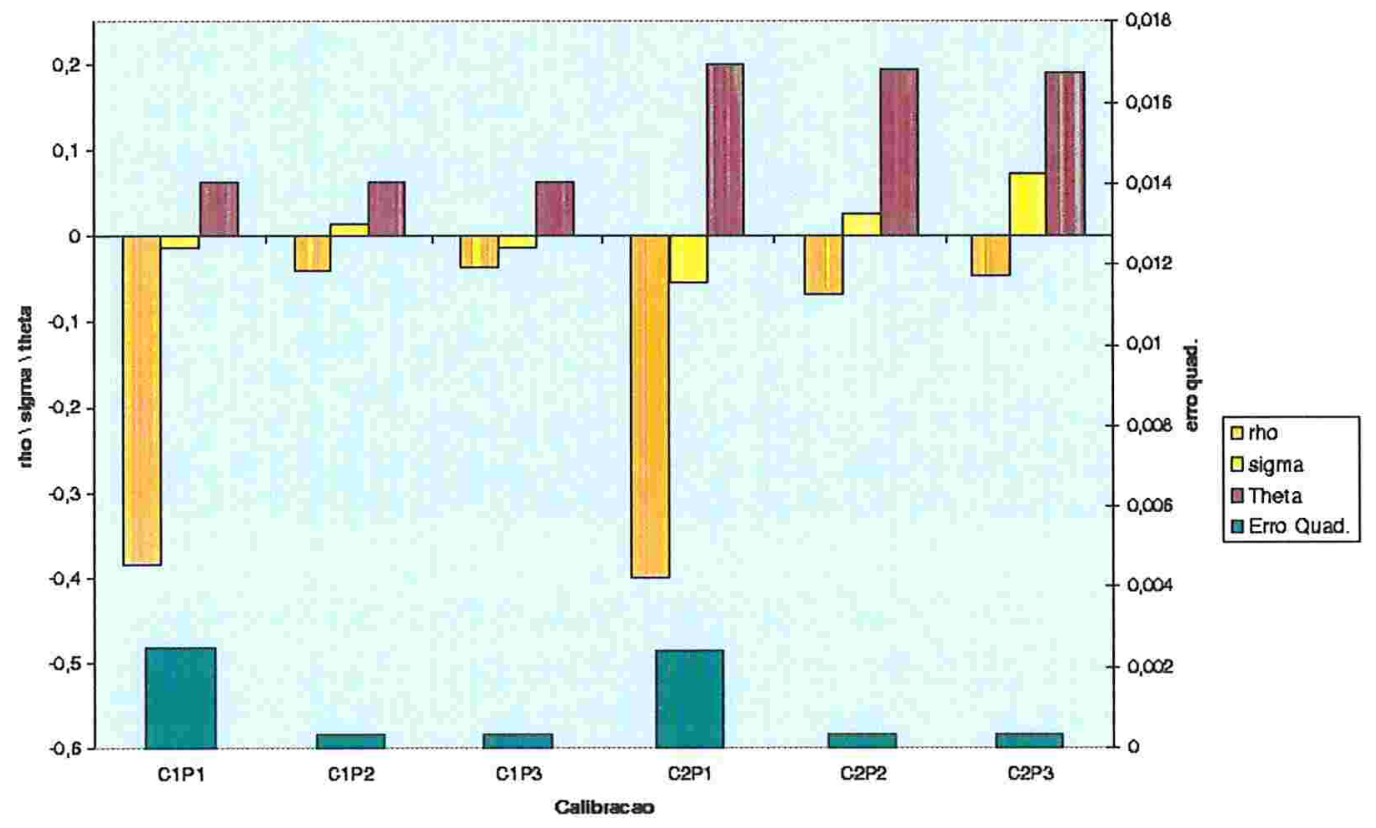

Figura 19 - Paramatros Ajustados na Callbraçāo em 02/09/2002 


\section{Capítulo 5}

\section{Conclusão}

Este trabalho descreveu o modelo de Heston e fez uma análise detalhada de seus parâmetros e sua implementação para o mercado brasileiro de opções de câmbio R\$/USD.

Observou-se pelos resultados da calibração que o modelo se mostrou aceitável para o mercado brasileiro. O modelo de Heston se apresentou estável para períodos menos voláteis e com algumas instabilidades para períodos de maior volatilidade. Os parâmetros do modelo nas diversas calibrações se mostraram na sua maioria estáveis e próximos dos valores obtidos por regressões econométricas ou por dados históricos. A utilização do vega e da moneyness como pesos para as funções de minimização foram eficientes na redução gradual dos erros para os períodos estáveis e pouco eficiente para períodos voláteis.

Apesar de $\rho$ e $\sigma$ apresentarem valores pequenos, sua utilidade na explicação do comportamento das opções e do respectivo ativo-objeto é bastante importante, principalmente para modelagem de riscos de mercado, onde através de simulações Monte-Carlo, por exemplo, pode-se obter as verdadeiras distribuições de probabilidade dos retornos esperados do $\mathrm{R} \$ /$ USD e conseqüentemente suas perdas.

Os valores de correlação se mostraram bem próximo de zero. Para os valores de $\sigma$, confirmou-se a existência de uma maior curtose na distribuição dos retornos esperados do $\mathrm{R} \$ / \mathrm{USD}$.

Conforme discutido no terceiro capítulo, fatos estilizados são observados no mercado 
brasileiro de câmbio e a calibração de modelos robustos como o de Heston é um trabalho árduo de modo a se contemplar esses fatos estilizados. Por outro lado, esta é a grande vantagem do modelo de Heston quando comparado ao modelo de Garman-Kohlhagen.

Uma desvantagem evidente no modelo de Heston quando comparado com o modelo de Garman-Kohlhagen é o tempo de processamento de cálculo do preço da opção, além do custo computacional para a calibração do modelo periodicamente.

Espera-se que este trabalho seja o início de próximos desenvolvimentos sobre o tema que parece ser muito vasto e aplicável ao mercado brasileiro. Como sugestões pode-se montar estratégias de negociação, por exemplo, delta-neutro para se verificar as possibilidades de ganhos de arbitragem para diferentes períodos, a incorporação de processos de saltos ao modelo de Heston, a incorporação de taxas de juros estocásticas ao modelo dentre outros passos de forma a se contemplar melhor todos estes fenômenos.

Uma das preocupações do autor também foi apresentar todos os passos necessários para o apreçamento das opções de câmbio no mercado brasileiro tal que este documento sirva de referência para aqueles iniciantes que buscam se aprofundar no tema. 


\section{Bibliografia}

[1] Black F., Scholes M., 1973, The Pricing of Options and Corporate Liabilities ,Journal of Political Economy 81.

[2] Black F., 1976, The Pricing of Commodity Contracts ,Journal of Financial Economics, vol. 3 .

[3] Breeden, D. T. , 1979, An Intertemporal Asset Pricing Model with Stochastic Consumption and Investment Opportunities. Journal of Financial Economics, 7, 265-296.

[4] Cox, J. C., J. E. Ingersoll, and S. A. Ross. An Intertemporal General Equilibrium Model of Asset Prices. Econometrica, 53 (march 1985), 363-384.

[5] Cox, J. C., J. E. Ingersoll, and S. A. Ross. A Theory of Term Structure of Interest Rates. Econometrica, 53 (march 1985), 385-408.

[6] DeRosa, David F., 1998, Currency Derivatives: Pricing Thoery, Exotic Options, and Hedging Applications, John Wiley \& Sons, Collection of Scientific Articles.

[7] Fouque,J., Papanicolaou,G., Sircar, K., 2000, Derivatives in Financial Markets with Stochastic Volatility, Cambridge University Press.

[8] Garman, M. B., and Kohlhagen, S. W., 1983, Foreign Currency Option Values, Journal of International Money and Finance, 2 , 231-237.

[9] Ghahramani, Saeed, 2000, Fundamentals of Probability, Prentice Hall, 2nd Edition. 
[10] Haug, Espen G., 1997, The Complete Guide to Options Princing Formulas, McGrawHill.

[11] Heston, S., 1993, A Closed-Form Solution for Options with Stochastic Volatility with Applications to Bond and Currency Options, The Review of Financial Studies,6(2).

[12] Hull J., White A., 1987, The Pricing of Options on Assets with Stochastic Volatilities, Journal of Finance, 42 .

[13] Hull J., White A., 1988, An Analysis of the Bias in Option Pricing Caused by a Stochastic Volatility, Advances in Futures and Options Research,3.

[14] Hull J., 1993, Options, Futures and Other Derivatives, Prentice Hall, 4th Edition.

[15] LEMGRUBER, E. F. (1999), Cupom Limpo, Cupom Sujo e Assincronismo na Coleta de Informações.

[16] LEMGRUBER, E. F., CUNHA D. (2002), Opções de Dólar no Brasil com Taxas de Juro e de Cupom Estocásticos.

[17] Melino, A.,Turnbull, S.J., 1991, The Pricing of Foreign Currency Options, Canadian Journal of Economics 24, 251-281.

[18] Merton, R. C., Theory of Rational Option Pricing, Bell J. Econ. and Management Sci., Spring 1973,4: 141-183

[19] Scott, L. O. Option Pricing when the Variance Changes Randomly: Theory, Estimation, and an Application. Journal of Financial and Quantitative Analysis, 22 (Dec. 1987), 419-438.

[20] Stein E.M., Stein J.C., 1991, Stock Price Distributions with Stochastic Volatility, The Review of Financial Studies, 4 (4).

[21] Wiggins J.B., 1987, Option Valuation Under Stochastic Volatility, Journal of Financial Economics, 19. 
Apêndice I - Tabelas de Dados

Utilizados na Calibração do Modelo de Heston 


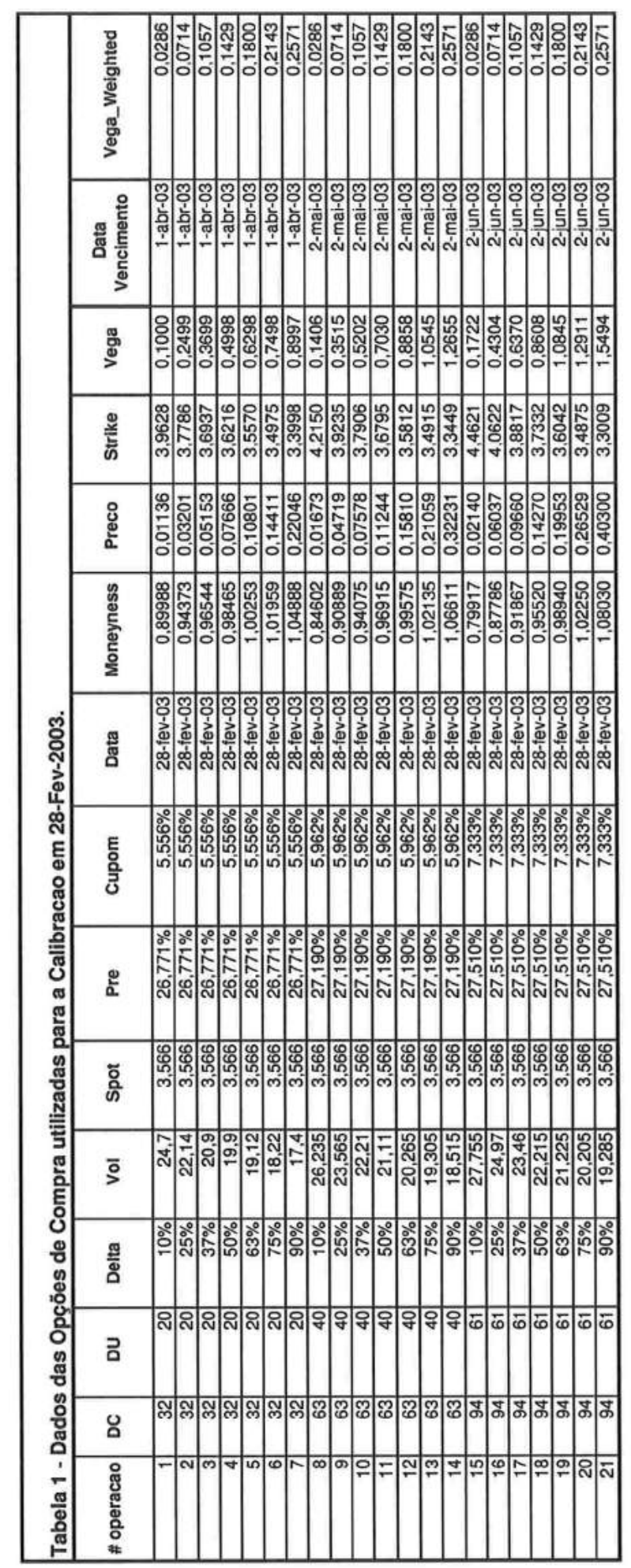




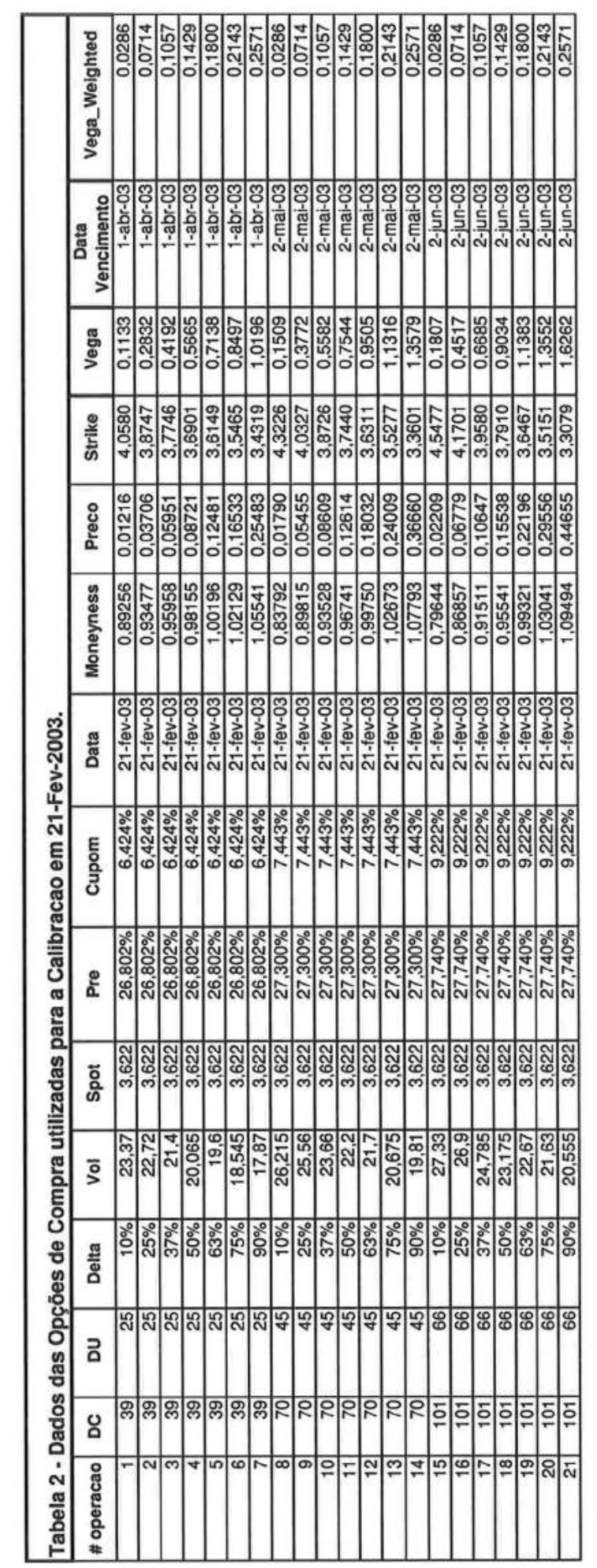




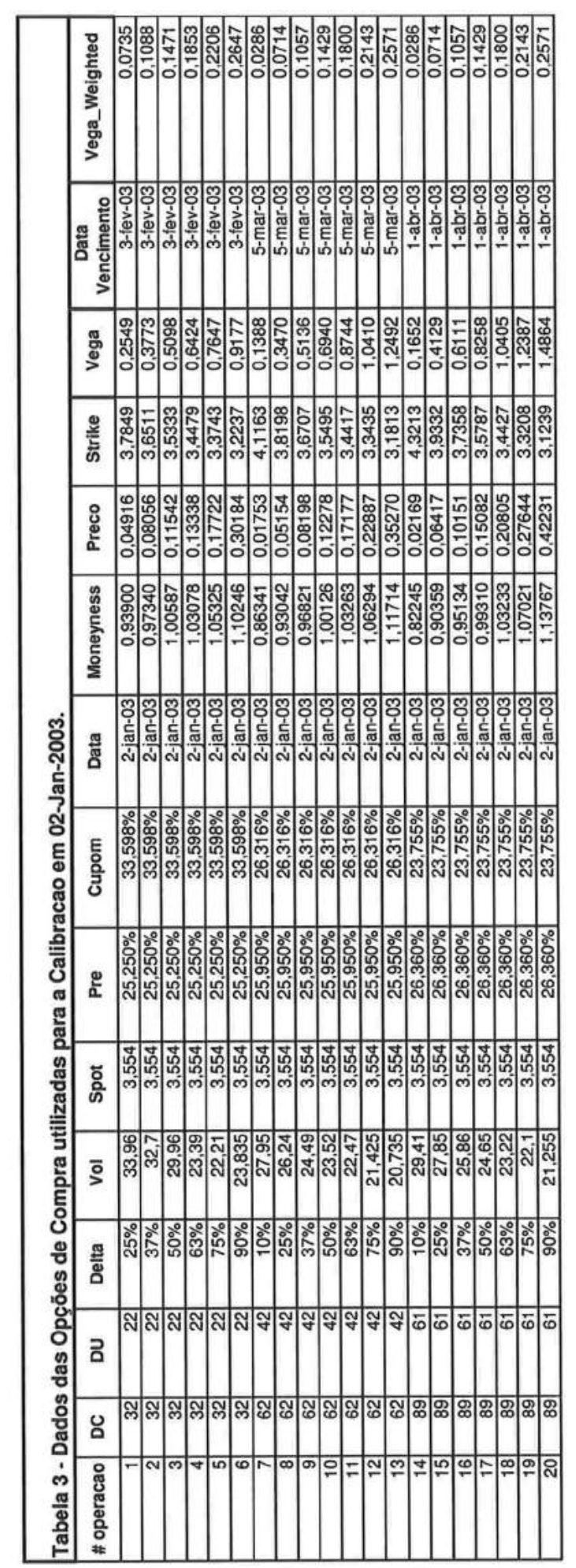




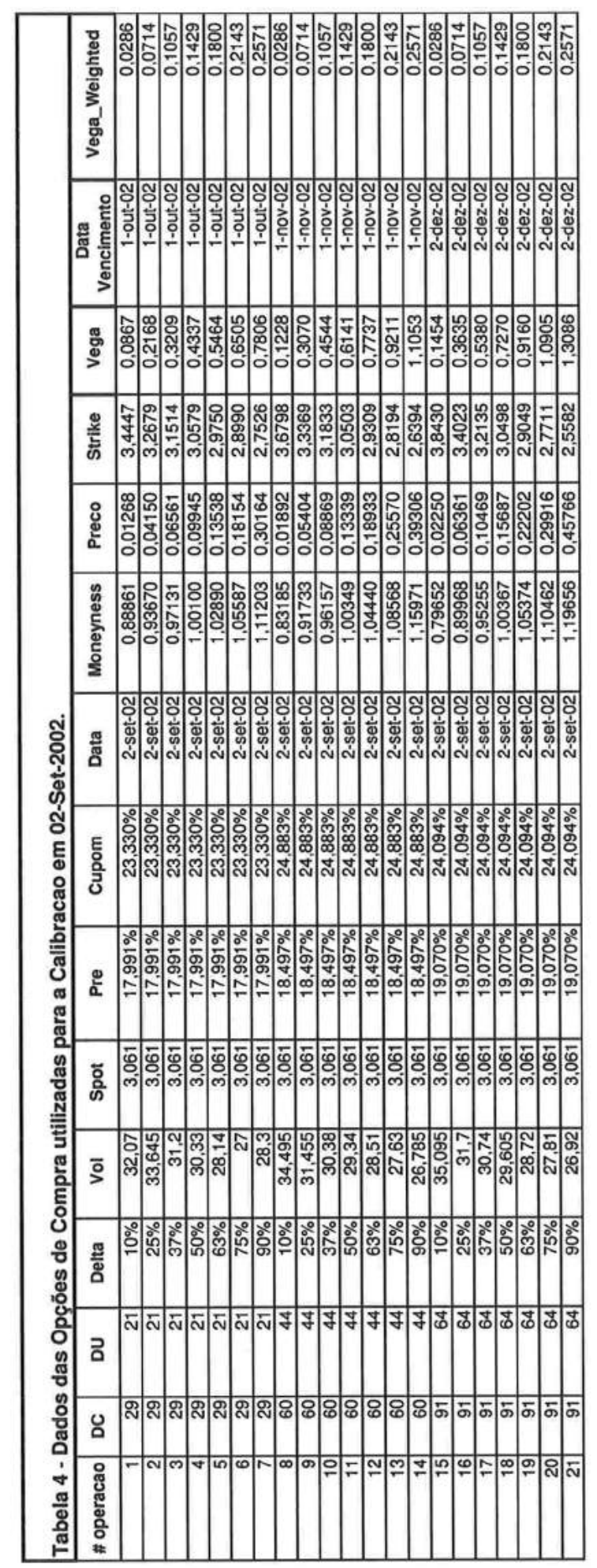


Apêndice II - Resultados das

Calibrações do Modelo de Heston 

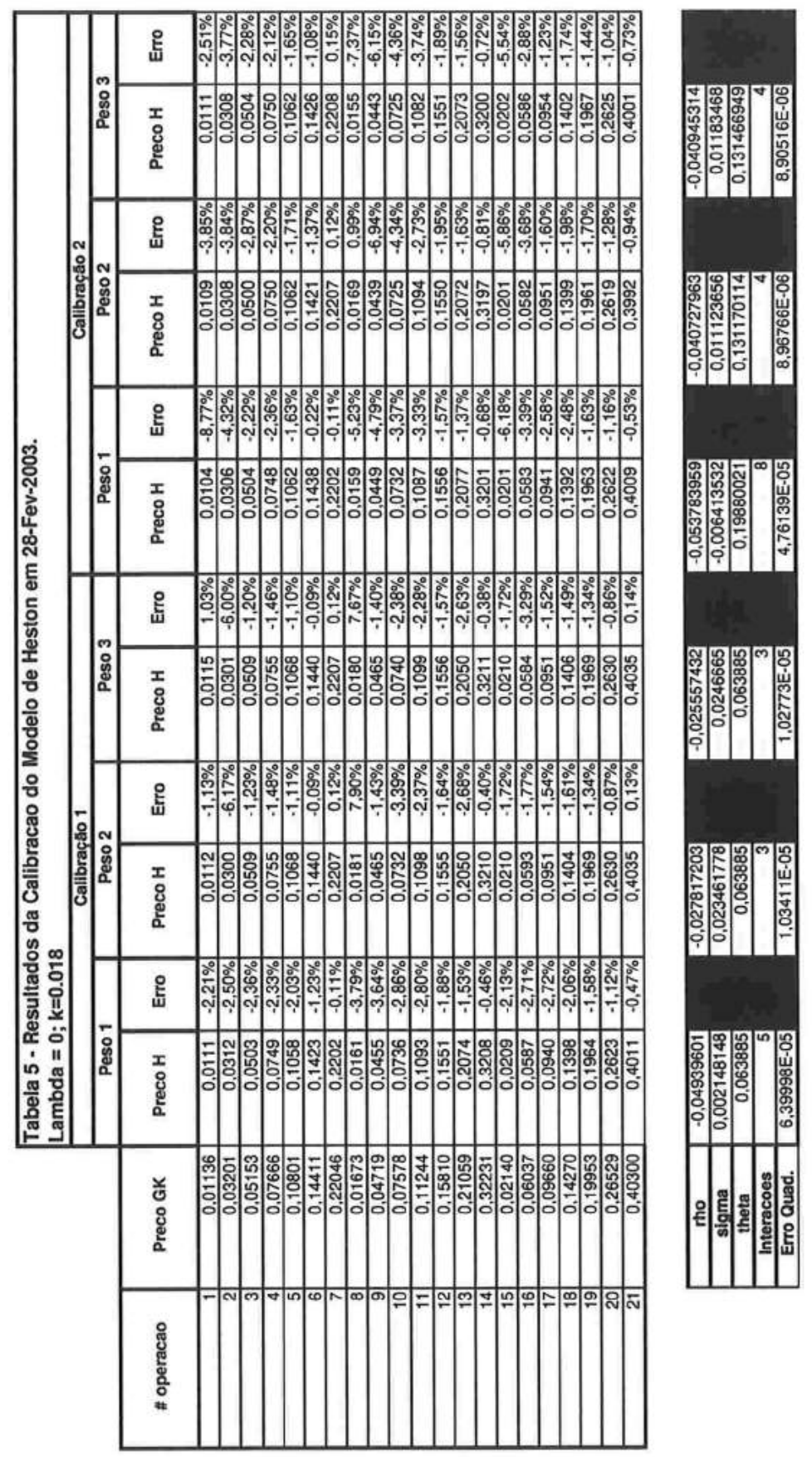


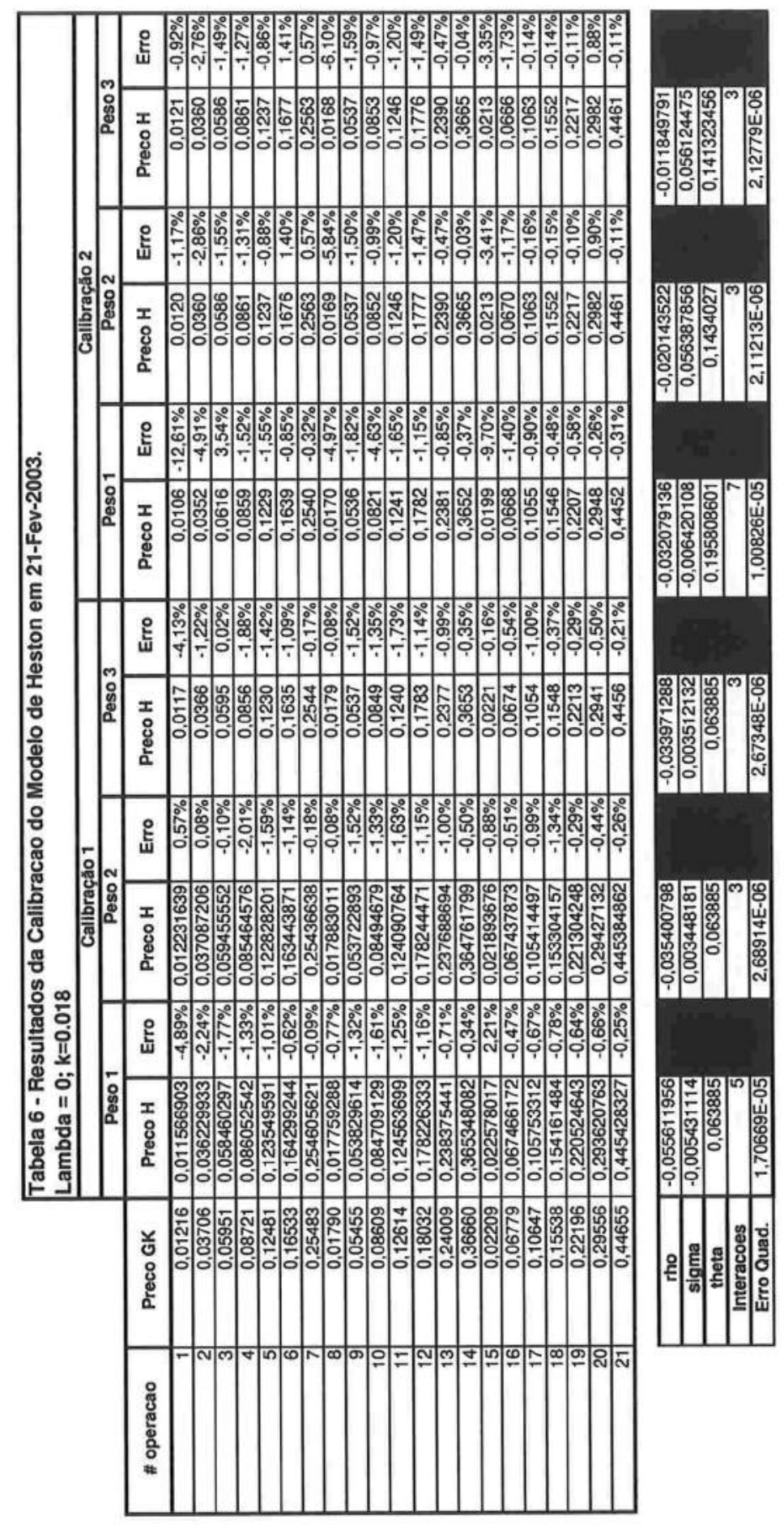




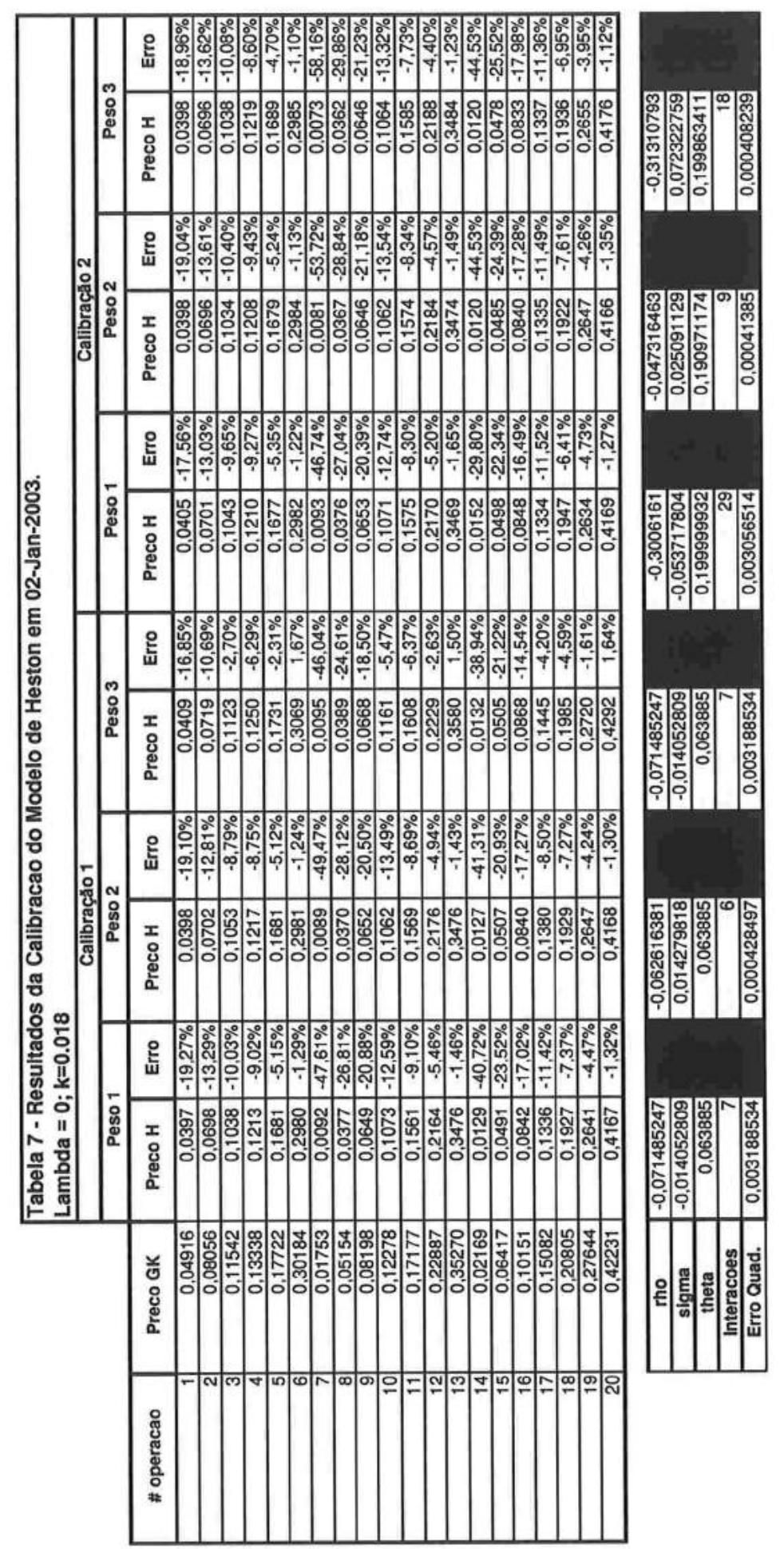




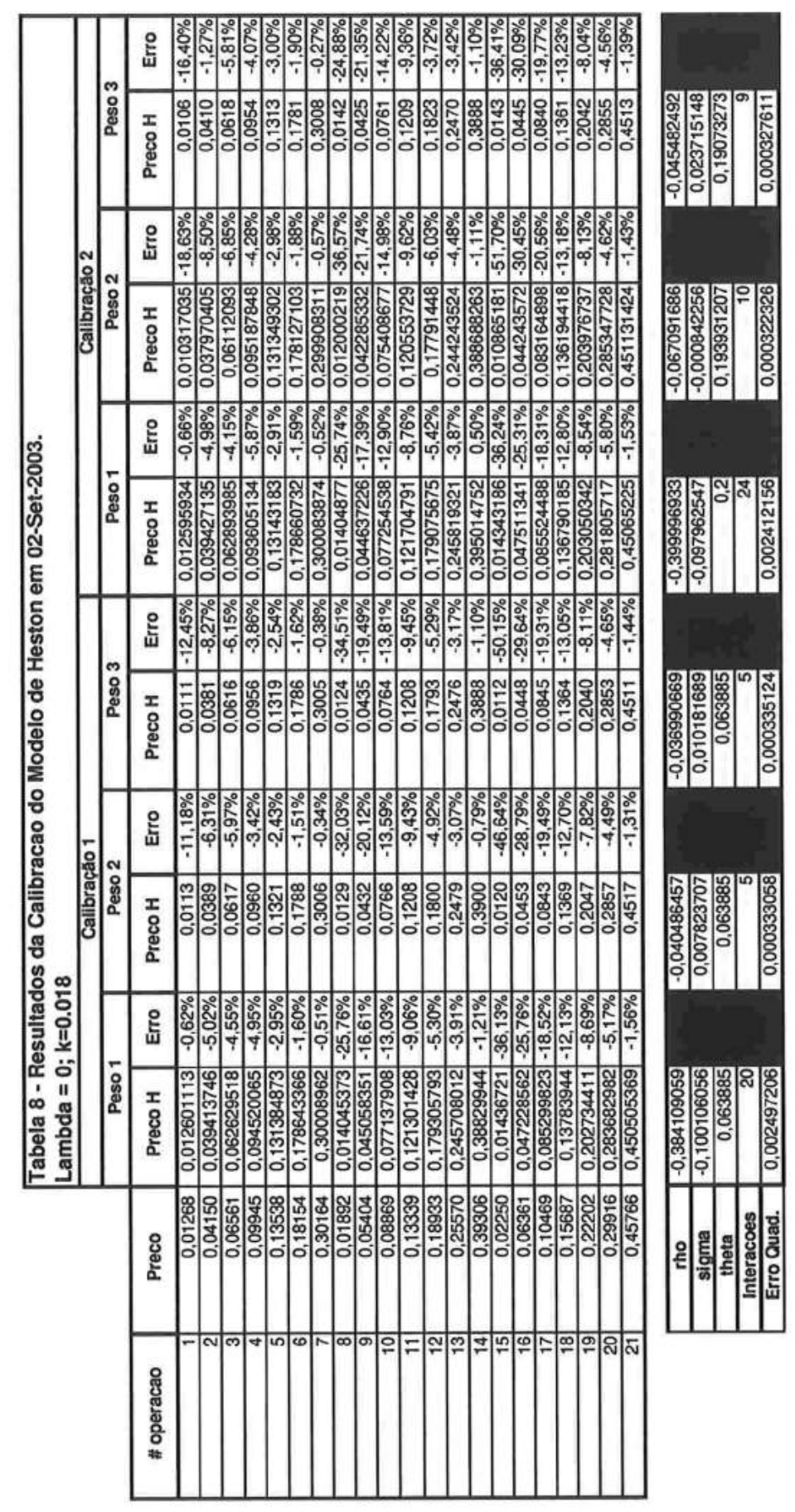




\section{Apêndice II - Códigos em MATLAB}

\section{Função calibration_rho_sigma.m}

\section{\%\%\%\%\%\%\%\%\%\%\%\%\%\%\%\%\%\%\%\%\%\%\%\%\%\%\%\%\%\%\%\%\%\%\%\%\%\%\%\%\%\%\%\%\%\%\%\%\%\%\%\%\%\%\%\%\%\%\%\%\%\%\%\%\%}

$\%$ CALIBRACAO DO MODELO DE HESTON

\% Calibracao utilizando rho e sigma como parametros do modelo

$\%$ Autor: MARCELO COSTA

$\%$ Data: $12 / 04 / 2003$

\%\%\%\%\%\%\%\%\%\%\%\%\%\%\%\%\%\%\%\%\%\%\%\%\%\%\%\%\%\%\%\%\%\%\%\%\%\%\%\%\%\%\%\%\%\%\%\%\%\%\%\%\%\%\%\%\%\%\%\%\%\%\%\%\%\%\%\%\%

function $\mathrm{F}$ =calibration_rho_sigma(matriz)

$[a, b]=s i z e($ matriz);

inicio $=1 ;$ final $=a ; w=1$;

$\% \% \% \% \% \% \% \% \% \% \% \% \% \% \%$ definicao dos parametros fixos $\% \% \% \% \% \% \% \% \% \% \% \% \% \%$

theta $=0.063885 ; \mathrm{kk}=0.018477 ;$ lambda $=0.0$;

$\% \% \% \% \% \% \% \% \% \% \% \% \% \% \% \% \% \% \%$ dados de mercado\%\%\%\%\%\%\%\%\%\%\%\%\%\%\%\%\%\%\%\%\%\%\%\%\%\%\%\%\%

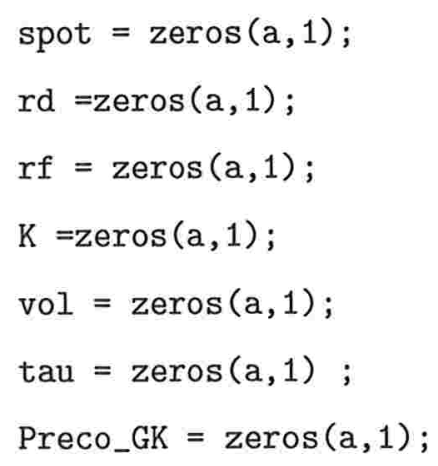




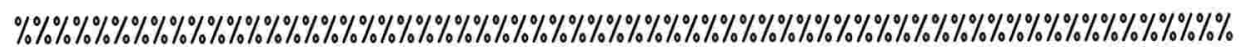

$\% \quad$ Inicio do for para a calibracao do modelo

\%\%\%\%\%\%\%\%\%\%\%\%\%\%\%\%\%\%\%\%\%\%\%\%\%\%\%\%\%\%\%\%\%\%\%\%\%\%\%\%\%\%\%\%\%\%\%\%\%\%\%\%\%\%\%\%\%\%\%\%\%\%\%\%\%\%\%\%

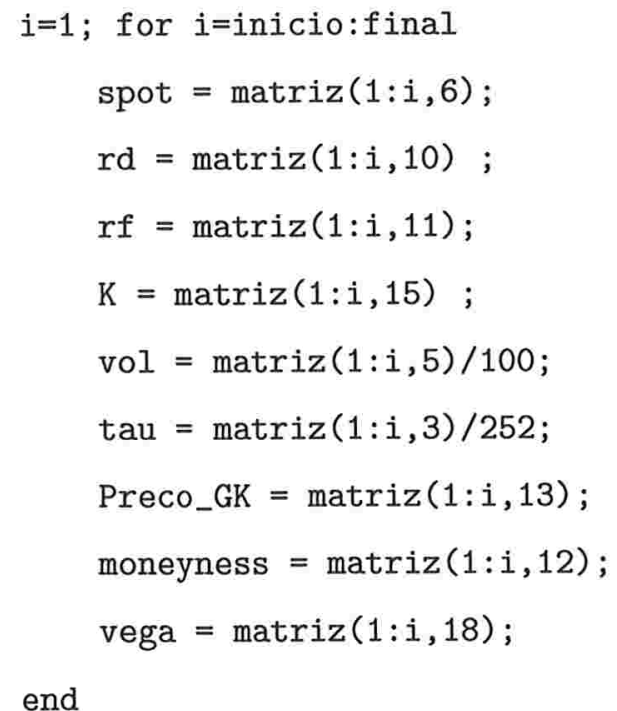

end

$\% \% \% \% \% \% \% \% \% \% \% \% \% \%$ valor inicial e condicoes de fronteira $\% \% \% \% \% \% \% \% \% \% \% \% \% \% \% \% \% \% \%$

$\mathrm{x} 0=\left[\begin{array}{ll}-0.05 & -0.0378\end{array}\right] ;$

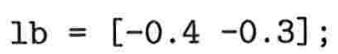

$\mathrm{ub}=\left[\begin{array}{ll}0.4 & 0.3\end{array}\right]$;

\%\%\%\%\%\%\%\%\%\%\%\%\%\%\%\%\%\%\%\% \%

options = optimset ('LargeScale', 'on' , 'LevenbergMarquardt', 'off') ;

$[\mathrm{x}$, resnorm, residual, exitflag, output $]=$

lsqnonlin('Heston_call_rho_sigma2', $x 0$, lb ,ub ,options , spot ,rd

,rf ,K ,vol , tau ,Preco_GK, theta ,kk , lambda, vega,moneyness);

iterations = getfield(output, 'iterations')

algorithm = getfield(output, 'algorithm')

$F=[x$ resnorm iterations exitflag $]$ 


\section{Função Heston_call_rho_sigma2.m}

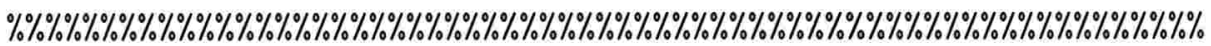

$\%$ Funcao Heston_call_rho_sigma2

\% Calcula o preço da opçao europeia de compra/venda

$\%$ de cambio pelo modelo de Heston

\% Autor: Marcelo Costa - 10/01/2003

\%\%\%\%\%\%\%\%\%\%\%\%\%\%\%\%\%\%\%\%\%\%\%\%\%\%\%\%\%\%\%\%\%\%\%\%\%\%\%\%\%\%\%\%\%\%\%\%\%\%\%\%\%\%\%\%\%\%\%\%\%\%\%\%\%\%\%\%\%\%

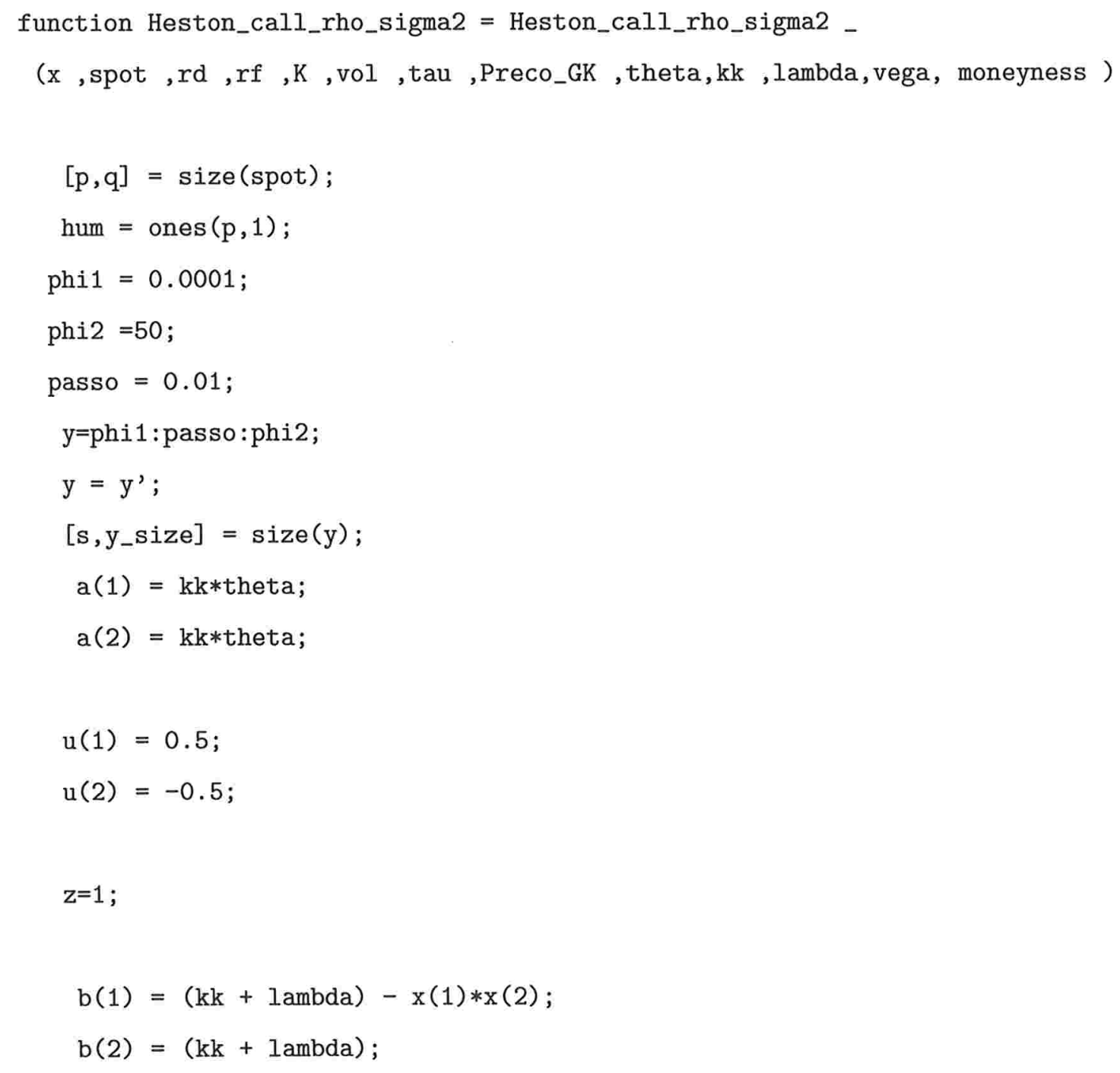


soma1 $=\operatorname{zeros}(\mathrm{p}, 1)$;

$\operatorname{soma2}=\operatorname{zeros}(p, 1)$;

$j=1$; for $j=1: p$

$x x(j)=\log (\operatorname{spot}(j) * \exp ((\operatorname{rf}(j)-\operatorname{rd}(j)) * \operatorname{tau}(j))) ;$

for $w=1: s-1$

for $\mathrm{z}=1: 2$

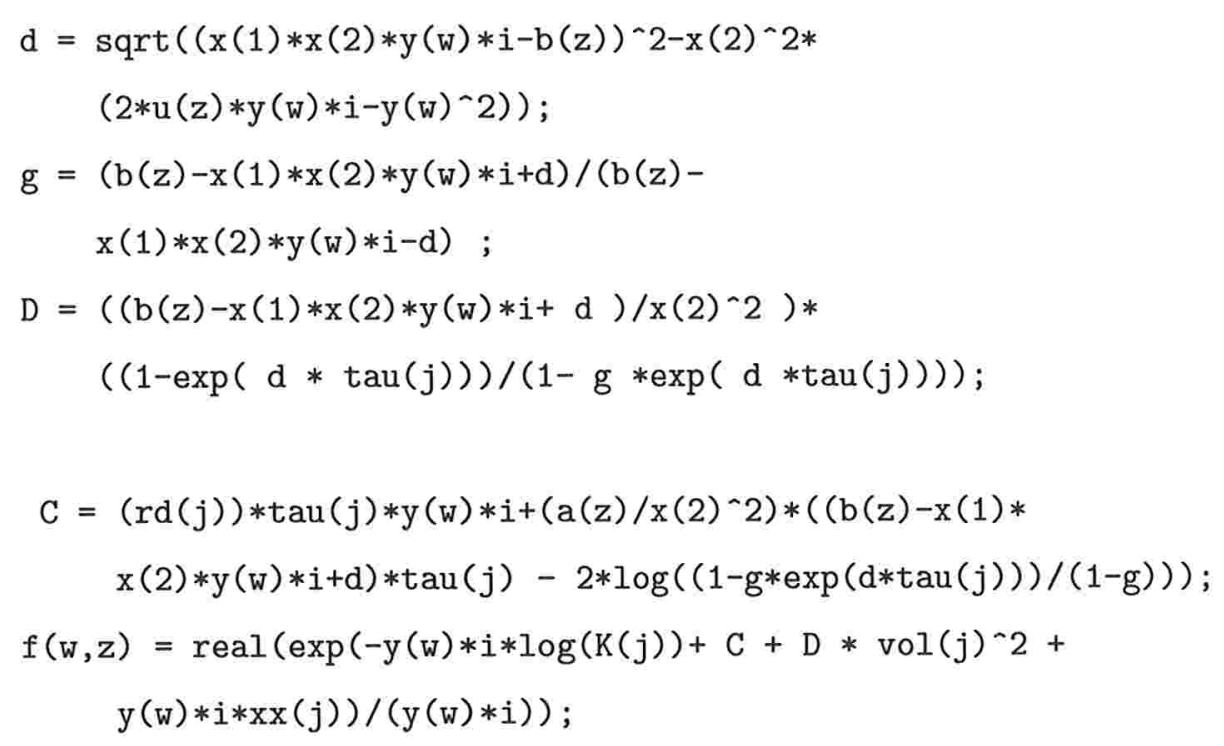




$$
(\exp (-\operatorname{rd}(j) * \operatorname{tau}(j))) * \operatorname{soma} 2(j) ;
$$

$\% \% \% \% \% \% \% \% \% \% \% \% \% \% \% \%$ Aqui pode-se alterar a função para diferentes pesos $\% \% \% \% \% \% \% \% \% \% \% \% \% \% \% \% \% \%$

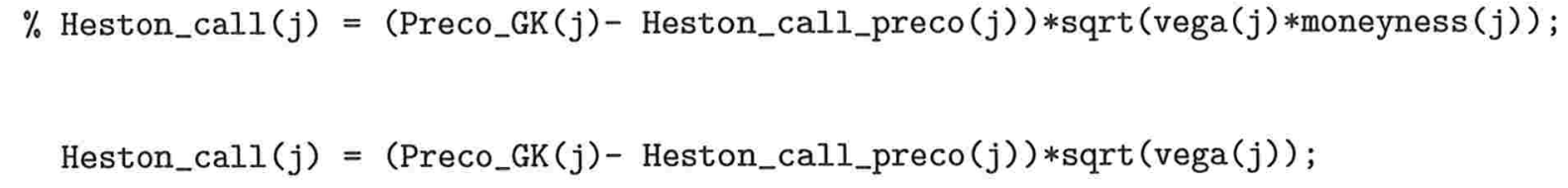




\section{Função calibration_rho_sigma_theta.m}

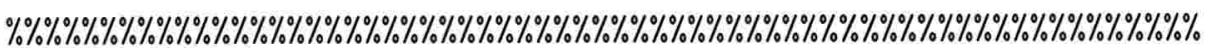

$\%$ CALIBRACAO DO MODELO DE HESTON

\% Calibracao utilizando rho , sigma e theta como parametros do modelo

$\%$ Autor: MARCELO COSTA

$\%$ Data: $12 / 04 / 2003$

\%\%\%\%\%\%\%\%\%\%\%\%\%\%\%\%\%\%\%\%\%\%\%\%\%\%\%\%\%\%\%\%\%\%\%\%\%\%\%\%\%\%\%\%\%\%\%\%\%\%\%\%\%\%\%\%\%\%\%\%\%\%\%\%\%\%\%\%\%\%

function $\mathrm{F}$ =calibration_rho_sigma_theta(matriz)

$[\mathrm{a}, \mathrm{b}]=\operatorname{size}($ matriz) ;

inicio $=1 ;$ final $=a ; w=1 ;$

$\% \% \% \% \% \% \% \% \% \% \% \% \% \% \% \%$ parametros do mode10\%\%\%\%\%\%\%\%\%\%\%\%\%\%\%\%\%\%\%\%\%\%\%\%\%\%\%\%

$\mathrm{kk}=0.018477 ;$ lambda $=0.0$;

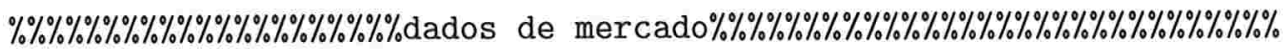

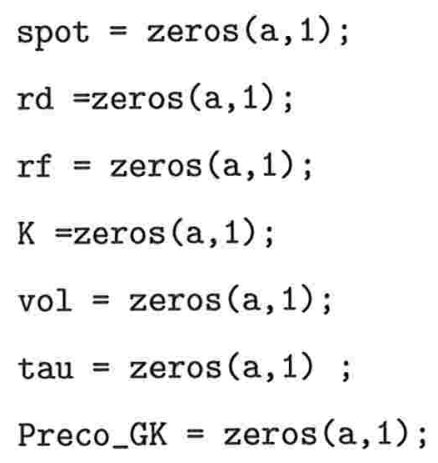

$\% \% \% \% \%$ Inicio do for para a calibracao do modelo $\% \% \% \% \% \% \% \% \% \% \% \%$ $i=1$; for $i=i n i c i o: f i n a l$

spot $=\operatorname{matriz}(1: i, 6)$;

$r d=\operatorname{matriz}(1: i, 10)$;

rf $=\operatorname{matriz}(1: i, 11)$;

$\mathrm{K}=\operatorname{matriz}(1: i, 15)$;

vol = $\operatorname{matriz}(1: i, 5) / 100$;

$\operatorname{tau}=\operatorname{matriz}(1: i, 3) / 252$;

Preco_GK $=$ matriz $(1: i, 13)$; 


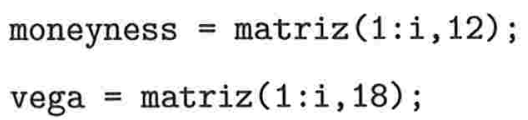

end

$\% \% \% \% \% \% \% \% \% \% \% \% \%$ valor inicial e condicoes de contorno $\% \% \% \% \% \% \% \% \% \% \% \% \%$

$$
\begin{aligned}
& \mathrm{x} 0=\left[\begin{array}{lll}
-0.05 & -0.0378 & 0.063885
\end{array}\right] ; \\
& \mathrm{lb}=\left[\begin{array}{lll}
-0.4 & -0.3 & 0.0001
\end{array}\right] ; \\
& \mathrm{ub}=\left[\begin{array}{lll}
0.4 & 0.3 & 0.2
\end{array}\right] ;
\end{aligned}
$$

$\% \% \% \% \% \% \% \% \% \% \% \% \% \% \% \% \%$ funcao de otimizacao $\% \% \% \% \% \% \% \% \% \% \% \% \% \% \% \% \% \% \% \% \% \% \% \% \%$

options = optimset ('LargeScale', 'on', 'LevenbergMarquardt', 'off') ;

$[\mathrm{x}$, resnorm, residual, exitflag, output] = lsqnonlin('Heston_call_rho_sigma_theta', x0 ,

lb , $\mathrm{ub}$,options, spot, rd ,rf ,K , vol ,tau ,Preco_GK , kk, lambda,vega,moneyness);

iterations = getfield(output, 'iterations')

algorithm = getfield(output, 'algorithm')

$\mathrm{F}=[\mathrm{x}$ resnorm iterations exitflag $]$ 


\section{Função Heston_call_rho_sigma_theta.m}

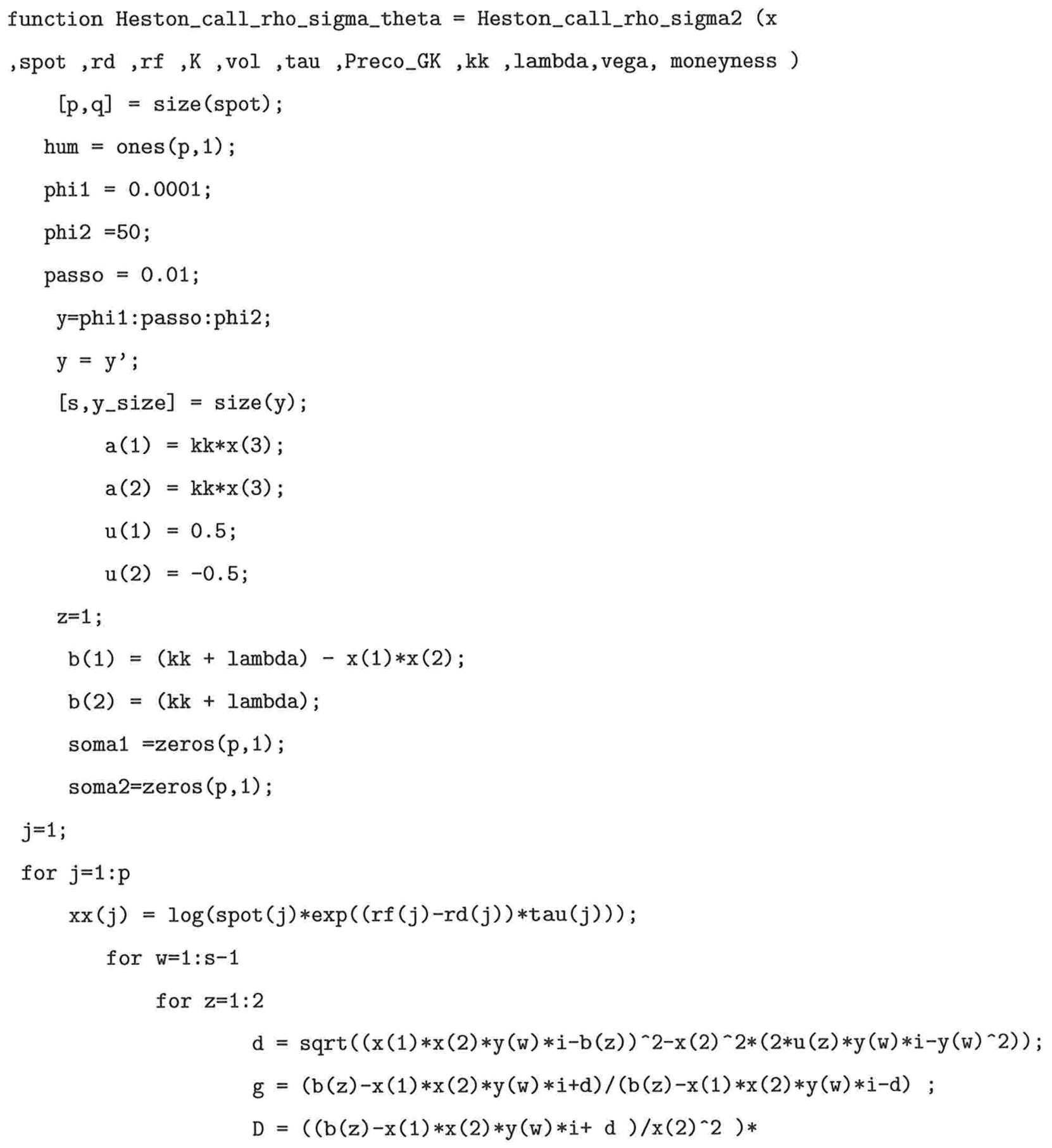




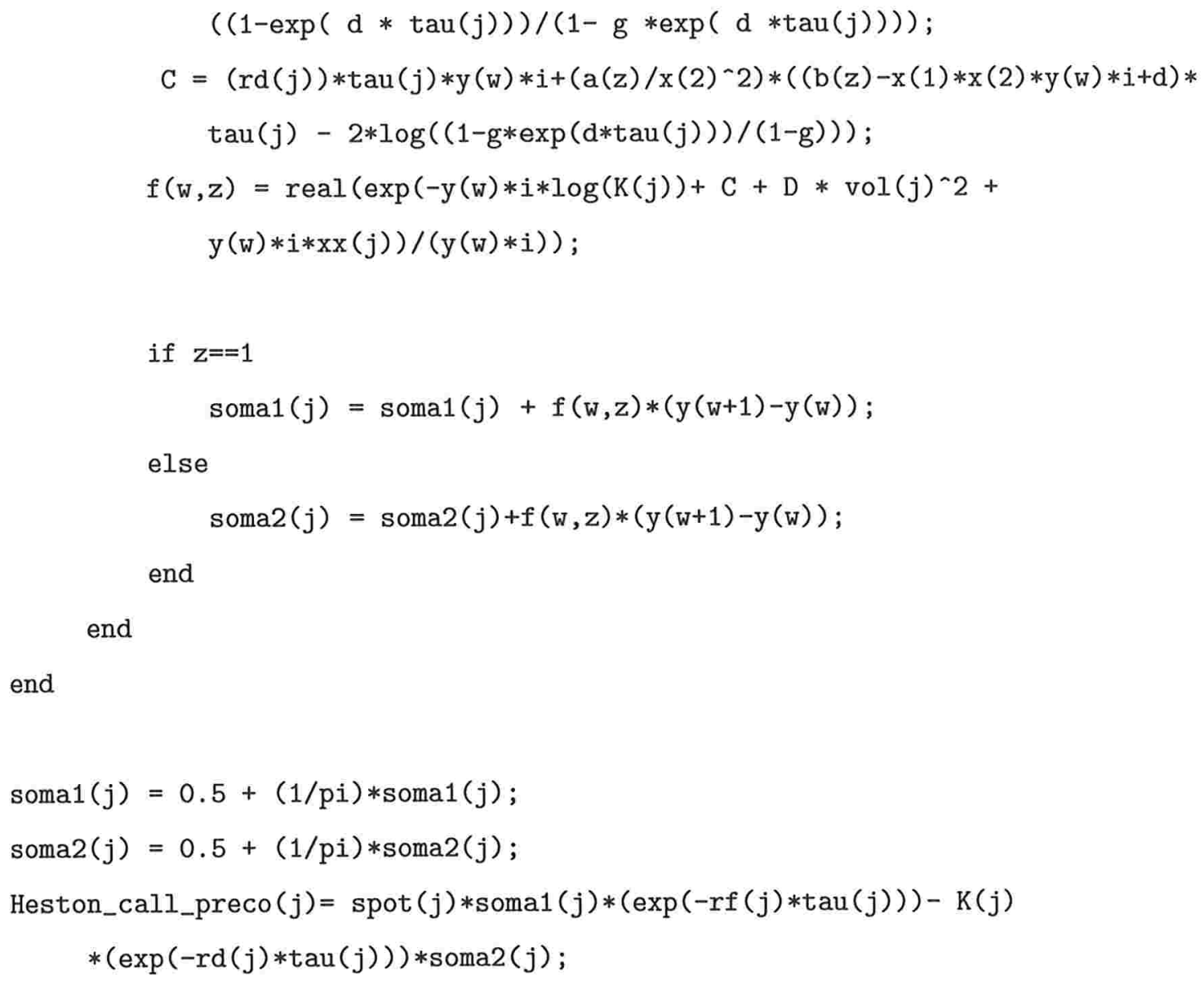

$\% \% \% \% \% \% \% \% \% \% \% \% \%$ Aqui pode-se alterar a função para diferentes pesos $\% \% \% \% \% \% \% \% \% \% \% \% \% \% \% \% \% \%$

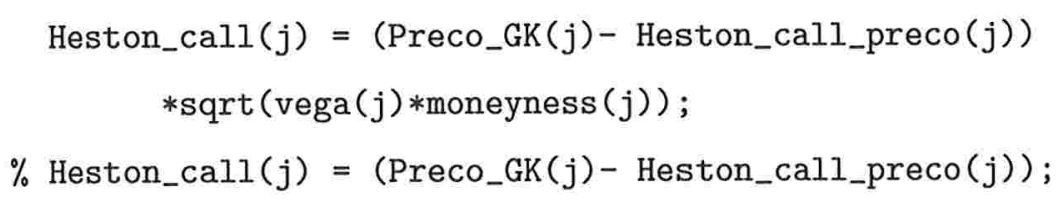




\section{Função CallHeston_MC.m}

\section{\%\%\%\%\%\%\%\%\%\%\%\%\%\%\%\%\%\%\%\%\%\%\%\%\%\%\%\%\%\%\%\%\%\%\%\%\%\%\%\%\%\%\%\%\%\%\%\%\%\%\%\%\%\%\%\%\%\%\%\%\%\%\%\%\%\%}

\% Calculo do Preco/fdp do modelo de Heston

$\%$ Autor: MARCELO COSTA

$\%$ Data: $12 / 04 / 2003$

\%\%\%\%\%\%\%\%\%\%\%\%\%\%\%\%\%\%\%\%\%\%\%\%\%\%\%\%\%\%\%\%\%\%\%\%\%\%\%\%\%\%\%\%\%\%\%\%\%\%\%\%\%\%\%\%\%\%\%\%\%\%\%\%\%\%\%

function $\mathrm{F}=$ CallHeston_MC (matriz, n_simulacao, rho)

$\%$ esta funcao calcula preco de call por simulacao de monte carlo

$\mathrm{dt}=1 / 252 ;$

spot $=\operatorname{matriz}(1,15)$;

$r d=\operatorname{matriz}(1,10)$;

$\mathrm{rf}=\operatorname{matriz}(1,11)$;

$\mathrm{K}=\operatorname{matriz}(1,15)$;

vol $=\operatorname{matriz}(1,5) / 100$;

$\operatorname{tau}=\operatorname{matriz}(1,3) / 252$;

Preco_GK $=\operatorname{matriz}(1,13)$;

V_ini $=$ vol^ 2 ;

sigma $=0.05 ;$

theta $=$ vol^2;

$\mathrm{kk}=0.02$;

passo $=\mathrm{tau} / \mathrm{dt}$;

soma $=0$;

aleatorio_x1 $=\operatorname{zeros}($ n_simulacao, passo);

aleatorio_x2 $=\operatorname{zeros}\left(\mathrm{n}_{-}\right.$simulacao, passo);

aleatorio_s = zeros (n_simulacao, passo);

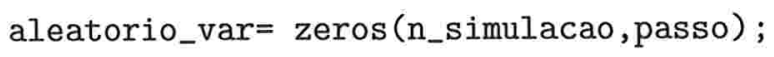


$k=1 ; j=1$;

for $\mathrm{k}=1$ :passo

for $j=1: n_{-}$simulacao

aleatorio_x1 $(j, k)=r a n d n$;

aleatorio_s $(j, \mathrm{k})=$ aleatorio_x1 $(\mathrm{j}, \mathrm{k})$;

end

end

$\%$ randn ('state', 0 );

$k=1 ; j=1$;

for $\mathrm{k}=1$ : passo

for $j=1: n_{-}$simulacao

aleatorio_x2 $(\mathrm{j}, \mathrm{k})=\mathrm{randn}$;

aleatorio_var $(j, k)=$ rho* aleatorio_x1 $(j, k)+$

sqrt $\left(1-r h 0^{\wedge} 2\right) *$ aleatorio_x2 $(j, k)$;

end

end

payoff $=\operatorname{zeros}\left(n_{-}\right.$simulacao, 1$)$;

$k=1 ; j=1 ;$

for $j=1$ :n_simulacao

$$
\begin{aligned}
& \mathrm{V}(j, 1)=\mathrm{V}_{-} \text {ini }+\mathrm{kk} *\left(\text { theta }-\mathrm{V}_{-} \text {ini }\right) * \mathrm{dt}+\operatorname{sigma} * \operatorname{sqrt}\left(\mathrm{V}_{-} i n i\right) * \\
& \text { aleatorio_var }(j, 1) * \operatorname{sqrt}(d t) \text {; } \\
& S(j, 1)=\operatorname{spot} * \exp ((((r d-r f)-((V(j, 1)) / 2)) * d t)+ \\
& (\operatorname{sqrt}(V(j, 1)) * \text { aleatorio_s }(j, 1) *(d t \cdots(1 / 2)))) \text {; }
\end{aligned}
$$




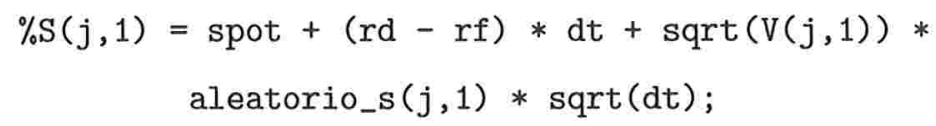

end

$j=1$;

if passo $>1$

for $\mathrm{k}=2$ :passo

for $j=1: n_{-}$simulacao

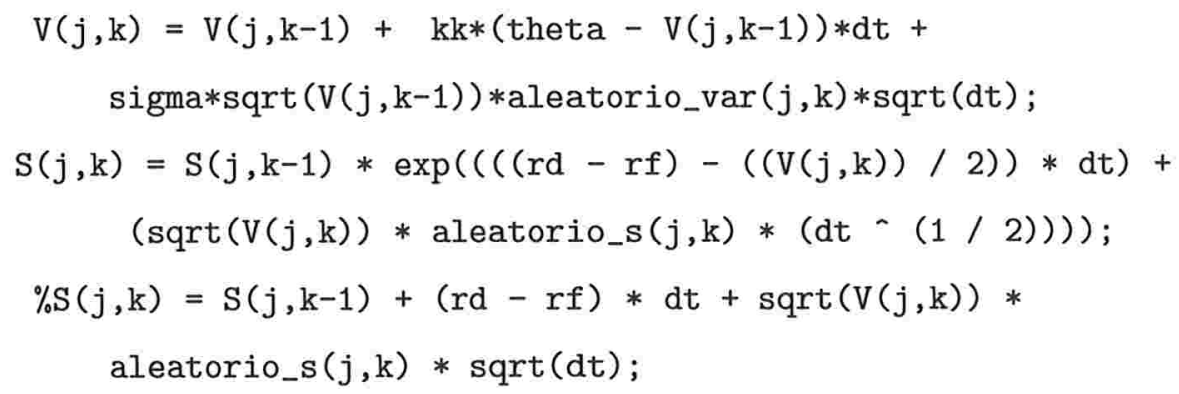


med = soma / n_simulacao;

$j=1 ;$ for $j=1: n_{-}$simulacao

$\operatorname{hist}(j, 1)=(S(j$, passo $)-$ spot $) /($ spot $) ;$

end

$\% \%$ Pode-se abaixo escolher os retornos ou o preco como resultado\% $\% \% \% \% \% \% \% \% \% \% \% \%$

$\mathrm{F}=$ hist ;

$\% \mathrm{~F}=[$ Preco_GK med $* \exp (-(\mathrm{rd}-\mathrm{rf}) *$ tau $)]$; 


\section{Função moneyness.m}

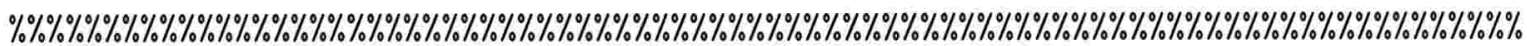

$\%$ Funcao Moneyness

\% Calcula a moneyness de uma opcao europeia de cambio

\% Parametro de entrada: dias_uteis, taxas pre e cupom na forma continua, N(d1)

$\%$ Calculo atraves do metodo de Newton onde Nd1_virtual_first representa a

$\%$ primeira derivada de $\mathrm{N}(\mathrm{d} 1)$ e $\mathrm{X}(\mathrm{j})$ representa a moneyness (spot/strike).

$\% \quad 0$ valor inicial para a interacao numerica e $\mathrm{X}(1)=1$ ( opcao in-the-money)

$\%$ e o erro da interacao de $10 \mathrm{e}-6$.

\% Autor: Marcelo Costa - 10/01/2003

\%\%\%\%\%\%\%\%\%\%\%\%\%\%\%\%\%\%\%\%\%\%\%\%\%\%\%\%\%\%\%\%\%\%\%\%\%\%\%\%\%\%\%\%\%\%\%\%\%\%\%\%\%\%\%\%\%\%\%\%\%\%\%\%\%\%\%\%\%\%\%\%\%\%\%\%\%\%\%\%\%\%\%\%\%\%\%\%

function money $=$ moneyness (matriz)

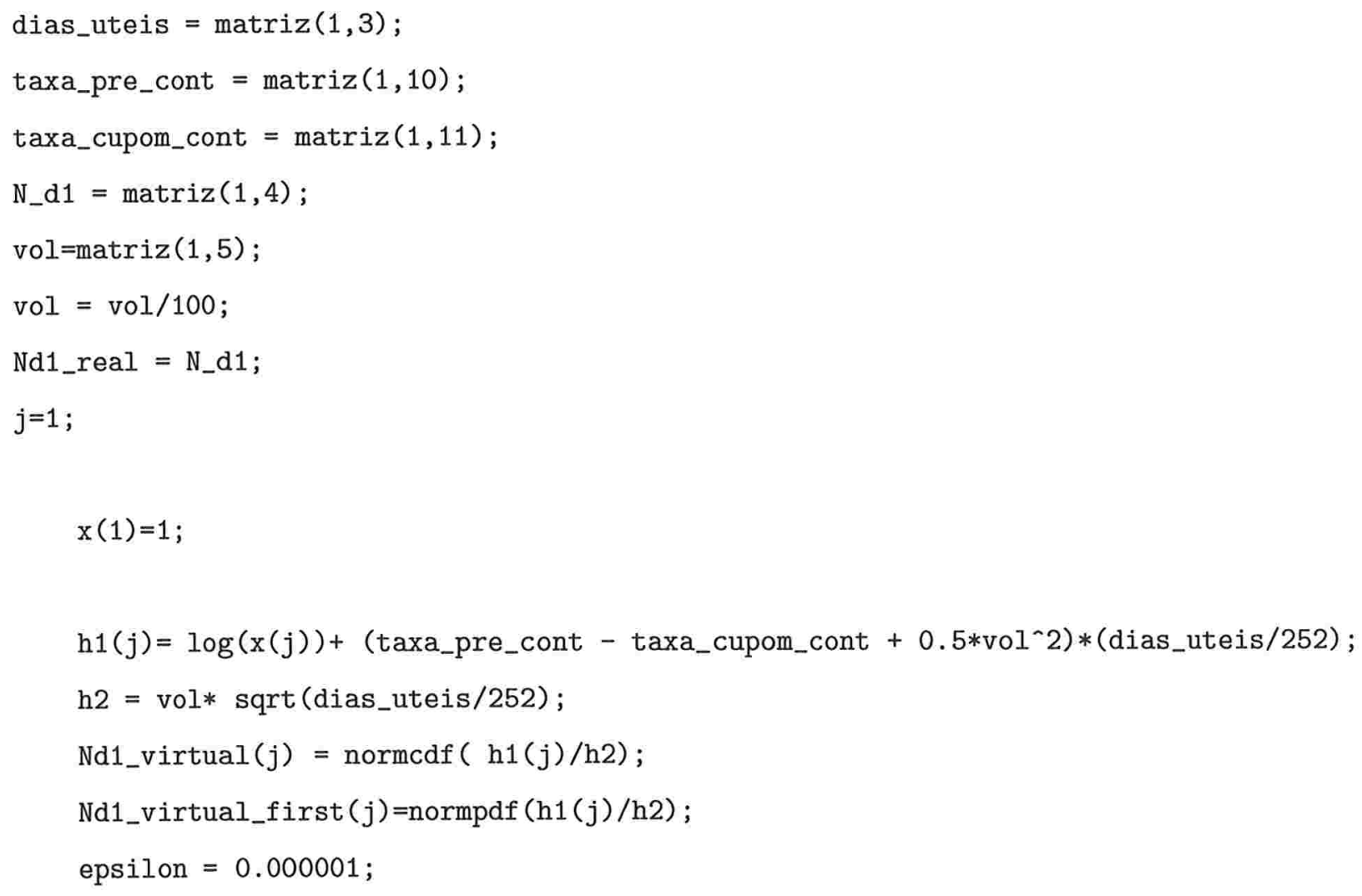


\%\%\%\%\%\%\%\%\%\%\%\%\%\%\%\%\%\%\%\%

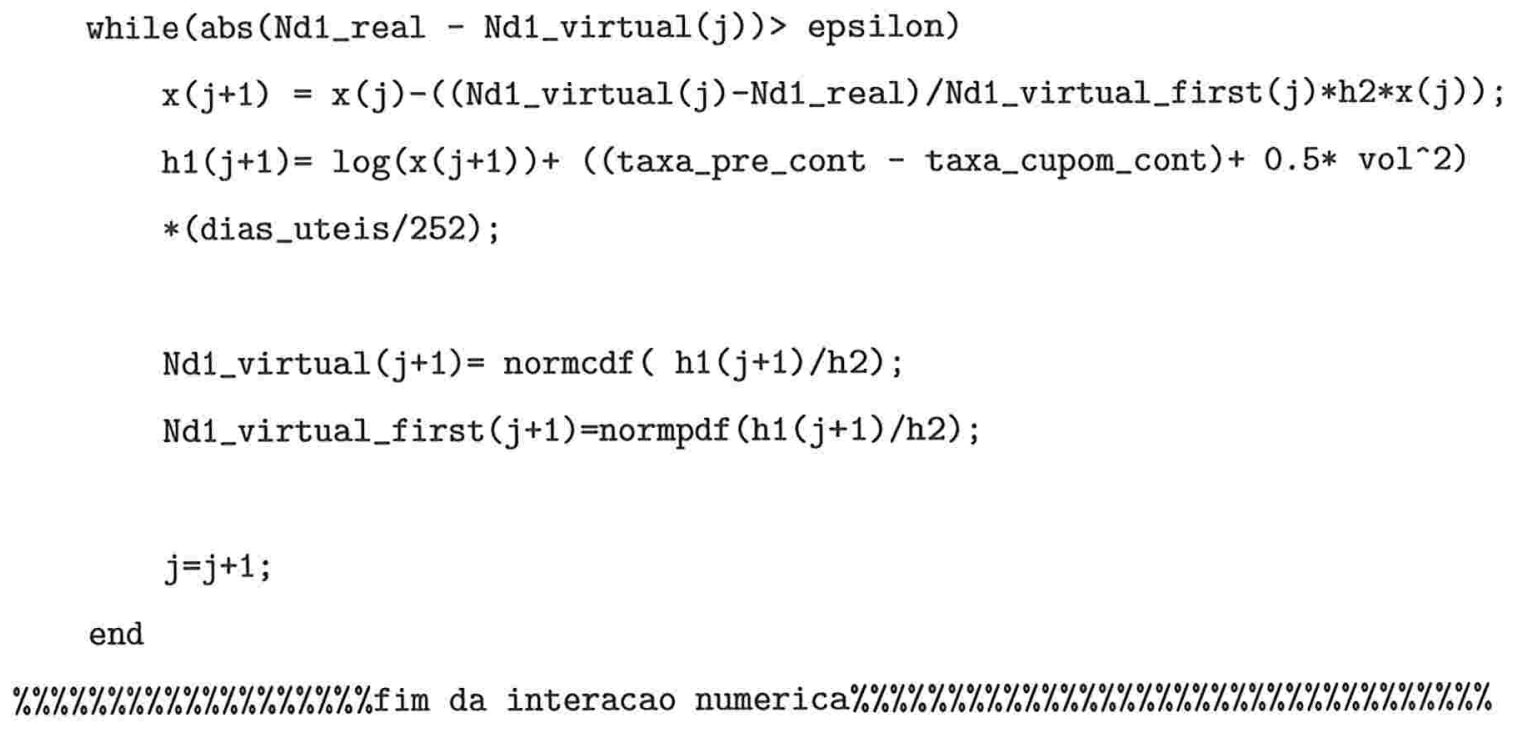




\section{Função garmanc.m}

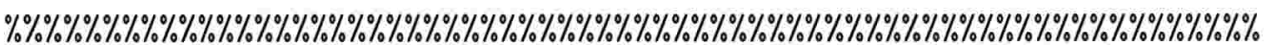

$\%$ Funcao garmanc

\% Calcula o preço da opçao europeia de compra/venda de cambio

$\%$ utilizando o modelo de Garman-Kohlhagen

$\%$ Autor: Marcelo Costa - 10/01/2003

\%\%\%\%\%\%\%\%\%\%\%\%\%\%\%\%\%\%\%\%\%\%\%\%\%\%\%\%\%\%\%\%\%\%\%\%\%\%\%\%\%\%\%\%\%\%\%\%\%\%\%\%\%\%\%\%\%\%\%\%\%\%\%\%\%\%\%\%\%\%

function gkcall $=$ garmanc (matriz)

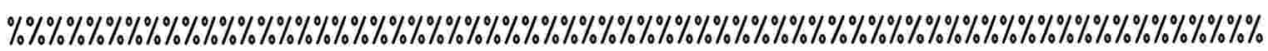
$\%$

Definicao dos dados de entrada

\%\%\%\%\%\%\%\%\%\%\%\%\%\%\%\%\%\%\%\%\%\%\%\%\%\%\%\%\%\%\%\%\%\%\%\%\%\%\%\%\%\%\%\%\%\%\%\%\%\%\%\%\%\%\%\%\%\%\%\%\%\%\%\%\%\%\%\%\%

$\mathrm{rd}=\operatorname{matriz}(1,10)$;

$\mathrm{rf}=\operatorname{matriz}(1,11)$;

spot $=\operatorname{matriz}(1,6)$;

sigma=matriz $(1,5)$;

$\mathrm{T}=\operatorname{matriz}(1,3) ;$

money $=\operatorname{matriz}(1,12)$;

N_d1 =matriz $(1,4)$;

sigma $=$ sigma $/ 100 ;$

tipo $=\operatorname{matriz}(1,1) ;$

$\mathrm{T}=\mathrm{T} / 252$;

$\operatorname{den} 1=N_{-} d 1$;

$\mathrm{d} 1=\operatorname{norminv}(\operatorname{den} 1)$;

$\mathrm{d} 2=\mathrm{d} 1-(\operatorname{sigma} *(\mathrm{~T}-(1 / 2))) ;$

den2 $=\operatorname{normcdf}(\mathrm{d} 2)$;

\%\%\%\%\%\%\%\%\%\%\%\%\%\%\%\%\%\%\%\%\%\%\%\%\%\%\%\%\%\%\%\%\%\%\%\%\%\%\%\%\%\%\%\%\%\%\%\%\%\%\%\%\%\%\%\%\%\%\%\%\%\%\%\%\%\%\%\%\%\%\%\%

$\% \quad$ Calculo para o tipo $1 \gg$ Call

\%\%\%\%\%\%\%\%\%\%\%\%\%\%\%\%\%\%\%\%\%\%\%\%\%\%\%\%\%\%\%\%\%\%\%\%\%\%\%\%\%\%\%\%\%\%\%\%\%\%\%\%\%\%\%\%\%\%\%\%\%\%\%\%\%\%\%\% 
if $($ tipo $==1) c 1=\operatorname{spot} * \exp (-r f * \mathrm{~T}) * \operatorname{den} 1$;

$\mathrm{c} 2=($ spot/money $) * \exp (-\mathrm{rd} * \mathrm{~T}) * \operatorname{den} 2 ; \mathrm{g}$

$\mathrm{kcall}=\mathrm{c} 1-\mathrm{c} 2$;

end

\%\%\%\%\%\%\%\%\%\%\%\%\%\%\%\%\%\%\%\%\%\%\%\%\%\%\%\%\%\%\%\%\%\%\%\%\%\%\%\%\%\%\%\%\%\%\%\%\%\%\%\%\%\%\%\%\%\%\%\%\%\%\%\%\%\%\%

$\%$

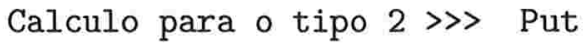

\%\%\%\%\%\%\%\%\%\%\%\%\%\%\%\%\%\%\%\%\%\%\%\%\%\%\%\%\%\%\%\%\%\%\%\%\%\%\%\%\%\%\%\%\%\%\%\%\%\%\%\%\%\%\%\%\%\%\%\%\%\%\%\%\%\%\%\%

if $($ tipo $==2) \mathrm{p} 1=\operatorname{spot} * \exp (-\mathrm{rf} * \mathrm{~T}) *(1-\operatorname{den} 1)$;

$\mathrm{p} 2=($ spot/money $) * \exp (-\mathrm{rd} * \mathrm{~T}) *(1-\mathrm{den} 2) ;$ gkcall $=\mathrm{p} 2-\mathrm{p} 1 ;$ end 


\section{Função taxa_cont.m}

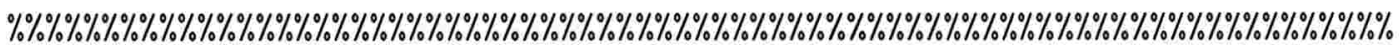

$\%$ Funcao taxa_cont

\% Calcula taxas continuas na base dias uties 252 para PRE e CUPOM

\% Parametro tipo: 1 - PRE e 2 - CUPOM

\% Autor: Marcelo Costa - 10/01/2003

\%\%\%\%\%\%\%\%\%\%\%\%\%\%\%\%\%\%\%\%\%\%\%\%\%\%\%\%\%\%\%\%\%\%\%\%\%\%\%\%\%\%\%\%\%\%\%\%\%\%\%\%\%\%\%\%\%\%\%\%\%\%\%\%\%\%\%\%\%\%\%\%\%\%\%

function taxa $=$ taxa_cont $($ matriz, tipo $)$

dias_corridos $=$ matriz $(1,2) ;$ dias_uteis $=\operatorname{matriz}(1,3) ;$ taxa_pre $=$ matriz $(1,7)$; taxa_cupom $=$ matriz $(1,8)$;

if $($ tipo $==1)$

taxa_cont $=\log (1+$ taxa_pre $)$;

end

if $($ tipo $==2)$

taxa_cont $=(252 /$ dias_uteis $) * \log (1+($ dias_corridos*taxa_cupom $) / 360)$;

end

taxa $=$ taxa_cont; 